Universidad de Lima

Facultad de Ingeniería y Arquitectura

Carrera de Ingeniería Industrial

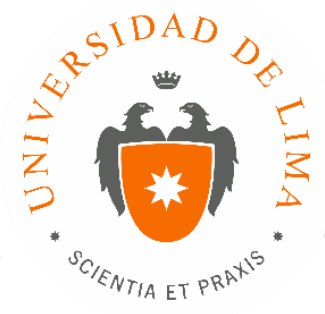

\title{
ESTUDIO DE PRE FACTIBILIDAD PARA LA INSTALACIÓN DE UNA PLANTA PROCESADORA DE ESCAMAS DE POLIPROPILENO RECICLADO
}

Trabajo de investigación para optar el Título Profesional de Ingeniero Industrial

\section{Diego Gustavo Morales Brazzoduro} Código 20120855

Joao Alberto de Azambuja Hevia

Código 20122376

Asesor

Rosa Patricia Larios

Lima - Perú

Abril de 2018 


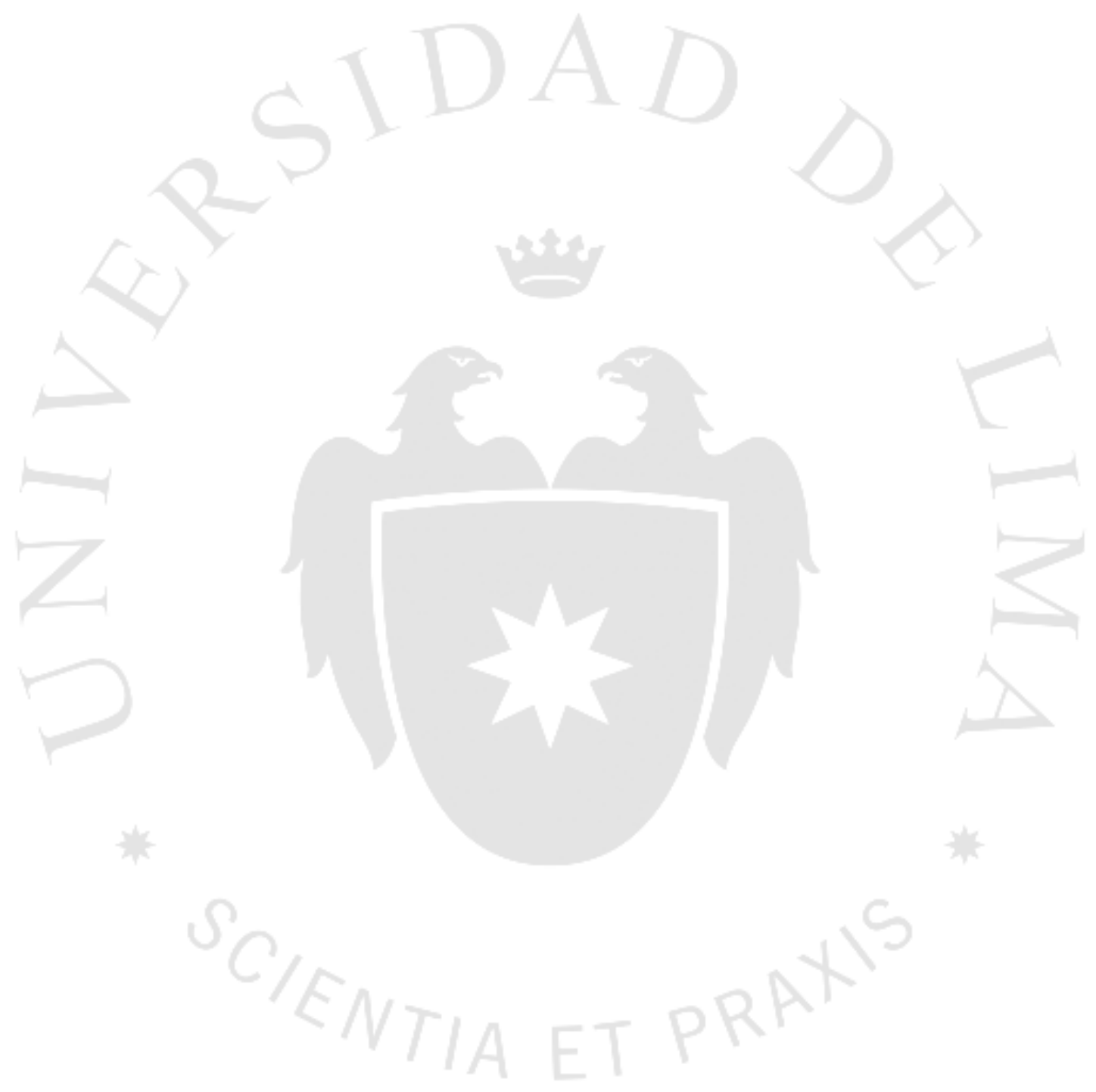




\section{ESTUDIO DE PRE FACTIBILIDAD PARA LA INSTALACIÓN DE UNA PLANTA PROCESADORA DE ESCAMAS DE POLIPROPILENO RECICLADO}




\section{TABLA DE CONTENIDO}

RESUMEN EJECUTIVO .....................................................................................1

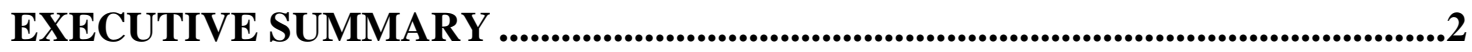

CAPÍTULO I: ASPECTOS GENERALES...............................................................3

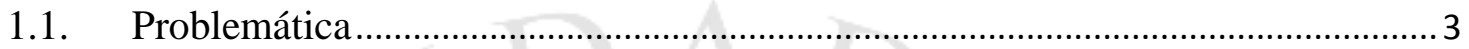

1.2. Objetivos de la Investigación .............................................................................. 3

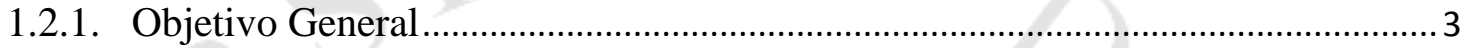

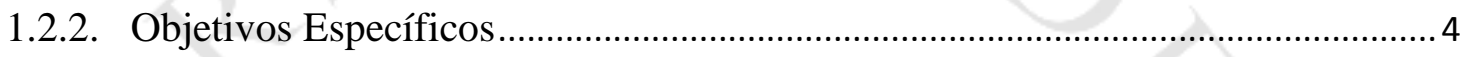

1.3. Alcance y limitaciones de la investigación ............................................................ 4

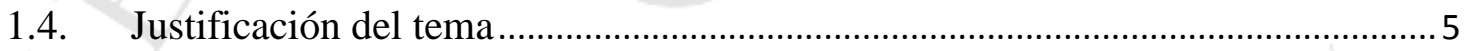

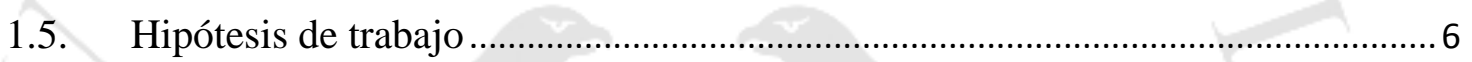

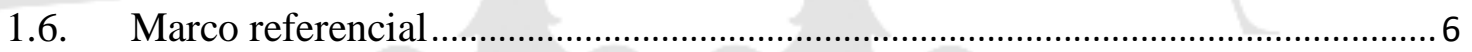

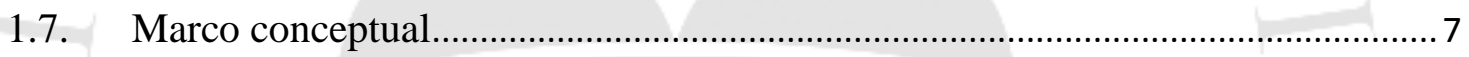

CAPÍTULO II: ESTUDIO DE MERCADO .............................................................9

2.1. Aspectos generales del estudio de mercado ...................................................... 9

2.1.1. Definición comercial del producto ................................................................. 9

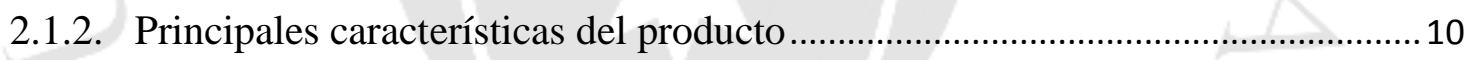

2.1.3. Determinación del área geográfica que abarcará el estudio................................12

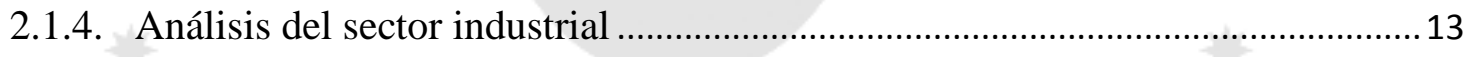

2.1.5. Metodología a emplear en la investigación de mercado....................................... 16

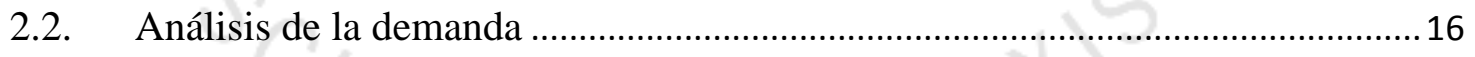

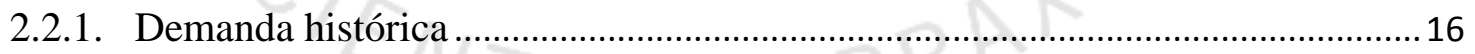

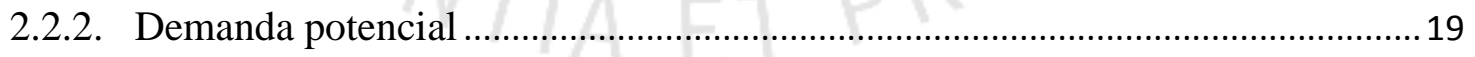

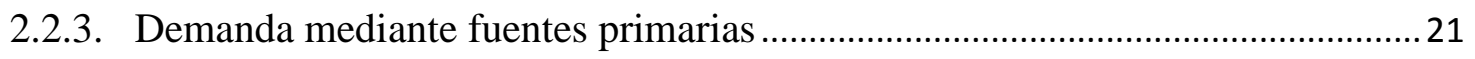

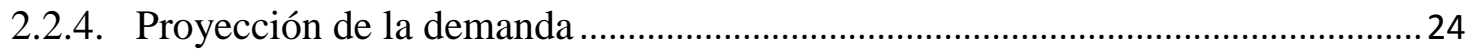

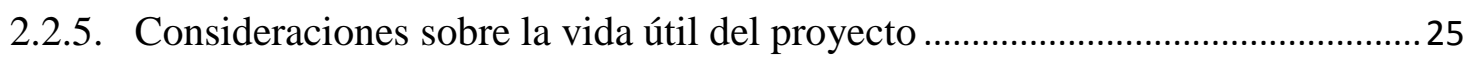

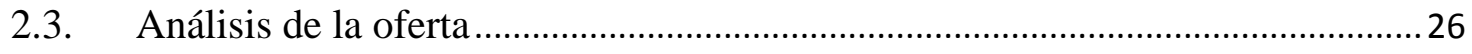

2.3.1. Empresas productoras, importadoras y comercializadoras .................................26 
2.3.2. Competidores actuales y potenciales ............................................................... 28

2.4. Determinación de la demanda para el proyecto.................................................... 30

2.4.1. Segmentación del mercado ............................................................................... 30

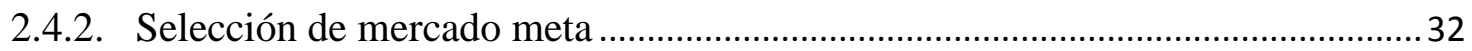

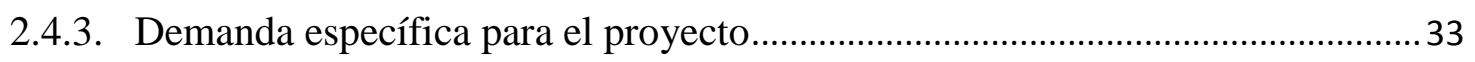

2.5. Definición de la estrategia de comercialización ................................................... 34

2.5.1. Políticas de comercialización y distribución........................................................34

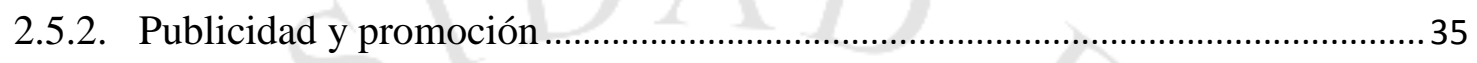

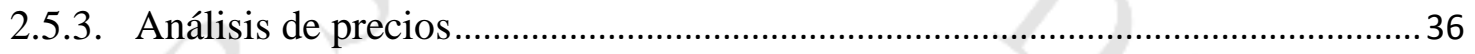

2.6. Análisis de disponibilidad de los insumos principales ......................................38

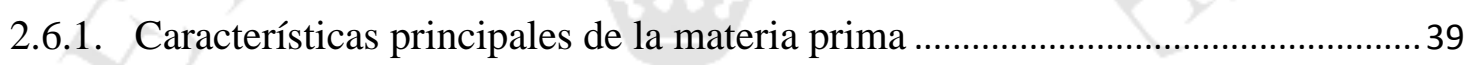

2.6.2. Disponibilidad de la materia prima ..................................................................... 39

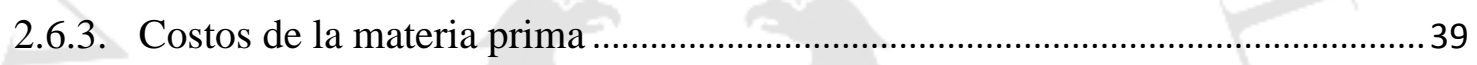

CAPÍTULO III: LOCALIZACIÓN DE PLANTA .....................................................40

3.1. Identificación y análisis detallado de los factores de localización.......................40

3.2. Identificación y descripción de las alternativas de localización ............................46

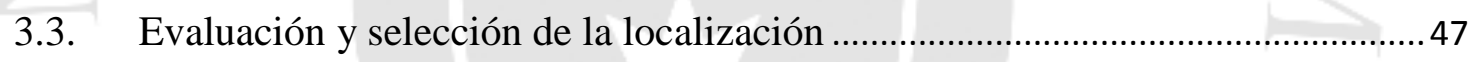

3.3.1. Evaluación y selección de la macro localización ................................................ 47

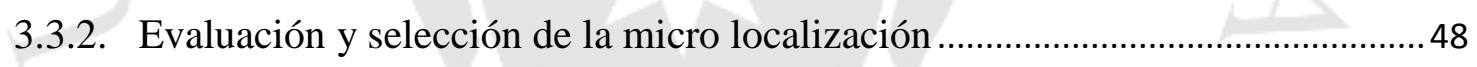

CAPÍTULO IV: TAMAÑ̃ DE PLANTA ..................................................................51

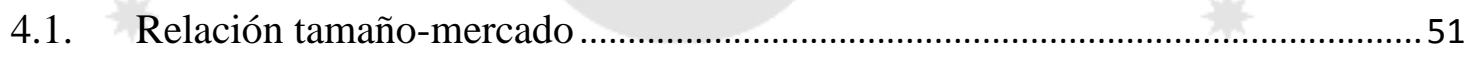

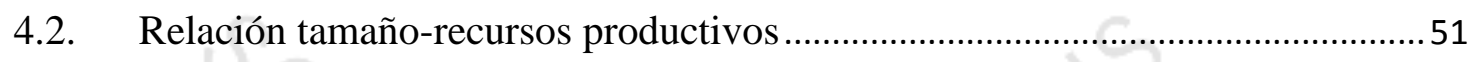

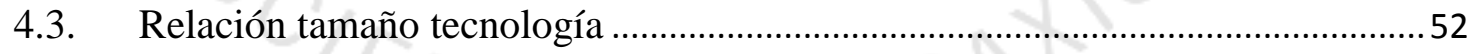

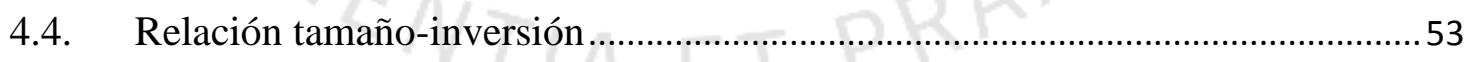

4.5. Relación tamaño-punto de equilibrio ............................................................... 54

4.6. Selección del tamaño de planta.......................................................................... 55

CAPÍTULO V: INGENIERÍA DEL PROYECTO .................................................57

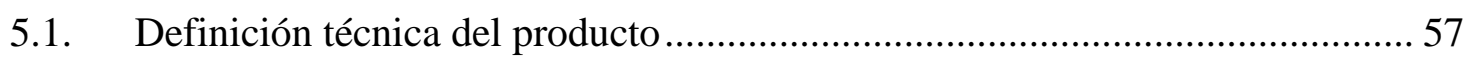

5.1.1. Especificaciones técnicas del producto............................................................57

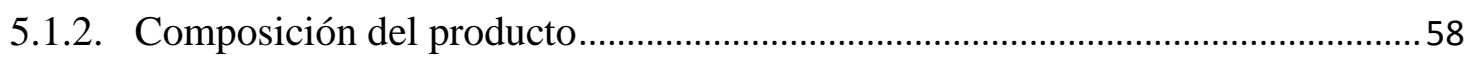




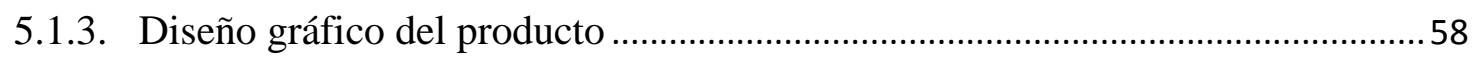

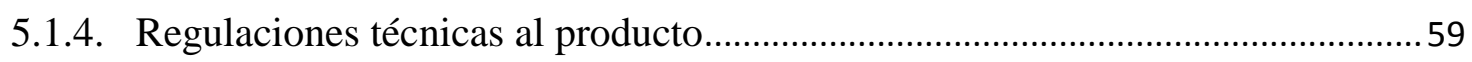

5.2. Tecnologías existentes y procesos de producción ...............................................60

5.2.1. Naturaleza de la tecnología requerida .............................................................61

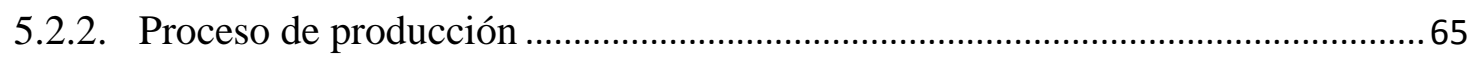

5.3. Características de las instalaciones y equipos................................................... 75

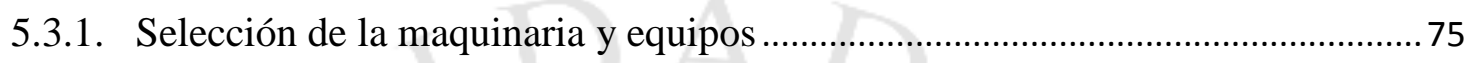

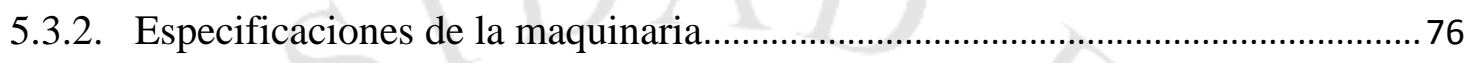

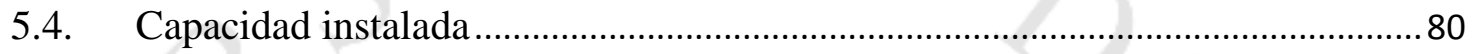

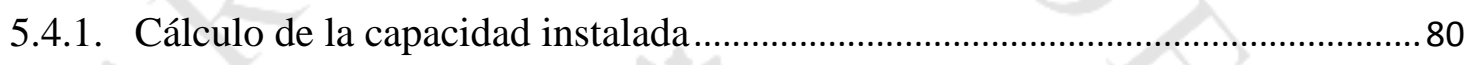

5.4.2. Cálculo detallado del número de máquinas y operarios requeridos.....................82

5.5. Resguardo de la calidad o inocuidad del producto............................................... 83

5.5.1. Calidad de la materia prima, de los insumos, del proceso y del producto ..........84

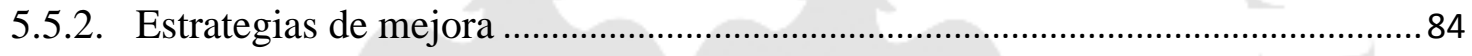

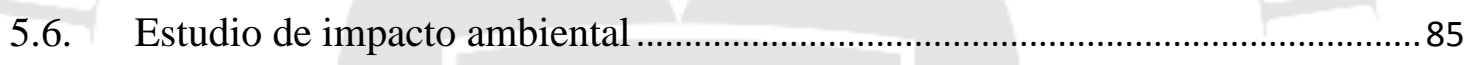

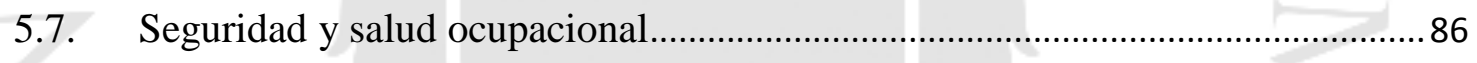

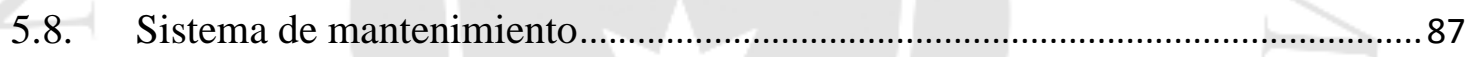

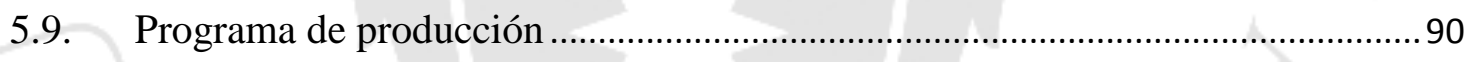

5.9.1. Factores para la programación de la producción .................................................90

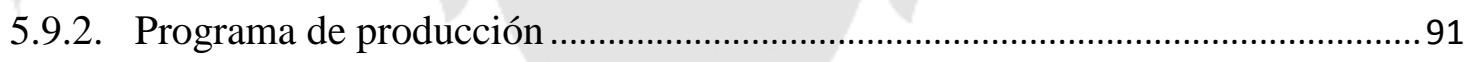

5.10. Requerimiento de insumos, servicios y personal indirecto ................................91

5.10.1. Materia prima, insumos y otros materiales ....................................................... 91

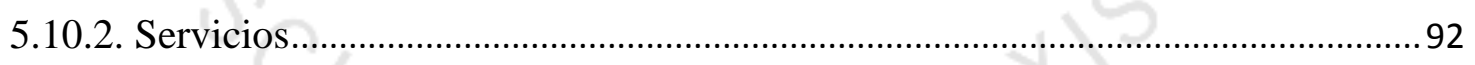

5.10.3. Determinación del número de operarios y trabajadores indirectos .....................93

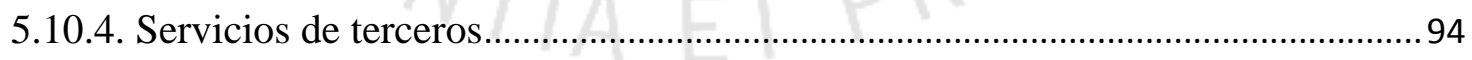

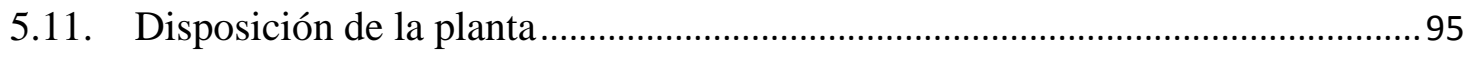

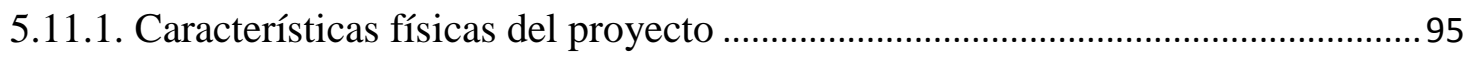

5.11.2. Determinación de las zonas físicas requeridas .................................................98

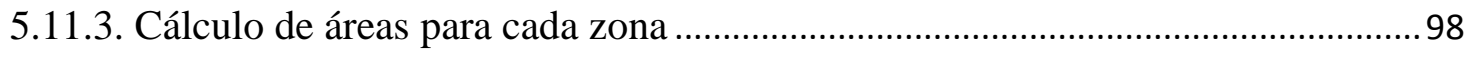

5.11.4. Dispositivos de seguridad industrial y señalización........................................... 102 
5.11.6. Disposición de detalle de la zona productiva....................................................... 108

5.12. Cronograma de implementación del proyecto .................................................. 110

CAPÍTULO VI: ORGANIZACIÓN Y ADMINISTRACIÓN ................................111

6.1. Formación de la organización empresarial ............................................111

6.2. Requerimientos de personal directivo, administrativo y de servicios y funciones

6.3. Estructura organizacional

CAPÍTULO VII: PRESUPUESTOS Y EVALUACIÓN DEL PROYECTO ......116

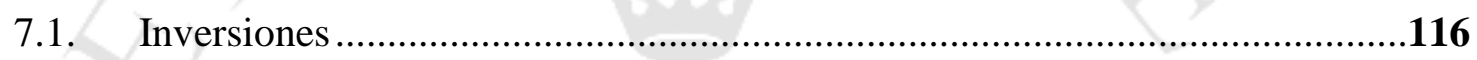

7.1.1. Estimación de las inversiones de largo plazo (tangibles e intangibles) ...........116

7.1.2. Estimación de las inversiones de corto plazo (capital de trabajo) ..................117

7.2. Costos de producción..........................................................................117

7.2.1. Costos de las materias primas .............................................................18

7.2.2. Costo de la mano de obra directa............................................................118

7.2.3. Costo indirecto de fabricación .............................................................118

7.3. Presupuesto operativo .....................................................................19

7.3.1. Presupuesto de ingreso por ventas ........................................................119

7.3.2. Presupuesto operativo de $\operatorname{costos}$..........................................................119

7.3.3. Presupuesto operativo de gastos .........................................................120

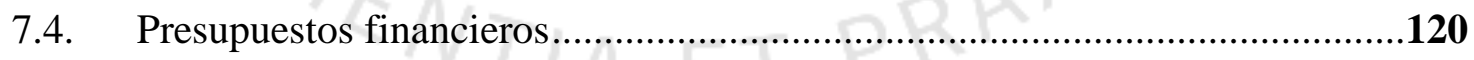

7.4.1. Presupuesto de servicio de deuda ......................................................120

7.4.2. Presupuesto de estado de resultados .......................................................121

7.4.3. Presupuesto de estado de situación financiera (apertura) ..............................122

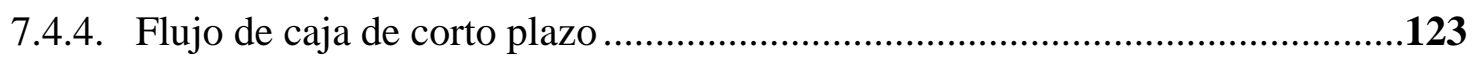

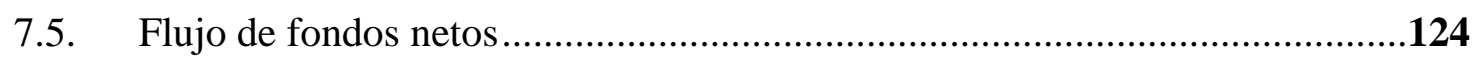


7.5.1. Flujo de fondos económicos

7.5.2. Flujo de fondos financieros

CAPÍTULO VIII: EVALUACIÓN ECONÓMICA/FINANCIERA.

8.1. Evaluación económica: VAN, TIR, B/C, PR

.125

8.2. Evaluación financiera: VAN, TIR, B/C, PR

126

8.3. Análisis de ratios (liquidez, solvencia, rentabilidad) e indicadores económicos y financieros del proyecto

8.4. Análisis de sensibilidad del proyecto .129

CAPÍTULO IX: EVALUACIÓN SOCIAL DEL PROYECTO

9.1. Identificación de las zonas y comunidades de influencia del proyecto

9.2. Análisis de indicadores sociales (valor agregado, densidad de capital, intensidad de capital, generación de divisas)

CONCLUSIONES .135

RECOMENDACIONES .136

REFERENCIAS .137

ANEXOS. .145 


\section{ÍNDICE DE TABLAS}

Tabla 2. 1. CIIU de la empresa 10

Tabla 2. 2. Tabla comparativa de las principales características del polipropileno virgen y reciclado

Tabla 2.3. Listado de aditivos y su función 12

Tabla 2.4. Lista de colorantes 13

Tabla 2.5. Demanda interna aparente del polipropileno en toneladas 18

Tabla 2.6. Importaciones anuales de polipropileno en dólares y soles 21

Tabla 2.7. Características de PP reciclado por orden de importancia.............................. 24

Tabla 2.8. Proyección de la DIA de los próximos 5 años en toneladas ............................ 24

Tabla 2.9. Empresas importadoras de polipropileno ........................................... 27

Tabla 2.10. Participación de competidores actuales .................................................. 28

Tabla 2.11. Proporciones de cantidad de empresas y ventas por tamaño ......................... 31

Tabla 2.12. Composición del VAB manufacturado del año 2015 por industria................. 31

Tabla 2.13. Demanda del proyecto en los próximos 5 años ........................................ 34

Tabla 3.1. Kilogramos de residuos recolectados de forma diaria por departamento en el año 2016

Tabla 3.2. Distancias entre capitales y Lima 41

Tabla 3.3. PEA del año 2015 y promedio de años de estudio del 2014 por $\quad x$ departamento.

Tabla 3.4. Población total y PEA estimada de distrito potenciales en Lima del año 2015 42

Tabla 3.5. Producción de Gigawatts/hora por departamento 43

Tabla 3.6. Porcentaje de la red vial Nacional asfaltada por departamento al 2014 43 
Tabla 3.7. Cobertura de agua potable y producción de agua potable por empresa 44

Tabla 3.8. Temperatura promedio anual por departamento..... 44

Tabla 3.9. Generación de residuos sólidos por persona y en total del año 2013 45

Tabla 3.10. Cantidad de delitos cometidos registrados por distrito del año 2014 45

Tabla 3.11. Precios promedios de propiedad por distrito del año 2016 46

Tabla 3.12. Tabla de enfrentamiento macro localización 48

Tabla 3.13. Ranking de factores macro localización 48

Tabla 3.14. Tabla de enfrentamiento micro localización 50

Tabla 3.15. Ranking de factores micro localización 50

Tabla 4.1. Proyección de la DIA para los próximos cinco años 51

Tabla 4.2. Datos históricos de residuos sólidos generados en Lima Metropolitana 2011 2015 52

Tabla 4.3. Proyección de residuos sólidos generados en Lima Metropolitana 2016 2020 52

Tabla 4.4. Disponiblidad de materia prima al 2020 .....................................................52

Tabla 4.5. Alternativas de líneas de producción con capacidad de producción de 1000 $\mathrm{kg} / \mathrm{h}$ 53

Tabla 4.6. Costos y gastos fijos y variables ….................................................... 55

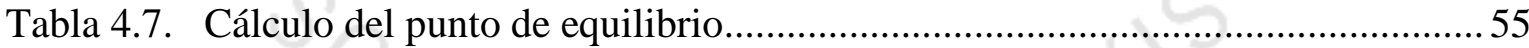

Tabla 4.8. Cuadro resumen de tamaños de planta ...................................................... 56

Tabla 5.1. Especificaciones de línea de producción Pagani de 1000 kg/h ..................... 77

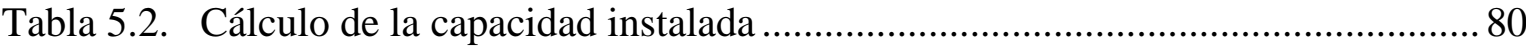

Tabla 5.3. Cálculo de la capacidad productiva y operativa ............................................ 81

Tabla 5.4. Resumen del cálculo del número de operarios requeridos ............................. 83

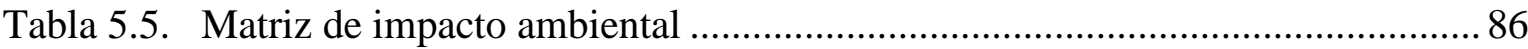


Tabla 5.6. Matriz de identificación de peligros, evaluación de riesgos y control 87

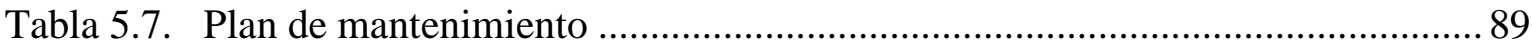

Tabla 5.8. Programa de producción ..................................................................... 91

Tabla 5.9. Resumen de consumo de recursos 2016 - 2020 ......................................... 92

Tabla 5.10. Resumen de costos de agua 2016 - 2020 .............................................. 93

Tabla 5.11. Resumen de costos de energía 2016 - 2020 ............................................ 93

Tabla 5.12. Resumen de costos de transporte 2016 - 2020.......................................... 95

Tabla 5.13. Dimensiones finales de las áreas ................................................................ 102

Tabla 5.14. Método de Guerchet para determinar el área de producción ......................... 109

Tabla 7.1. Inversión en activos fijos tangibles.................................................... 116

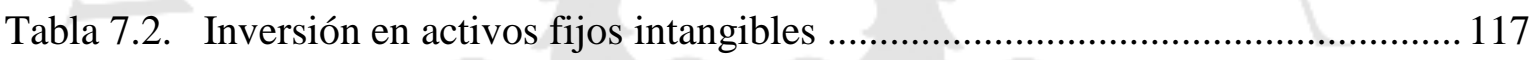

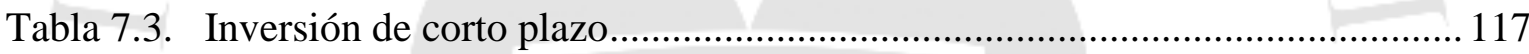

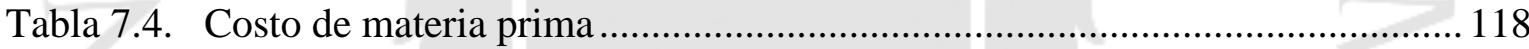

Tabla 7.5. Costo de mano de obra directa........................................................... 118

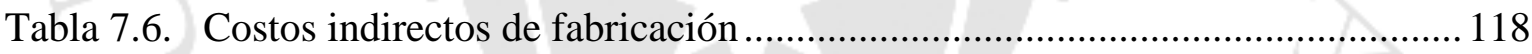

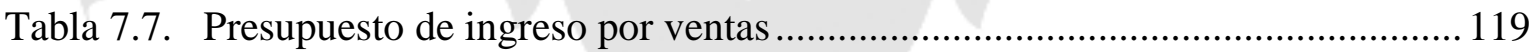

Tabla 7.8. Presupuesto operativo de costos .................................................................... 119

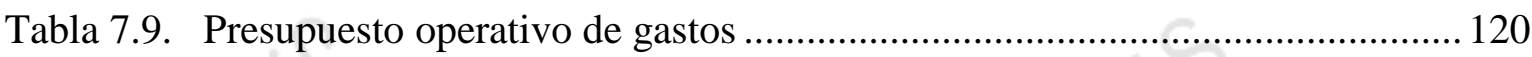

Tabla 7.10. Presupuesto de servicio de deuda .................................................... 120

Tabla 7.11. Presupuesto de estado de resultados .......................................................... 121

Tabla 7.12. Presupuesto de estado de situación financiera ........................................ 122

Tabla 7.13. Flujo de caja de corto plazo .............................................................. 123

Tabla 7.14. Flujo de fondos económico........................................................... 124

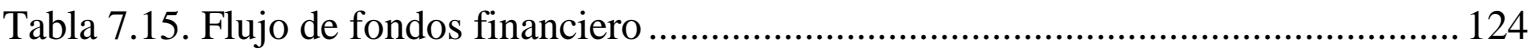


Tabla 8.1. Evaluación económica del proyecto

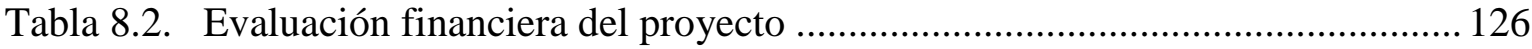

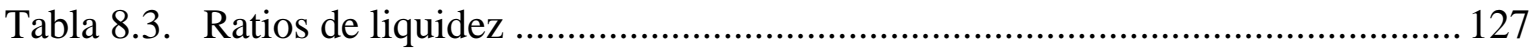

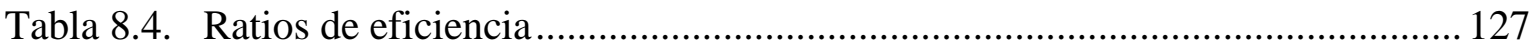

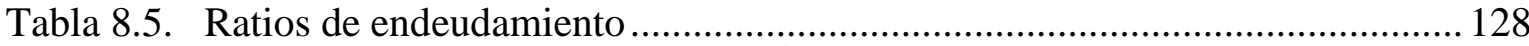

Tabla 8.6. Evaluación económica/financiera de los escenarios ................................... 129

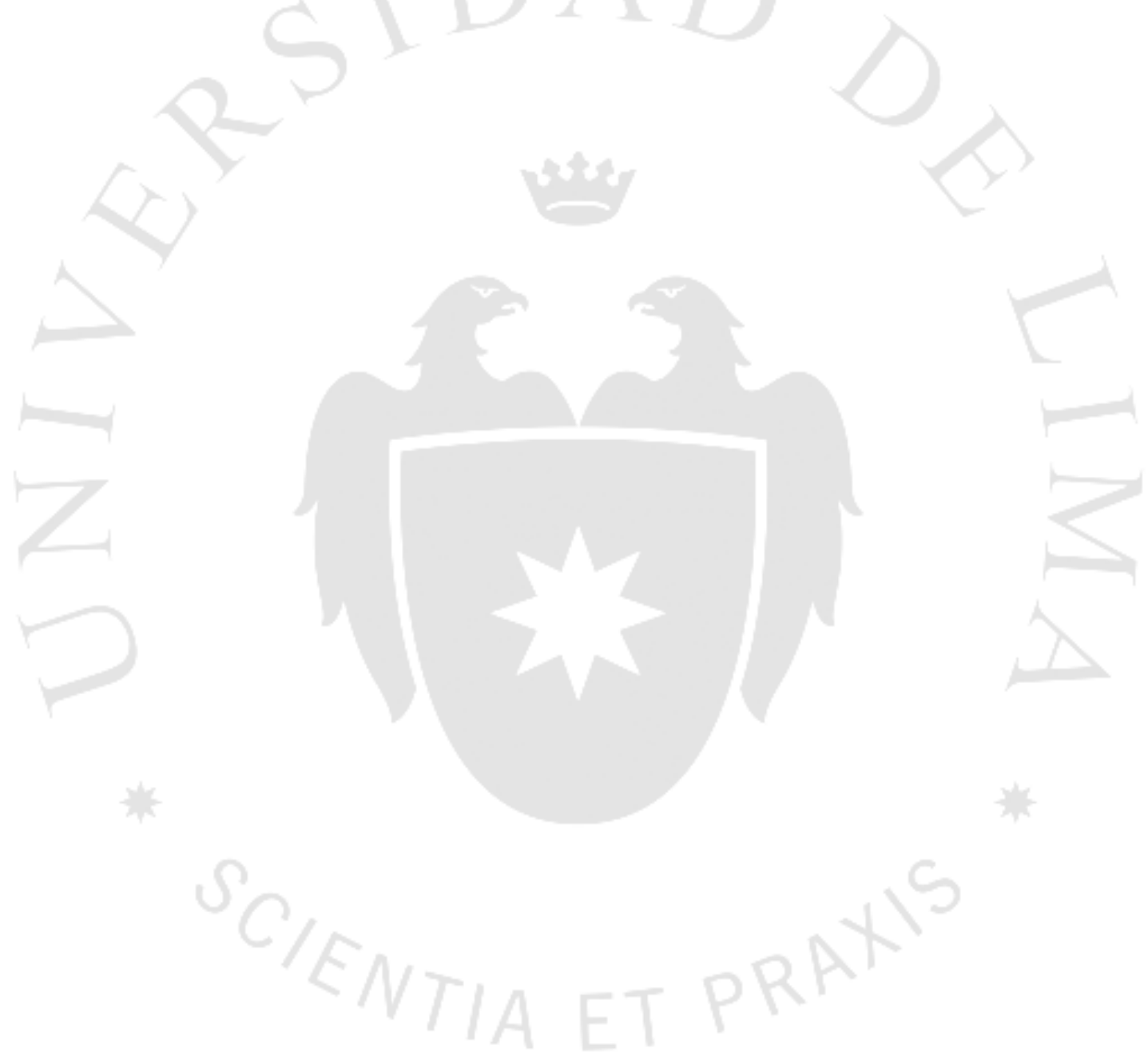




\section{ÍNDICE DE FIGURAS}

Figura 2.1. Demanda interna aparente del polipropileno en toneladas. 19

Figura 2.2. Demanda interna aparente histórica y proyectada.................................... 25

Figura 2.3. Participación de competidores actuales.................................................... 28

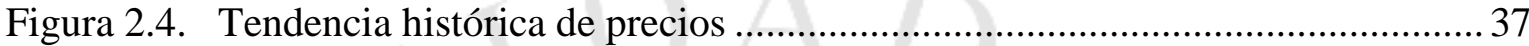

Figura 2.5. Comparación de precios actuales .................................................................... 38

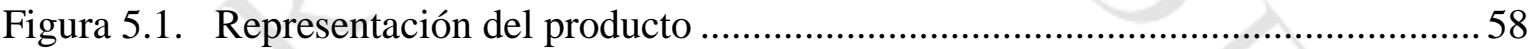

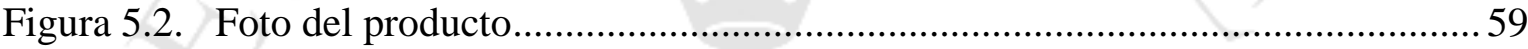

Figura 5.3. Diagrama de flujo simple del reciclaje mecánico .....................................62 62

Figura 5.4. Representación de usos de reciclaje por pirólisis ....................................... 63

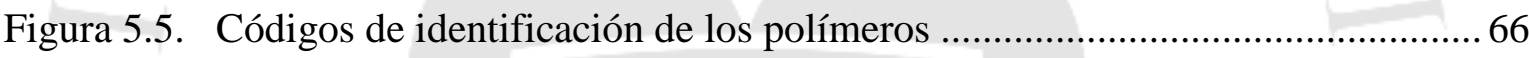

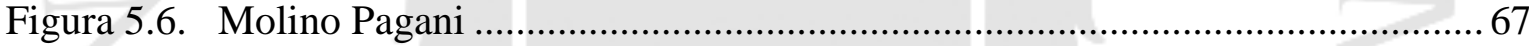

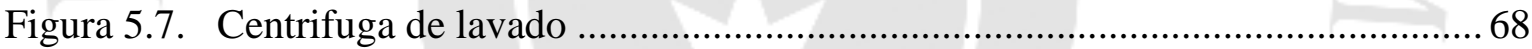

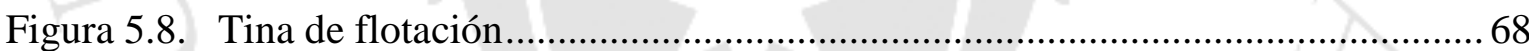

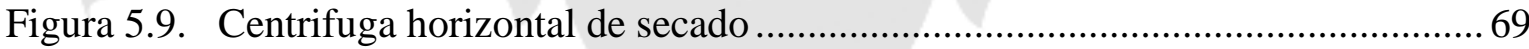

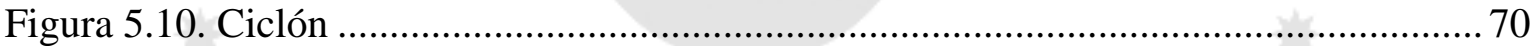

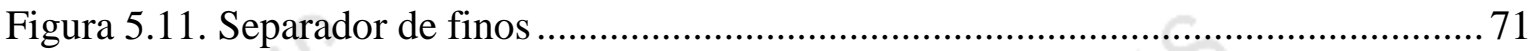

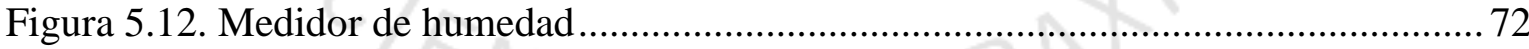

Figura 5.13. Diagrama de operaciones del proceso ….............................................. 73

Figura 5.14. Balance de materia para producción de polipropileno reciclado ................... 74

Figura 5.15. Bosquejo de la línea de producción........................................................ 78

Figura 5.16. Bosquejo de la línea de producción con dimensiones totales ....................... 78

Figura 5.17. Foto referencial 1 de la línea de producción completa Pagani ....................... 79 
Figura 5.18. Foto referencial 2 de la línea de producción completa Pagani.

Figura 5.19. Cálculo de área para almacén de materias primas ....................................... 99

Figura 5.20. Cálculo de área para almacén de insumos ................................................ 100

Figura 5.21. Cálculo de área para almacén de productos terminados........................... 101

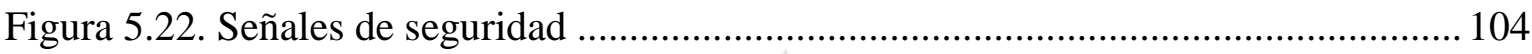

Figura 5.23. Método de análisis relacional para distribución de las áreas ....................... 105

Figura 5.24. Diagrama relacional para distribución de las áreas ................................... 106

Figura 5.25. Plano de disposición de la planta y leyenda .......................................... 107

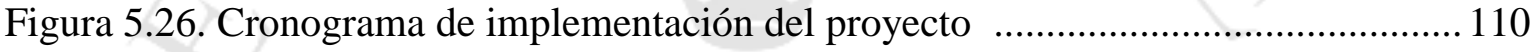

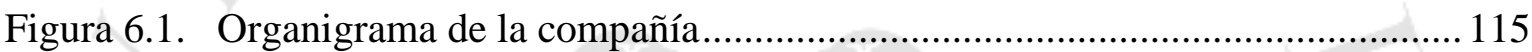




\section{ÍNDICE DE ANEXOS}

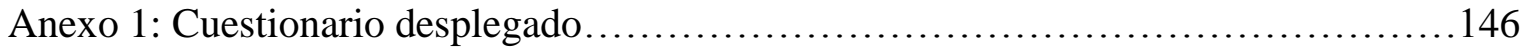

Anexo 2: Glosario de términos............................................... 147

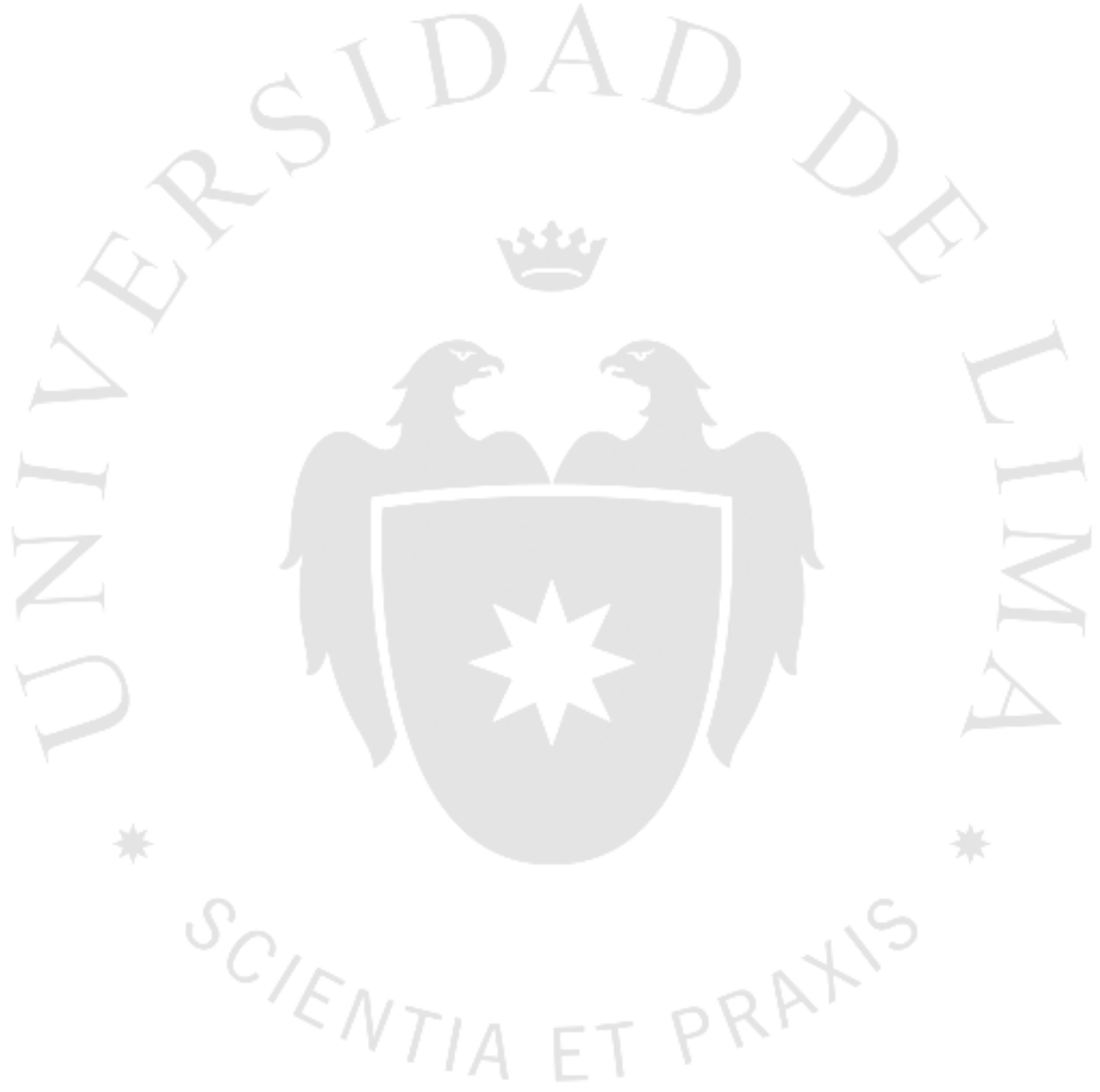




\section{RESUMEN EJECUTIVO}

El presente proyecto de investigación profundiza en la viabilidad de la instalación de una planta procesadora de escamas de polipropileno reciclado. Esto va de la mano con la problemática identificada tanto a nivel nacional como mundial, que es la contaminación causada por la cantidad de desechos y residuos sólidos que los seres humanos producimos. La solución para esto es el reciclaje, tema que se trabaja en el transcurso de la presente investigación, enfocándolo en polímeros puntualmente.

En el trascurso del documento se abordan los temas del estudio de mercado y demanda del proyecto para entender a fondo el sector industrial al que se ingresa, la demanda tanto histórica como potencial, la oferta, el mercado objetivo y las estrategias de comercialización. Luego, se revisa la localización y tamaño óptimo de la planta en base a los factores macro y micro más críticos para asegurar el éxito del proyecto y en base a eso se sustentará la selección de la ubicación. Más adelante, se trabaja la ingeniería del proyecto con las especificaciones del producto, la tecnología y maquinaria a utilizar, la capacidad instalada, los requerimientos de producción y disposición de planta. Seguido a eso, se plantea la organización y administración y por último se elabora un análisis económico, financiero y social para evaluar el proyecto y alcanzar las conclusiones.

Todo esto se realiza para determinar si el proyecto es factible económica, financiera y socialmente. En el caso de la evaluación económica, se obtiene un VAN positivo de S/ 706 176 y un TIR de 25,04\% y en el escenario financiero, un VAN positivo de S/ 1003242 y un TIR de 31,60\%. En ambos casos el proyecto demuestra ser rentable y con un TIR mayor al costo de oportunidad calculado del mercado equivalente a 18,51\%. En el aspecto social, todos los indicadores sociales muestran ser favorables como se demuestra con los resultados de intensidad de capital $(0,36)$ y de generación de divisas $(0,05)$. 


\section{EXECUTIVE SUMMARY}

This research project's main objective is to understand the viability of installing a recycled polypropylene pellets manufacturing plant. This goes in hand with the identified issue at both a national and international level, related to the amount of garbage and waste that human beings are producing. The solution for this issue is recycling, which is the topic developed in this investigation, focused specifically on polymers.

Along the document, several themes will be developed which include the market study and project demand in order to fully understand the industrial sector being approached, both the historical and potential demand, the supply, target market and commercial strategies. Then, the plant localization and optimum size are analyzed based on the critical macro and micro factors determined to guarantee the success of the project and explain the selection of the localization. Later, the project engineering is developed with the product specifications, technology and machinery to be used, installed capacity, production requirements and plant arrangement. Further on, the organization and administration is proposed and finally an economic, financial and social analysis is performed to evaluate the project and lead to solid conclusions.

All of this is done to determine if the project is feasible economically, financially and socially. In the economic evaluation, a positive VAN of S/ 706176 is obtained and a TIR of 25,04\%, while in the financial evaluation the result is a positive VAN of S/ 1003242 and a TIR of $31,60 \%$. In both cases, the project demonstrates that it is profitable and with a higher TIR in comparison to the market cost opportunity calculated to be $18,51 \%$. In the social aspect, all social indicators are favorable as it is shown in the results of capital intensity $(0,36)$ and revenue generation $(0,05)$. 


\section{CAPÍTULO I: ASPECTOS GENERALES}

\subsection{Problemática}

En la actualidad, un creciente problema tanto a nivel nacional como mundial es la cantidad de desechos y residuos sólidos que los seres humanos producimos. A raíz de esto, ya hace algunas décadas surgió el reciclaje como la solución. Lamentablemente, aún los seres humanos no somos capaces de reciclar todos los desechos que podríamos por falta tanto de tecnología, como de conciencia en algunos casos. De acuerdo con el INEI en su Anuario de Estadísticas Ambientales del 2016, para el 2015 los distritos que componen Lima Metropolitana generaban casi 3 millones de toneladas de residuos sólidos de carácter domiciliario. Esto es un número alarmante, ya que se traduce en una producción promedio al día de 0.9 kilos por habitante, número que sigue en aumento año a año. Para cerrar la figura, en el 2014 y 2015 de las aproximadamente 160 municipalidades que realizaron recojo de basura dentro de Lima Metropolitana, tan solo el 25\% de ellas involucraron al reciclaje como una forma de destino para dichos residuos. En muchas ocasiones, se iba a un botadero a cielo abierto, a un relleno sanitario o se quemaba, entre otros. (Ambiente, 2016)

\subsection{Objetivos de la Investigación}

En este acápite se procede a detallar tanto el objetivo general como los específicos que se desarrollan en el transcurso del estudio.

\subsubsection{Objetivo General}

Determinar la viabilidad, tanto técnica, económica como social, de instalar una planta procesadora de escamas de plástico, en este caso polipropileno reciclado. Junto a esto, el objetivo es crear conciencia del cuidado del medio ambiente mostrando el nivel de daño que produce un mal manejo de los desechos humano y al mismo tiempo, lograr que sea una industria rentable y formal que beneficie al Perú. 


\subsubsection{Objetivos Específicos}

Los principales objetivos identificados son siete:

- Determinar la demanda del proyecto para escamas de polipropileno reciclado en base al estudio de mercado.

- Seleccionar la localización óptima de la planta dentro del Perú.

- Definir el tamaño de planta óptimo acorde a los objetivos de la empresa.

- Precisar la ingeniería del proyecto que permita alcanzar un producto atractivo para el mercado.

- Diseñar las instalaciones de la planta que permitan materializar la ingeniería del proyecto.

- Comprobar la rentabilidad de fabricar este producto y, por ende, del proyecto mismo por medio de la evaluación económica y financiera.

- Comprobar la sostenibilidad social del proyecto mediante la evaluación social del mismo

\subsection{Alcance y limitaciones de la investigación}

El alcance será con foco en Lima Metropolitana, núcleo del negocio, debido a que de esta zona geográfica se obtendrá toda la materia prima reciclada por la alta concentración de población presente y, por ende, la cantidad de desechos producidos. En lo que respecta al mercado, este también se concentra en esta ubicación, y se enfocará en todas las empresas de Lima como potenciales clientes, con la opción de extender la cobertura a lo largo de la costa peruana si el potencial lo amerita.

Sin embargo; las dos principales limitaciones para esta investigación son el alto porcentaje del mundo del reciclaje que se encuentra sometido a la informalidad, motivo por 
el cual existe una carencia de información con respecto al mercado, competidores, tecnologías utilizadas, volúmenes de producción, etc. La segunda limitación, se encuentra relacionada a la falta de información asociada al reciclaje del polipropileno debido a la poca popularidad de esta práctica en comparación con el reciclaje de otros plásticos como el poli tereftalato de etileno (PET) o el polietileno (PE). Por este motivo algunos puntos durante el trabajo se basan principalmente en las opiniones de expertos en el tema.

\subsection{Justificación del tema}

El presente estudio de pre factibilidad es un estudio preliminar para evaluar la viabilidad de una planta procesadora de escamas de polipropileno (también denominado PP) reciclado. La selección de este tema recae en dos motivos principales: cuidado del medio ambiente y desarrollo del mercado peruano.

Respecto al primer punto, en las últimas décadas cada vez hay más conciencia respecto a cuidar los recursos naturales ya que son limitados (Evaluaciones del desempeño ambiental del Perú, 2016). Con el reciclaje se logra este objetivo, ya que se reutilizan recursos que fueron descartados antes como basura. En paralelo, los plásticos tardan hasta cientos de años en degradarse y más del 70\% de estos terminan en vertederos y en los océanos (BBC, 2017); por lo que encontrarles uso a estos desechos es beneficioso para el ambiente, para los animales y para los seres humanos. La situación es tan preocupante, que, según BBC News, “de no tomarse medidas, para el 2050, se habrá generado más de 12,000 millones de toneladas de residuos plásticos”. (BBC, 2017)

En el segundo punto, según un experto en el medio de la empresa Gexim, M. Gelmi (comunicación personal, 9 de abril, 2016), en Perú el mercado de los plásticos es mayoritariamente importador. Si se logra que el plástico recuperado sea una competencia para el plástico virgen (puro), se puede reducir la importación e incentivar la producción local. Velarde y Pérez (1998) observaron que ninguna empresa afiliada (formal) se encontraba en el ámbito de reciclaje. De las muchas (500 en 1998) pequeñas y limitadas empresas que existen dedicadas al plástico, pocas realmente se interesan del aspecto ambiental y al mismo tiempo suelen ser muy ineficientes. 
El enfoque de los materiales a reciclar son los termoplásticos, como por ejemplo el polipropileno (PP), polietileno (PE) o el tereftalato de polietileno (PET). Esto es porque pueden ser moldeados varias veces tras hacer el proceso de calentar y enfriar, mientras que los termoestables luego de calentarse una primera vez tienen una reacción química llamada degradación en la que sus moléculas se enlazan permanentemente.

\subsection{Hipótesis de trabajo}

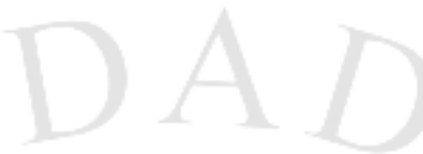

La hipótesis es que la instalación de una planta procesadora de escamas de polipropileno si será viable técnica, económica y socialmente. Por lo tanto, representa una gran oportunidad para el cuidado del medio ambiente y el desarrollo del mercado peruano.

\subsection{Marco referencial}

- Tesis de Juan José Marina Casique: Estudio de pre factibilidad para la implementación de una planta de producción y comercialización de escamas de PET reciclado (2009). Trata acerca del PET, que es otro termoplástico el cual es trabajable tras reciclar. Aunque el enfoque no es en polipropileno, el objetivo principal de reciclaje es lo que se observa.

- Proyecto final de Solange Olazar Oviedo y Gonzalo Eliel López: Reciclado de Polipropileno (2016). Este trabajo ofrece una perspectiva actualizada y comparable de otro país de Latinoamérica, Argentina, lo cual es necesario para entender más allá de la perspectiva nacional. En este caso se concluyó que no era viable económicamente, con lo que se puede analizar potenciales riesgos.

- Tesis de Cristian Enrique Villar Navarro: Evaluación técnica y económica para implementar una planta de procesamiento de plástico reciclado en Chincha (2013). Esta tesis se enfoca en otra región del Perú que es un mercado a menor escala que Lima. Sirve para analizar el mercado fuera de Lima que viene a ser el "núcleo" comercial y poblacional del Perú. 
- Tesis de Lorena Avalos y Percy Torres: Plan de negocios para la implementación de una planta de reciclaje de plástico (2014). Es directamente comparable en el aspecto geográfico al enfocarse en Lima, pero no es exclusiva de reciclaje de polipropileno al incluir también PET y PEAD.

- Tesis de Cesar Augusto Lanchipa Merino: Investigación de pre factibilidad para la instalación de una planta de reciclaje de plástico (1998). El enfoque de esta tesis es muy similar al que se utilizará para el presente trabajo. Por esta razón, sirve como una buena base referencial y teórica para iniciar el presente estudio.

- Tesis de Mario Alejandro Vallvé Pozaric: Estudio de pre factibilidad para la instalación de una planta de desechos plásticos (1992). Al igual que la anterior, el tema es muy parecido al que se tratará actualmente por lo cual se eligió como base referencial. La limitación es que ya es desactualizada. En más de 20 años de lapso, si hay diferencias en la situación que vive el Perú.

\subsection{Marco conceptual}

El tema que origina la realización de la presente investigación es la elevada generación de residuos sólidos, en especial plásticos, que se presenta en el Perú y en el mundo. Según la conocida cadena de noticias BBC News, "hay tantos residuos plásticos en el mundo que podrían cubrir un país como Argentina" (BBC, 2017). En el caso puntual de la provincia de Lima, la generación de residuos sólidos ha incrementado a un ritmo promedio de casi $4 \%$ por año en los 10 últimos años (Ambiente, 2016) llegando a un nivel de casi 3 millones de toneladas anuales; de las cuales aproximadamente un 10\% corresponde a plásticos (Anuario de estadísticas ambientales del Perú, 2015).

Una de las soluciones planteadas para este problema tanto a nivel país como a nivel mundial es el reciclaje, lo cual consiste en una "transformación de los residuos a través de distintos procesos, que permiten restituir su valor económico, evitando así su disposición 
final" (Olazar Oviedo y López, 2016). El reciclaje es un proceso que cada vez se hace más común en el mundo; sin embargo, en el Perú es un tanto primitivo, hecho que evidencia al tener solo un 25\% de municipalidades en Lima Metropolitana que usan dichas prácticas como destino final de los residuos generados (Ambiente, 2016).

Dentro del reciclaje, la presente investigación se concentra en el de plásticos y de manera específica en el PP. Dicho proceso se lleva a cabo de dos principales formas: reciclaje químico y reciclaje mecánico. La gran diferencia entre ambos consiste en que el reciclaje de carácter químico involucra una descomposición y reestructuración a nivel molecular de los plásticos, mientras que el reciclaje mecánico es tan solo a un nivel físico. Se brinda mayor detalle en torno a dicha clasificación más adelante en la investigación.

Con la finalidad de una mejor comprensión del panorama completo del presente trabajo, se definen los términos más críticos a continuación en base a lo recopilado en los libros de Ureta Barrón y Wade:

- Reciclaje: Proceso para devolver utilidad a materiales de desecho, con el objetivo de reducir la contaminación del medio ambiente.

- Polipropileno: Compuesto químico termoplástico obtenido por polimerización del propileno.

- Plástico virgen: Plástico que ha sido manufacturado bajo pedido específico y se utilizará por primera vez.

- Plástico recuperado: Plástico obtenido por medio del reciclaje.

A modo de complemento se presenta una lista de términos relevantes en el anexo 2 del presente documento.

Finalmente, el objetivo de esta buena práctica consiste en retirar la mayor cantidad de residuos de PP que genera la población y darles un nuevo uso, para así evitar que este material no degradable fácilmente, se acumule y genere daños al ambiente, los humanos y los animales. 


\section{CAPÍTULO II: ESTUDIO DE MERCADO}

\subsection{Aspectos generales del estudio de mercado}

En este acápite se procede a detallar el producto foco del estudio, bienes sustitutos y complementarios, área geográfica a abarcar, análisis del sector industrial y metodología a emplear para la investigación.

\subsubsection{Definición comercial del producto}

La propuesta consiste en preparar escamas de polipropileno reciclado que puedan competir con el polipropileno virgen. Esto se logrará asegurando la pureza del material mediante un proceso de separación tanto por color como por polímero. Cuando se logra diferenciar por color, el cliente es capaz de producir plásticos de diversos colores en vez de solo negro o verdoso oscuro. Respecto al polímero, muchas veces el polipropileno se entrega contaminado con polietileno y viceversa, ya que son plásticos muy similares y pocas empresas dan el valor agregado de separarlos. Por último, se enfocará en dar un producto sin humedad; factor, que según expertos del tema (Plastics technology Mexico, 2016) (Tecnología de los plásticos, 2011), es muy importante en el mercado de plásticos para que la materia prima pueda ser trabajada correctamente en procesos posteriores como por ejemplo la extrusión.

El formato de presentación final del producto será en sacos de 25 kilogramos de escamas de PP reciclado $\widehat{\mathrm{cos}}$, que se comercializará directamente a empresas o distribuidores. 
Los potenciales CIIU identificados para la empresa fueron:

Tabla 2.1

CIIU de la empresa

\begin{tabular}{c|l}
\hline CIIU & \multicolumn{1}{|c}{ Descripción } \\
\hline 25200 & Fabricación de productos plásticos \\
2013 & Fabricación de plásticos y caucho sintético en formas primarias \\
2220 & Fabricación de productos de plástico \\
\hline
\end{tabular}

Elaboración propia

Se han considerado dos partidas arancelarias, que son las más relevantes con nuestro producto, que son:

- Polipropileno, en formas primarias - 3902100000

- Copolímeros de polipropileno, en formas primarias - 3902300000

\subsubsection{Principales características del producto}

En este acápite se procede a detallar los usos y características del producto y los bienes que son sustitutos y complementarios para el mismo.

\subsubsection{Usos y características del producto}

Las escamas de polipropileno reciclado son una materia prima que por sus propiedades versátiles puede utilizarse para diversas aplicaciones o rubros como los de envases, transporte, maquinaria, artículos domésticos, electrodomésticos, construcción, entre otros. (Garzón Caballero, González Peña, Galeano, Flechas, y Montenegro). En otras palabras, las empresas que compren este producto tendrán la facilidad de que pueden transformarlo en lo que necesiten por medio de procesos de fundición, extrusión, inyección, entre otros. Esto se puede aplicar tanto para bienes de carácter industrial (herramientas, partes, maquinaria) o para el consumidor final (botellas, sillas, juguetes y otros). 
Las principales características del producto final son la ausencia de humedad, la pureza y la calidad, las cuales permiten que sea un producto altamente competitivo. Además, es importante recalcar que se complementa con sus propiedades generales inherentes como su carácter de termoplástico, resistencia eléctrica, baja permeabilidad, flotación en agua, resistencia a bacterias y al ataque químico (Garzón Caballero, González Peña, Galeano, Flechas, y Montenegro).

\subsubsection{Bienes sustitutos y complementarios}

Los bienes sustitutos son dos: el plástico virgen y el plástico reciclado sin mayor procesamiento. El primero es debido al mayor grado de calidad que ofrece y que se fabrica a pedido, es decir que tiene las características específicas deseadas por el cliente. El segundo esta un paso atrás en la cadena de valor (sin los procesos de separación, secado, entre otros). Este último representa un fuerte peligro debido a que los clientes pueden integrarse hacia atrás u optar por una opción más económica si no les interesa la calidad.

Tabla 2.2

Tabla comparativa de las principales características del polipropileno virgen y reciclado

\begin{tabular}{l|ccc}
\hline \multicolumn{1}{c|}{ Características } & Escamas de poliproplieno virgen & $\begin{array}{c}\text { Escamas de polipropileno } \\
\text { reciclado sin procesamiento }\end{array}$ & $\begin{array}{c}\text { Escamas de polipropileno } \\
\text { reciclado con separación de color } \\
\text { y polímero }\end{array}$ \\
\hline $\begin{array}{l}\text { Pureza } \\
\text { Versatilidad de } \\
\text { colores en } \\
\text { productos finales }\end{array}$ & Alta & Media & Alta \\
$\begin{array}{l}\text { Resistencia } \\
\text { Precio }\end{array}$ & Alta & Baja & Alta \\
Humedad & Alta & Media alta & Media alta \\
\hline
\end{tabular}

Fuente: J. Gutiérrez (comunicación personal, 14 de junio, 2016)

Los bienes complementarios son cualquiera que se utilice para incrementar la calidad del plástico, como por ejemplo los aditivos y colorantes. 


\section{Tabla 2.3}

Listado de aditivos y su función

\begin{tabular}{|c|c|}
\hline Tipo & Función \\
\hline Rellenos & $\begin{array}{c}\text { Permiten que se produzcan grandes volúmenes de material } \\
\text { polímerico con muy poca resina }\end{array}$ \\
\hline Plastificantes & Aumentan la flexibilidad y elasticidad de los plásticos. \\
\hline Estabilizantes & $\begin{array}{c}\text { Impiden o retardan el deterioro del polímero debido a } \\
\text { efectos del entorno }\end{array}$ \\
\hline $\begin{array}{c}\text { Agentes } \\
\text { antiestáticos }\end{array}$ & $\begin{array}{l}\text { Reducen acumulación de cargas electrostáticas en la } \\
\text { superficie de los plásticos }\end{array}$ \\
\hline $\begin{array}{l}\text { Agentes de } \\
\text { acoplamiento }\end{array}$ & $\begin{array}{c}\text { Mejoran la adhesión del plástico a los materiales de } \\
\text { relleno inorgánicos }\end{array}$ \\
\hline $\begin{array}{l}\text { Retardantes de } \\
\text { flama }\end{array}$ & Reducen la inflamabilidad de los plásticos \\
\hline Agentes insuflantes & Permiten crear una estructura celular, es decir, espuma \\
\hline Lubricantes & $\begin{array}{l}\text { Facilitan la elaboración de resinas y mejoran la apariencia } \\
\text { del producto final }\end{array}$ \\
\hline Reforzantes & Mejoran la resistencia y rigidez de los polímeros \\
\hline
\end{tabular}

Fuente: Olazar, S. y López, G. (2016) 
Tabla 2.4

Lista de colorantes

\begin{tabular}{c|c}
\hline Tipo & Descripción \\
\hline Pigmentos & $\begin{array}{r}\text { Partículas finamente molidas que quedan uniformemente } \\
\text { dispersas en el polímero }\end{array}$ \\
Tintes & $\begin{array}{r}\text { Menos utilizados que los pigmentos, ya que imparten } \\
\text { colores con menor solidez }\end{array}$ \\
Negros de humo & $\begin{array}{r}\text { Colorantes utilizados para proteger los plásticos de la } \\
\text { degradación térmica y por UV y como fibra de refuerzo }\end{array}$ \\
\hline
\end{tabular}

Fuente: Olazar, S. y López, G. (2016)

\subsubsection{Determinación del área geográfica que abarcará el estudio}

Como ya se mencionó en el acápite 1.3, el foco principal el proyecto de factibilidad tiene como zona de aplicación a Lima Metropolitana donde actualmente hay una población de 9 904727 habitantes (INEI, 2016) y una producción anual de casi 3 millones de toneladas de residuos sólidos. Si realmente existe potencial técnico, económico y social como se propone en los objetivos y la hipótesis del proyecto, se puede considerar extender el área a toda la costa peruana o departamentos adyacentes a Lima, como Ica, Arequipa o La Libertad. Todos estos son departamentos con alto potencial debido al tamaño de la población y la cantidad de residuos sólidos producidos.

De igual manera, es importante remarcar que es poco probable en el corto plazo que el proyecto se expanda fuera de Lima, que es donde el mercado se concentra debido a que es donde las empresas actuales (formales e informales) operan. Si se involucra los departamentos mencionados en todo caso es como fuente de materia prima, porque lamentablemente aún hay muy poca conciencia respecto al reciclaje en Perú y esto se intensifica en provincias.

\subsubsection{Análisis del sector industrial}

Según el modelo de Michael E. Porter se procedió a realizar el análisis estructural del sector en el que se competiría: 
- Amenaza de nuevos ingresos: En este sector la amenaza de ingreso es alta, ya que las barreras de entrada son bajas. Esto es debido a tres razones principales: Hay baja diferenciación del producto, ya que es difícil resaltar notoriamente entre diferentes plásticos reciclados. Los requisitos de capital dependen de la calidad de la maquinaria adquirida pero el costo total se estima entre un millón y millón y medio de dólares, cantidad que representa una inversión importante; sin embargo, esta no se compara con lo que podría llegar a invertirse en otras industrias como las de la cerveza, por ejemplo. Por último, los costos cambiantes, es decir para cambiar de proveedor, son bajos por lo que puede decirse que no hay mucha lealtad.

- Rivalidad entre los competidores existentes: En lo que respecta al mercado de producción interna, en el cual se planea competir, la rivalidad se consideraría baja. De igual manera, tomando en cuenta al mercado externo de empresas internacionales (del que se importa) sigue representando una rivalidad baja, porque no llegan a competir directamente. Estos ofrecen otro producto totalmente diferente, en la forma del polipropileno virgen. Con respecto a esta fuerza se identificaron 2 factores principales que son: el número de competidores, que es bajo dentro de Perú y no tienden a canibalizarse entre ellos, información que se visualiza posteriormente en el acápite 2.3.2. Por otro lado, el crecimiento del sector no es lento, más bien crece de forma constante y cada vez más acelerada.

- Amenaza de productos sustitutos: La amenaza es alta, por el hecho de que se ofrecen también los aditivos de forma directa a las potenciales empresas compradoras. Con estos, los clientes pueden comprar plástico de menor calidad y utilizar el aditivo para que sea más fácil trabajarlo. Es importante considerar esto, y si es posible usarlo a favor. Esto significa que internamente también se utilice aditivos para mejorar la calidad de nuestro producto aún más (esto demuestra que los aditivos pueden ser una espada de doble filo, pueden resultar siendo tanto productos complementarios como sustitutos si no se aprovechan correctamente). Es por esta fuerza de Porter, que es importante tener un enfoque en diferenciación, y no en costos ya que el producto debe ser capaz de convencer a los clientes de adquirirlo directamente en vez de utilizar 
aditivos. El gran peligro de este sustituto radica en que puede producir pérdida de rentabilidad al quedarse un paso atrás del proceso, al ofrecerse escamas sin procesar para que se trabajen con el aditivo. El otro producto sustituto sería el que estamos intentando reemplazar, es decir el polipropileno virgen.

- Poder negociador de los clientes: Se aprecia un alto poder de los clientes, ya que tienen la capacidad de forzar la baja de precios si así lo desean. Se identificaron 4 razones para esto: el producto ofrecido no es tan diferenciado como se mencionó previamente. Ya que el polipropileno y el polietileno son tan similares, algunos optan por sacrificar la calidad del producto, en términos de pureza, a favor del precio, y a simple vista no es tan sencillo detectar este grado de pureza que se apunta a ofrecer. Esto se refleja con las pruebas de flotación, por ejemplo, lo cual es algo que se deberá dejar muy claro al momento de salir al mercado. El costo de nuestro producto como materia prima representa, según opinión de expertos en el tema, un porcentaje pequeño dentro de los costos totales de producción que pueden tener los clientes finales. También, aunque no es tan probable, podrían llegar a realizar integración hacia atrás si lo requirieran. Por último, el producto no es tan importante para la calidad final, eso ya lo pueden obtener comprando directamente el PP virgen.

- Poder negociador de los proveedores: Esta fuerza de Porter es la que representa la mayor ventaja para el mercado de materiales reciclados, debido a que los proveedores tienen un poder de negociación mínimo o incluso nulo. Esto es por cuatro razones principales: Hay un alto número de "empresas", en la forma de recolectores que consiguen plástico desechado y lo revenden. La importancia como cliente para el grupo proveedor es alta, ya que de no vender su producto es muy poco probable que otro tipo de empresa no especializada en reciclaje lo compre. Además, se enfrentan al problema de que no hay diferenciación de sus productos con los de la competencia (todos vienen a ser basura) y finalmente, es casi imposible que se integren hacia adelante debido a la inversión y conocimiento requerido para dar ese gran paso. 


\subsubsection{Metodología a emplear en la investigación de mercado}

Para la investigación se han utilizado dos fuentes primarias compuestas por las encuestas a potenciales clientes para entender la recepción que tendría el producto en el mercado y entrevistas a profundidad a competidores ya presentes en el medio. Los resultados combinados de ambas fuentes primarias son lo que se muestra en el acápite 2.2.3.1 donde se explica a mayor detalle.

A partir de datos y fuentes secundarias, que fueron Veritrade para las importaciones y exportaciones de los años 2011 a 2015, y combinado con el juicio de expertos para el nivel de producción interno, se obtuvo la demanda interna aparente de las escamas de polipropileno reciclado para ser capaces de ejecutar una proyección de la demanda en base al comportamiento que refleje (que puede ser lineal, exponencial, estacional, entre otros).

\subsection{Análisis de la demanda}

En este acápite se procede a detallar la Demanda Interna Aparente Histórica, la demanda potencial, demanda mediante fuentes primarias, la proyección de la demanda y consideraciones sobre la vida útil del proyecto.

\subsubsection{Demanda histórica}

En este acápite se procede a detallar como las importaciones, producción y exportaciones pasadas conforman la Demanda Interna Aparente histórica.

\subsubsection{Importaciones / Exportaciones}

En el presente estudio, las exportaciones e importaciones del polipropileno tienen realidades completamente diferentes; las exportaciones son sumamente pequeñas por no decir casi nulas como se puede observar en la tabla 2.5 a continuación. Por otro lado, las importaciones se presentan en grandes volúmenes conformando así casi la totalidad de la Demanda Interna Aparente (DIA). 


\subsubsection{Producción nacional}

Actualmente, gracias a información proporcionada por el gerente general de Polímeros y Empaques S.A.C, José Gutiérrez (en adelante Poliempaq) se ha determinado que se producen 800 toneladas métricas por mes de polipropileno reciclado a nivel nacional (comunicación personal, 14 de junio, 2016). Se entrará a más detalle de cómo se conforma la producción nacional, o en otras palabras la oferta presente en el mercado actualmente, en el acápite 2.3. Pero, debido a la informalidad y cantidad de productores pequeños, la oferta nacional está muy fragmentada y solo se han podido identificar 3 productores grandes (incluido Poliempaq) que producen el 32,50\% de las 800 toneladas métricas totales. El resto del mercado no es posible identificarlo con claridad ya que muchos no están registrados en SUNAT ni tienen RUC (informalidad) y el resto son muy pequeños independientemente.

Finalmente, esto se traduce a 9600 toneladas al año, lo cual compararemos con las importaciones en la tabla 2.5 a continuación.

\subsubsection{Demanda Interna Aparente (DIA)}

Para hallar la Demanda interna aparente, se empleará la fórmula:

\section{DIA = Producción + Importaciones - Exportaciones}

Para el cálculo en este acápite, se traducen todos los valores a valores de peso (toneladas), ya que se cuenta con información de la producción en toneladas (es decir, el volumen reciclado identificado), de las importaciones en USD CIF, y de las exportaciones en USD FOB. De esta forma, se logran valores comparables y se obtiene un análisis correcto al trabajar. 
Tabla 2.5

Demanda interna aparente del polipropileno en toneladas

\begin{tabular}{c|cccc}
\hline Año & $\begin{array}{c}\text { Importaciones } \\
\text { de PP (en ton) }\end{array}$ & $\begin{array}{c}\text { Producción de } \\
\text { PP (en ton) }\end{array}$ & $\begin{array}{c}\text { Exportaciones } \\
\text { de PP (en ton) }\end{array}$ & $\begin{array}{c}\text { DIA de PP (en } \\
\text { ton) }\end{array}$ \\
\hline 2011 & 198896,42 & 9600 & 4344,76 & 204151,66 \\
2012 & 221172,56 & 9600 & 5587,09 & 225185,47 \\
2013 & 233938,96 & 9600 & 7001,67 & 236537,29 \\
2014 & 245783,25 & 9600 & 6134,22 & 249249,03 \\
2015 & 254921,90 & 9600 & 5624,21 & 258897,69 \\
\hline
\end{tabular}

Fuente: Veritrade (2016)

Se observa un crecimiento anual histórico de la Demanda Interna Aparente impulsado por las importaciones, ya que estas crecen año a año de forma consistente. La DIA muestra un comportamiento con tendencia potencial, la cual da el valor $R^{2}$ más alto $(0,9959)$ y muy próximo a 1. Esto demuestra que cada día la demanda de las empresas para producir variados productos en base a plástico ha ido incrementando y se ha apoyado solamente en la oferta externa del país. Las exportaciones son mínimas y la producción se asume constante en base al juicio del señor Gutiérrez, gerente general de Poliempaq, ya que es muy difícil obtener una medida exacta por el alto grado de informalidad que hay en este rubro. Se estima que entre $30 \%$ y $40 \%$ de la producción de plástico reciclado en el interior del país recae en la informalidad, por lo que no hay manera de registrar un nivel de producción exacta. 
Figura 2.1

Demanda interna aparente del polipropileno en toneladas

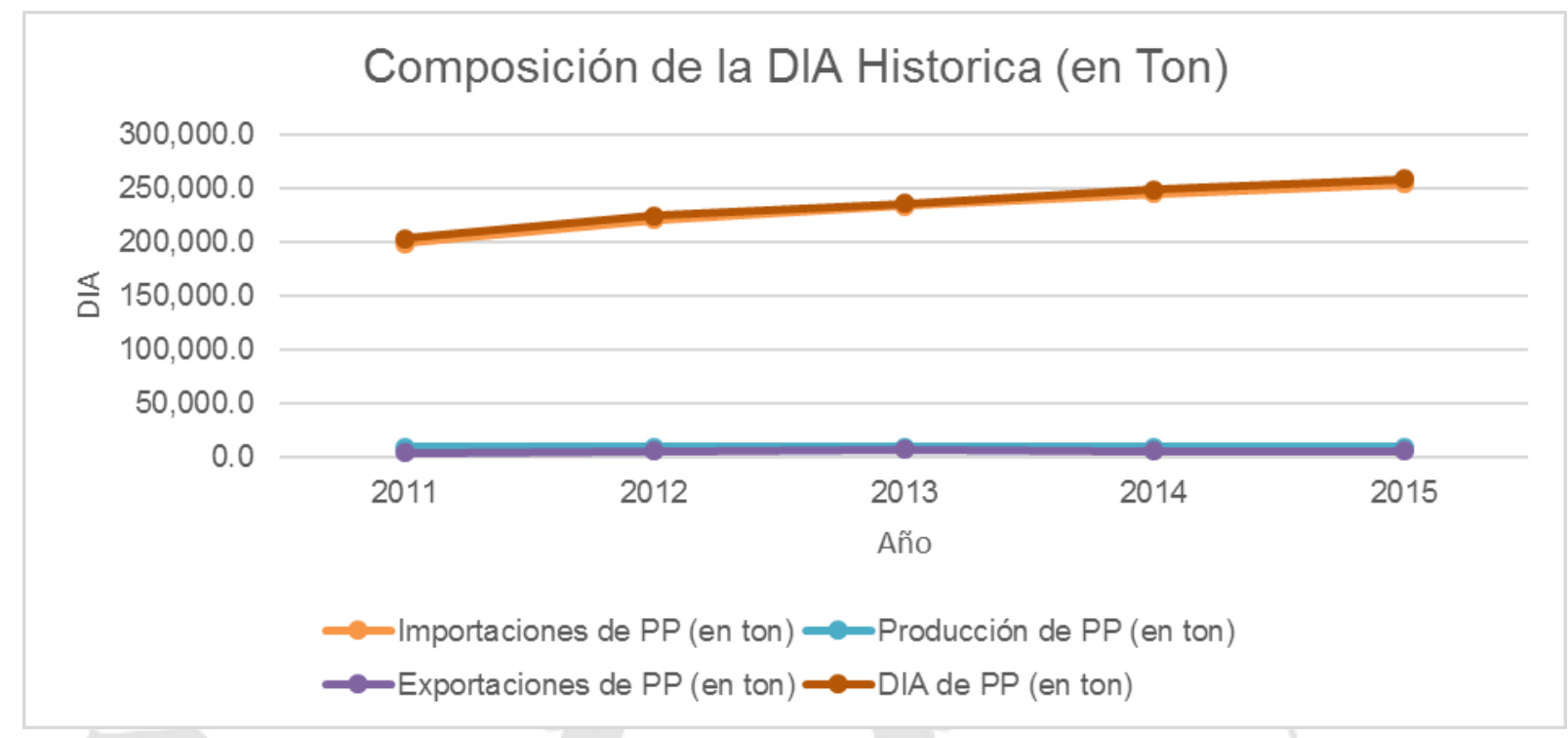

Elaboración propia

\subsubsection{Demanda potencial}

En este acápite se procede a detallar todos los patrones de consumo relevantes y la demanda potencial en función a estos.

\subsubsection{Patrones de consumo}

Debido a que la fuente de materia prima proviene en gran parte de productos de consumo masivo, es decir para el consumidor final (por ejemplo, chapas de botellas, envolturas, recipientes de productos para el pelo, etc.), muchos patrones demográficos como el incremento poblacional y densidad poblacional de cada región afectan directamente el consumo, ya que la cantidad de materia prima para el proyecto incrementa proporcionalmente con la mayor cantidad de residuos sólidos plásticos producidos. Según el Compendio Estadístico Perú, basta observar que en los últimos 10 años solamente, la población del Perú ha aumentado en 3341103 personas, cifra que es realmente considerable tomando en cuenta que representa el $12 \%$ de la población que había en ese momento. En la 
provincia de Lima se concentra gran parte de esta población ocasionando una densidad poblacional muy por encima del promedio nacional (3 344,3 contra 23,98 habitantes por kilómetro cuadrado), lo cual es realmente alarmante por la gran cantidad de desechos que son producidos, pero sin ningún tipo de control (Instituto Nacional de Estadistica e Informatica, 2015). Esto demuestra que es necesario un cambio de mentalidad y hábitos en general a nivel país, ya que no es sostenible que la población crezca en esos ritmos y no tenga una consciencia sobre el manejo de desechos, lo cual va de la mano con el tercer factor líneas abajo.

Otro factor importante que también afecta es el clima, ya que hay estacionalidad en base al verano y al invierno. Hay productos como las gaseosas y agua que se consumen en mayores cantidades en verano que en invierno. En este punto, por el efecto invernadero y el calentamiento global, en los últimos 11 años ha incrementado en 0,8 grados la temperatura máxima promedio anual en Lima.

Por último, el factor más obvio pero no menos importante, es el cultural, ya que cada día hay más concientización acerca de la relevancia del reciclaje, esto se evidencia a través de diversas tendencias como zapatillas hechas a base de botellas recicladas, planes de grandes empresas como Coca-Cola y Pepsi para reciclar envases de plástico utilizados y la apertura de una de las plantas de reciclaje más grande y sofisticada del país en el distrito de Surco (El Comercio, 2017). Cada vez hay más enfoque en el cuidado del medio ambiente por lo que el mercado al que queremos entrar es beneficiado directamente.

\subsubsection{Determinación de la demanda potencial}

Para obtener la demanda potencial, se asumirá que se reemplaza al 100\% las importaciones de polipropileno, y se forma un mercado autosuficiente dentro del país en el que se produce y recicla todo. Esta suposición es válida por dos principales razones: la producción local actual de polipropileno reciclado es relativamente pequeña por lo que genera un amplio espacio para el ingreso en este mercado con pocos competidores sólidos y las importaciones de polipropileno poseen precios más elevados que los planteados en este trabajo para el 
producto que se fabricará. Ambos motivos se detallan con mayor profundidad a lo largo del documento.

Por esta razón, se decidió evaluar al Perú mismo y no otro país, ya que actualmente este mercado se basa únicamente, o casi en su totalidad, en importaciones. Si se fuera capaz de asumir esta demanda, estamos hablando de un mercado de aproximadamente 367493266 dólares o 1249477104 soles en base al promedio de los últimos 5 años, obtenido a partir de la base de datos Veritrade según la tabla 2.3 a continuación. Estos montos son CIF, ya que lo que nos importa en el momento es el valor de los plásticos una vez que están dentro del país, ya con los costos de seguro y flete cargados.

Como se puede ver, el mercado potencial es enorme, representando más de un billón de soles.

Tabla 2.6

Importaciones anuales de polipropileno en dólares y soles

\begin{tabular}{l|ccccc}
\hline Año & $\mathbf{2 0 1 1}$ & $\mathbf{2 0 1 2}$ & $\mathbf{2 0 1 3}$ & $\mathbf{2 0 1 4}$ & $\mathbf{2 0 1 5}$ \\
\hline Monto USD & $\$ 352513654$ & $\$ 343017045$ & \$383288776 & \$417514403 & \$341 132452 \\
Monto S/ & S/ 1198546423 & S/ 1166257953 & S/ 1303181838 & S/ 1419548970 & S/ 1159850336 \\
\hline
\end{tabular}

Fuente: Veritrade (2016)

Por último, asumiendo que cada kilogramo de polipropileno se compra a aproximadamente 1,5 dólares (en base al promedio obtenido de Veritrade), podemos hablar de una demanda más o menos estable de 240 millones de kilogramos al año.

\subsubsection{Demanda mediante fuentes primarias}

En este acápite se procede a detallar como se trabajaron las encuestas para obtener la información relevante del público objetivo. 


\subsubsection{Diseño y aplicación de encuestas}

En base a lo definido en los criterios de segmentación se realizó un cuestionario, con la misión de determinar qué tan atractivo sería nuestro producto para las empresas identificadas como potenciales clientes, que coinciden con el perfil del mercado objetivo definido (como por ejemplo Plásticos Rey). El cuestionario, presente en los anexos del trabajo, se enfocó en identificar cuatro cosas principalmente:

- Intención de compra

- Intensidad de compra

- Frecuencia

- Características deseadas/esperadas del producto

Dicho cuestionario se aplicó a una muestra reducida de individuos en el medio, debido a que el público objetivo que se encuentra conformado por potenciales clientes según las características especificadas con anterioridad, no se presenta en abundancia en el medio en el que se desarrollará el negocio. Sin embargo, este número reducido de aplicaciones permitió la obtención de información sumamente valiosa ya que provenía de gente experta y perteneciente al medio.

Como se menciona previamente, en este estudio de mercado no se cuenta con una muestra de gran tamaño, debido a que se busca que la encuesta sea con expertos del medio los cuales no están presentes en grandes cantidades. En ese sentido, este estudio de mercado difiere de lo que se realizaría para un producto de consumo masivo que apunta al consumidor final.

Las encuestas se hicieron a personas de Gexim, Poliempaq y SGM, todas siendo empresas del rubro. El detalle de las preguntas realizadas con la encuesta se incluye en el anexo 1 al final del documento y los resultados fueron los siguientes: 
- Intención: El resultado fue de $100 \%$, todos los encuestados estarían dispuestos a comprar el producto ya que es atractivo.

- Intensidad de compra: Al darse un ranking del 1-10 para determinar qué tan dispuestos estaban a obtenerlo, se hizo un promedio de los resultados para obtener un porcentaje aproximado. El resultado fue 8, por lo tanto, la intensidad se determinó como $80 \%$.

- Frecuencia: La conclusión respecto a este punto fue que depende mucho del tamaño de la empresa y si nuestro producto llega a formar una parte importante de su proceso de producción (en términos de materia prima). Como referencia, se obtuvo del gerente general de SGM, que Plásticos Rey compraba entre 100 y 150 toneladas de plástico reciclado cada mes (comunicación personal, 21 de junio, 2016). Pero el rango, asumiendo que haya una demanda constante y es un insumo relevante para el cliente es que se compre con una frecuencia semanal o mensual.

- Cantidad comprada: Este punto al igual que el anterior depende mucho del cliente y puede variar enormemente. Algunas de las respuestas recolectadas variaban desde 15 hasta 50 toneladas por pedido semanal.

- Características deseadas: De las 6 características encuestadas, la más importante fue la pureza, es decir, cuando solo hay un polímero en la mezcla. Luego de esta, hubo un triple empate entre la humedad (si el polímero está húmedo, es muy difícil trabajarlo), el precio (competitivo) y el color (separado en vez de surtido).

Estos resultados se obtuvieron debido a que se asignó una puntuación en las encuestas para sacar una escala y los resultados fueron los siguientes: 
Tabla 2.7

Características de PP reciclado por orden de importancia

\begin{tabular}{c|c}
\hline Característica & Puntuación \\
\hline Pureza & 20 \\
Humedad & 17 \\
Precio & 17 \\
Color & 17 \\
Tamaño & 9 \\
Forma & 4 \\
\hline
\end{tabular}

Elaboración propia

\subsubsection{Proyección de la demanda}

En base al comportamiento de la DIA, obtenido en el acápite previo, podemos realizar la proyección de la demanda en base al método de la tasa de crecimiento anual compuesto o CAGR (por sus siglas en inglés). Este método consiste en obtener una tasa de crecimiento promedio en base al comportamiento pasado de un producto.

Para lograr esto se utiliza la fórmula: $C A G R=\left(\frac{\text { Valor Final }}{\text { Valor Inicial }}\right)^{\left(\frac{1}{\# A n ̃ o s}\right)}-1$

Con el uso de esta fórmula se obtuvo un CAGR de 6,1\% anual, y la proyección de la demanda:

Tabla 2.8

Proyección de la DIA de los próximos 5 años en toneladas

\begin{tabular}{l|ccccc}
\hline Año & $\mathbf{2 0 1 6}$ & $\mathbf{2 0 1 7}$ & $\mathbf{2 0 1 8}$ & $\mathbf{2 0 1 9}$ & $\mathbf{2 0 2 0}$ \\
\hline DIA (en toneladas) & 274740,06 & 291551,85 & 309392,38 & 328324,60 & 348415,32 \\
Crecimiento año a año & $6,1 \%$ & $6,1 \%$ & $6,1 \%$ & $6,1 \%$ & $6,1 \%$ \\
\hline
\end{tabular}

Elaboración propia 


\section{Figura 2.2}

Demanda interna aparente histórica y proyectada

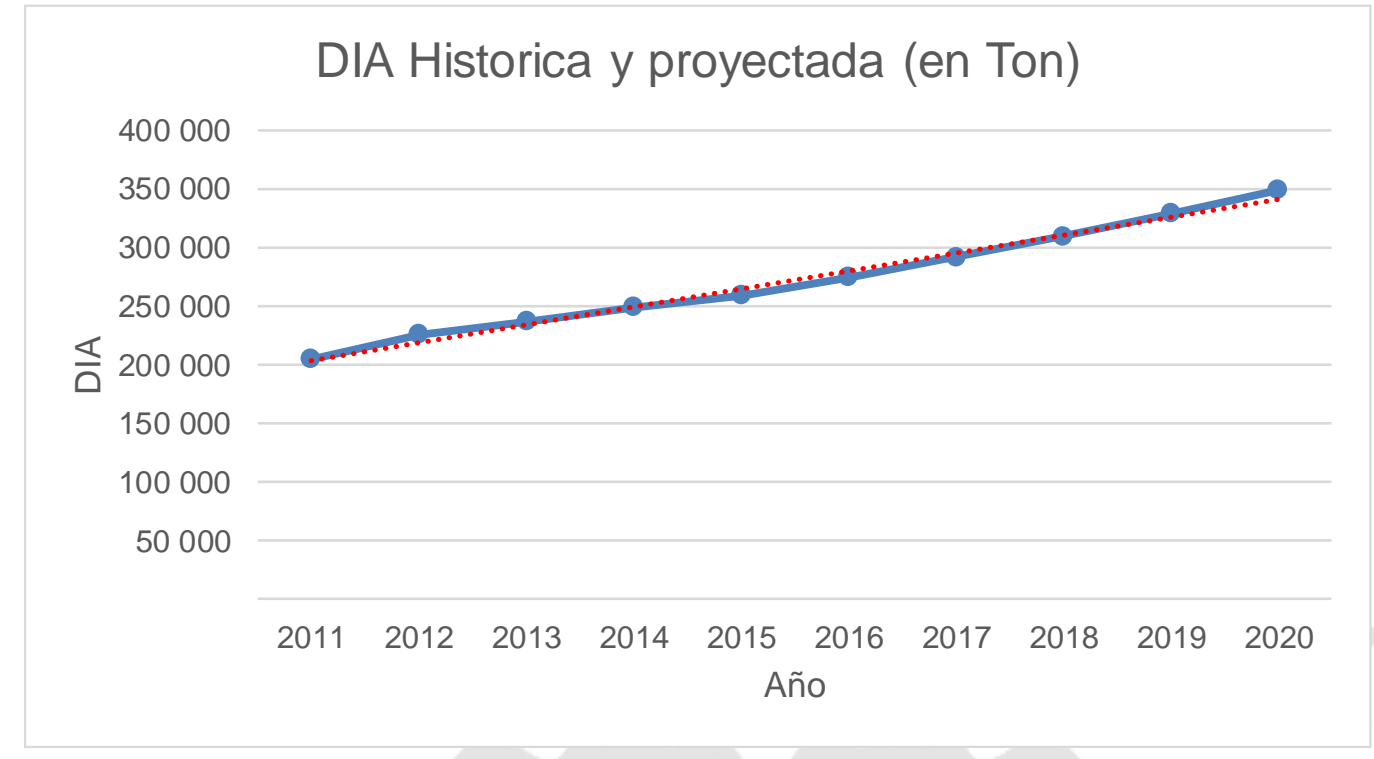

Elaboración propia

\subsubsection{Consideraciones sobre la vida útil del proyecto}

La vida útil designada para este proyecto es de cinco años. Este plazo se define en base a la investigación realizada sobre el mercado en cuestión y recomendaciones de expertos que se desenvuelven actualmente en dicho mercado. Se establece este plazo, a diferencia del plazo de siete años utilizado en la tesis de Juan José Marina Casique, principalmente por tres motivos: creciente innovación tecnológica, perseverancia de la informalidad en el mercado del reciclaje de plásticos e incertidumbre política en la que vive el país. Tomando en cuenta dichas consideraciones, se busca diseñar un proyecto cuyo periodo de recupero sea menor al horizonte de cinco años, de manera tal que sea viable. 


\subsection{Análisis de la oferta}

En este acápite se procede a detallar acerca de las empresas involucradas en el rubro y quiénes son los líderes del sector. Con esto, se puede entender cuáles son los competidores actuales y potenciales.

\subsubsection{Empresas productoras, importadoras y comercializadoras}

Como analizamos en el punto anterior, la producción en el mercado peruano es muy limitada, pero de igual manera se investigó al respecto. Actualmente se identificaron 3 empresas productoras principales, bajo el criterio de la cantidad significativa de polipropileno reciclado que producen. Una de estas es Poliempaq S.A.C que es uno de nuestros contactos principales para entender este mercado mejor, en términos de demanda y oferta. Las 3 empresas son:

- Polímeros y Empaques S.A.C (RUC: 20506852766)

- Oxiquímica Peruana (RUC: 20507486691), que actualmente se encuentra en baja de oficio según el estado de la SUNAT, esto significa que esta es informal

- $\quad$ Eco Logi-K Perú S.A.C (RUC 20551395121)

Según Veritrade, en lo que respecta a empresas importadoras existe una gran variedad y de varios países, pero las más relevantes hasta el año 2015 se detallan en la tabla a continuación. 
Tabla 2.9

Empresas importadoras de polipropileno

\begin{tabular}{l|cc}
\hline \multicolumn{1}{c|}{ Importador } & Volumen $(\mathbf{k g})$ & \% Part. \\
\hline POLIPROPILENO DEL CARIBE S.A. & 29624000,24 & $11,6 \%$ \\
BRASKEM S.A. & 29064001,43 & $11,4 \%$ \\
PETROQUIM S.A. & 26014745,00 & $10,2 \%$ \\
SABIC AMERICA.S INC. & 13761000,00 & $5,4 \%$ \\
RELIANCE INDUSTRIES LIMITED & 10333777,19 & $4,1 \%$ \\
Total general & 254921899,71 & $100,0 \%$ \\
\hline
\end{tabular}

Fuente: Veritrade (2016)

Entre estas se llevan más del $40 \%$ de las importaciones del Perú, en orden de importancia. También, esto muestra que el polipropileno se importa de diversos destinos y definitivamente es un mercado poderoso que mueve dinero. Esto se deduce porque si anualmente se están importando aproximadamente 250000 toneladas de polipropileno (e incrementando), hay una demanda que no se está satisfaciendo internamente y por lo tanto se recurre hacia fuera del país para lograrlo. Por lo tanto, el objetivo es revertir esa tendencia.

Por último, en este rubro no aplica realmente el término de empresas comercializadoras porque como veremos más a detalle en el punto 2.6 se aplica la venta directa.

Como adicional, hay prestadores de servicios como SGM (RUC 20268865200), en este caso del proceso de pelletizado. Por ejemplo, en el caso de Poliempaq, ellos no pelletizan personalmente el polipropileno proveniente de etiquetas o envolturas ya que es de una diferente densidad y, por ende, con diferentes requerimientos en la extrusora (en términos de presión, temperatura y otros). Por esta razón, sería necesario tener dos extrusoras diferentes o alternar turnos de producción, lo cual reduciría la eficiencia. Entonces, se toma la decisión de tercerizar el pelletizado de este polipropileno lo cual queda a cargo de empresas como SGM. 


\subsubsection{Competidores actuales y potenciales}

En cuanto a los competidores actuales y con el apoyo del gerente general de Poliempaq, se obtuvieron las participaciones de mercado de las 3 empresas productoras mencionadas en base a la producción promedio de 800 toneladas de polipropileno recuperado mensuales:

Tabla 2.10

Participación de competidores actuales

\begin{tabular}{c|c}
\hline Empresa & Participación \\
\hline Poliempaq & $12,50 \%$ \\
Oxiquimica & $15 \%$ \\
Eco Logi-K & $10 \%$ \\
Otros & $62,50 \%$ \\
\hline
\end{tabular}

Elaboración propia

Figura 2.3

Participación de competidores actuales

\section{Participación de competidores actuales}

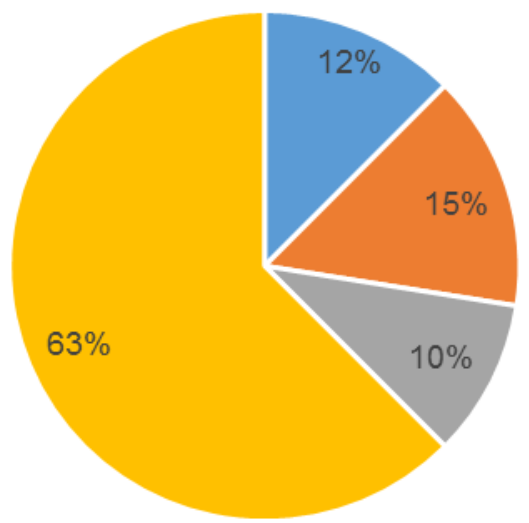

- Poliempaq - Oxiquimica =Eco Logi-K =Otros

Elaboración propia

Ese $62,5 \%$ de participación que en el cuadro anterior se ha denominado como "Otros", que según expertos en el rubro equivale a 500 toneladas, reside mayormente en lo 
informal. Esta es la parte más difícil de identificar ya que no hay registros legales de esta producción.

La cadena de suministro informal inicia cuando los recolectores de plástico entregan la materia prima a las empresas informales, y se les realiza el pago sin factura. Luego, estas empresas producen las escamas/pellets de polipropileno reciclado y las venden a clientes informales también, por lo que en ningún momento se generan registros. Según artículos encontrados en la web, casi el $90 \%$ de los recolectores de plástico para reciclaje en general son de carácter informal. (Hernandez Muro, 2016)

El otro porcentaje restante, aproximadamente $22,5 \%$ (62,5\% de otros menos el $40 \%$ de informalidad) pertenece a empresas pequeñas e independientes que se lo reparten entre ellas.

Por lo tanto, podemos ver que es un mercado muy fraccionado y de fácil entrada como se mencionó en el análisis de Porter. Debido a que existe un vasto mercado por cubrir, los competidores actuales no tienden a canibalizarse y tampoco hay un proveedor que sea notoriamente más grande o que amenace con formar un monopolio.

Por otro lado, no existe ningún competidor potencial específico, en este sentido el “competidor potencial" más peligroso es la misma informalidad. Esto es debido a que no permite que el mercado se desarrolle con naturalidad y a su máximo potencial, por varias razones como:

- Trae todos los precios abajo, al trabajar de forma informal y no pagar impuestos se puede vender a precios más bajos manteniendo el margen.

- Por la primera razón, el rubro pierde valor tanto de forma monetaria como en la percepción de los clientes. Queda la idea de que se pueden conseguir "mejores precios".

- Al tener un grado de informalidad tan alto, el rubro pierde seriedad. Se vuelve difícil medirlo correctamente y determinar si se está desarrollando.

- Por último, se vuelve un rubro no atractivo para acceder ya que nada le garantiza al trabajador una seguridad laboral y social. 
Si queremos hablar de un competidor potencial real, podríamos hablar del polipropileno virgen o de las escamas de polipropileno sin diferenciar por polímero ni por color. Esto significa ir hacia adelante o hacia atrás en la cadena de valor, pero si el cliente decide optar por estos significaría reemplazar la demanda de nuestro producto directamente. Dos ejemplos claros en este mercado de estos dos escenarios, sería que Polipropileno del Caribe, la empresa importadora de polipropileno más poderosa entre también al negocio de reciclado aparte de virgen. Por el otro lado que SGM, quien actualmente solo presta un servicio de pelletizado; ingrese al negocio y se vuelva un competidor en vez de un proveedor.

Un punto que es importante reconocer es que en este rubro hay muy poca lealtad del cliente, al ser un producto con tan poca diferenciación de por sí. El cliente se guía solamente del precio y calidad (y algunos otros factores relevantes del producto) para tomar la decisión de a quien comprarle su materia prima.

\subsection{Determinación de la demanda para el proyecto}

En este acápite se procede a detallar los criterios de segmentación del mercado, el mercado meta y la demanda especifica resultante.

\subsubsection{Segmentación del mercado}

Para definir el mercado objetivo se utilizarán tres criterios, tomando en cuenta que los clientes no son el consumidor final sino empresas en sí:

- Tamaño de la empresa: La primera variable a tomar en cuenta para realizar la segmentación es el tamaño de la empresa, este se encuentra definido según el volumen de ventas y fabricación de productos a base de polipropileno. Según este factor las empresas pueden ser clasificadas en grandes y medianas, pequeñas y microempresas. Según el estudio de mercado de polímero polipropileno de Roselly Vásquez Llontop del año 2014 se sabe que, dichos segmentos de empresas representan 2,5\%, 19,7\% y 77,8\% de la venta y fabricación de productos a base de polipropileno respectivamente. 


\section{Tabla 2.11}

Proporciones de cantidad de empresas y ventas por tamaño

\begin{tabular}{l|c}
\hline Tamaño de empresa & Volúmen de ventas (\%) \\
\hline Grande/Mediana & $2,50 \%$ \\
Pequeña & $19,70 \%$ \\
Micro & $77,80 \%$ \\
\hline
\end{tabular}

Fuente: Calle, C., et al. (2014)

- Sector/rubro de la empresa: Este criterio de segmentación se refiere a la industria en que participa la empresa cliente. Según este criterio de segmentación las empresas pueden ser clasificadas de diferentes maneras como se muestra en la tabla a continuación.

Tabla 2.12

Composición del VAB manufacturero del año 2015 por industria

\begin{tabular}{c|cc}
\hline Industria & VAB (millones S/) & \% Participacion \\
\hline Diversas industrias manufactureras & 3757,00 & $5,8 \%$ \\
Caucho y plástico & 2795,00 & $4,3 \%$ \\
Bebidas & 2513,00 & $3,9 \%$ \\
VAB Total Manufactura & 64895,00 & $100,0 \%$ \\
\hline
\end{tabular}

Fuente: Instituto Nacional de Estadística e Informática (2015)

- Porcentaje de mezcla: El último criterio a tomar en cuenta es el porcentaje de la mezcla que puede ser polipropileno reciclado. Esto quiere decir que cuando un consumidor produce un producto de plástico, dependiendo de sus requerimientos de calidad y características del producto mismo (dureza, forma, textura, entre otros), va a utilizar determinadas proporciones de polipropileno reciclado versus virgen. Por ejemplo, un producto que se hace bajo pedido con altos estándares de calidad es probable que no use polipropileno reciclado y si lo hace, sea en porcentajes mínimos. Por el otro lado, si es un producto de uso común como por ejemplo una silla o una mesa que no tiene estándares de calidad tan altos puede utilizar mayores porcentajes de recuperado para reducir costos de producción. 


\subsubsection{Selección de mercado meta}

Para cada uno de los criterios mencionados previamente se presenta a continuación el segmento seleccionado como parte del mercado meta.

- Tamaño de la empresa: El enfoque será en las grandes empresas con alto poder adquisitivo y con la capacidad para otorgar tanto una demanda estable como significativa. Esto no deja de lado por supuesto que pueda haber otros clientes, medianos y pequeños, ya que la idea siempre será ir desarrollando y adquiriendo nuevos clientes con el paso del tiempo. Estos clientes son los que ya están presentes en el mercado como:

○ Plásticos Rey

- Duraplast

- Polimplast

- Basa

- Q’Plast

- Fibra Forte

Se seleccionaron estas empresas como clientes principales debido a la recomendación de expertos del medio pertenecientes a las empresas "Gexim" y "Poliempaq" (Comunicación personal, 6 de junio, 2016) por el hecho de que son líderes en el mercado de plásticos peruano.

De los porcentajes visualizados en la tabla correspondiente a este factor en el acápite anterior, el correspondiente a este grupo de empresas equivale a $22,2 \%(2,5 \%+19,7 \%)$, cifra que se visualiza como primer factor multiplicador en la tabla 2.9 donde se calcula la demanda del proyecto.

- Sector/rubro de la empresa: En línea con las aplicaciones de las escamas de polipropileno reciclado, se ha apuntado a 3 industrias que conforman el 13,97\% del Valor Agregado Bruto que descuenta los Impuestos y Derechos de Importación del PBI total a nivel país (Producción, 2015). Estas son las industrias de Caucho y plástico, Bebidas y Diversas industrias manufactureras y sería el porcentaje total del mercado a considerar. 
- Porcentaje de mezcla: La finalidad de brindar un producto con las características mencionadas en los capítulos iniciales es permitir al cliente utilizar una mezcla con mayor grado de polipropileno reciclado. Pero, al haber requerimientos tan variables es difícil definir un porcentaje específico que todos los clientes utilicen. Por esta razón, en base a lo observado e investigado y en conjunto con el juicio de expertos se definió como porcentaje de reciclado el $50 \%$ de la mezcla, que en otras palabras es el total del polipropileno que circula en el mercado que podríamos reemplazar.

- Intención e Intensidad: El resultado de la encuesta fue que los entrevistados tenían un grado de interés de 8 de adquirir el producto del 1 al 10, siendo 10 el más alto y 1 lo más bajo. Esto se tradujo a un $80 \%$ de probabilidad de compra del mercado objetivo al ingresar.

En resumen, en base a estos 4 criterios, nuestro mercado objetivo está compuesto de empresas grandes, medianas y pequeñas que trabajan con plásticos (mayoritaria o totalmente vírgenes) y pertenecientes a sectores que comparten como factor común pertenecer al ámbito manufacturero, y, por último, estas serán residentes en Lima.

\subsubsection{Demanda específica para el proyecto}

En base a la demanda interna aparente, los criterios de segmentación y los resultados de la encuesta, se obtuvo la demanda del proyecto real: 
Tabla 2.13

Demanda del proyecto en los próximos 5 años

\begin{tabular}{|c|c|c|c|c|c|c|c|}
\hline \multirow[t]{2}{*}{ Año } & \multirow[t]{2}{*}{$\begin{array}{c}\text { DIA (en } \\
\text { toneladas) }\end{array}$} & $\begin{array}{c}\text { Empresas } \\
\text { grandes, } \\
\text { medianas y } \\
\text { pequeñas }\end{array}$ & $\begin{array}{c}\text { Empresas en } \\
\text { rubros } \\
\text { relevantes }\end{array}$ & $\begin{array}{c}\text { Porcentaje } \\
\text { de mezcla }\end{array}$ & $\begin{array}{l}\text { Intencion e } \\
\text { intensidad }\end{array}$ & \multirow[t]{2}{*}{$\begin{array}{c}\text { Demanda } \\
\text { del Proyecto } \\
\text { (en } \\
\text { toneladas) }\end{array}$} & \multirow[t]{2}{*}{$\begin{array}{c}\text { Demanda } \\
\text { del Proyecto } \\
\text { (en soles) }\end{array}$} \\
\hline & & $22,20 \%$ & $13,97 \%$ & $50,00 \%$ & $80,00 \%$ & & \\
\hline 2016 & 274740,1 & 60992,3 & 8519,8 & 4259,9 & 3407,9 & 3407,9 & 8179048,2 \\
\hline 2017 & 291551,9 & 64724,5 & 9041,2 & 4520,6 & 3616,5 & 3616,5 & 8679537,5 \\
\hline 2018 & 309392,4 & 68685,1 & 9594,4 & 4797,2 & 3837,8 & 3837,8 & 9210652,5 \\
\hline 2019 & 328324,6 & 72888,1 & 10181,5 & 5090,7 & 4072,6 & 4072,6 & 9774267,4 \\
\hline 2020 & 348415,3 & 77348,2 & 10804,6 & 5402,3 & 4321,8 & 4321,8 & 10372370,7 \\
\hline
\end{tabular}

Nota: Asumiendo que cada kilogramo se vende a S/ 2,4

Elaboración propia

Desde el primer año del proyecto, se podría acceder a una demanda mayor a 3400 toneladas de escamas de polipropileno reciclado u 8,1 millones de soles lo cual muestra que hay mucha demanda no cubierta. El otro factor positivo, es que la demanda del proyecto crece de forma consistente, lo cual también demuestra que es un proyecto prometedor a largo plazo.

\subsection{Definición de la estrategia de comercialización}

En este acápite se procede a detallar las políticas de comercialización y distribución, publicidad y promoción y análisis de precios.

\subsubsection{Políticas de comercialización y distribución}

Todo en este mercado se maneja por venta directa entre los productores y los clientes, al ser un producto industrial no se manejan mayoristas y minoristas como sería el caso de un producto de consumo masivo. Como mucho se podría manejar un centro de distribución si se alcanza un nivel de demanda suficientemente alto y con un área de distribución muy extensa, pero en una primera instancia es suficiente con la planta y un almacén dentro de la misma. 
En lo que respecta a la comercialización, al principio para entrar al mercado se contactará directamente a todos los potenciales clientes. En este punto haremos pruebas de calidad con todos ellos y les daremos muestras (10 kilogramos del producto terminado) para que prueben nuestro producto para mostrarles la calidad superior que ofrecemos. Con esto podemos comenzar a crear nuestra demanda y posicionarnos en el mercado, ya en este punto gran parte del crecimiento va a depender de la información boca a boca, cuando seamos reconocidos por nuestro producto diferenciado.

Por el otro lado de la distribución, el mercado se concentra en Lima por lo que es manejable a través de una red de distribución con uno o dos camiones para hacer las entregas a los clientes por medio de ruta. La demanda (según los resultados de la encuesta) sería de frecuencia semanal mínimo, por lo que no se requiere de una flota de camiones que este saliendo y entrando de forma constante.

\subsubsection{Publicidad y promoción}

En este caso, la publicidad masiva convencional no aplica, lo que importa realmente es que los clientes vean y crean en el desempeño del producto. Los canales tradicionales y más conocidos como la radio y la televisión no son relevantes para nuestro producto ya que no seriamos capaces de captar a nuestro público objetivo de forma eficiente. Por lo tanto, nuestro principal medio de publicidad va a ser la página web que crearemos para nuestra empresa, ya que en la actualidad es crítica la presencia en las redes. Aquí podrán aprender más de nosotros, podrán contactarnos, podrían revisar nuestro portafolio y hacer pedidos.

Otros medios de publicidad relevantes para este rubro serían ferias de plástico como la Expoplast que se da de forma anual y reúne a muchas empresas no solo del Perú, sino del exterior. Por lo tanto, representa una excelente oportunidad de entrar en contacto y tener exhibición con el medio. Por último, se puede acceder a las revistas especializadas de química o de plásticos específicamente. Dos revistas identificadas de este tipo fueron Tecnología del Plástico o Mundoplast que están al tanto de lo que pasa con el ámbito en el momento. Si se logra tener publicidad o incluso aparecer en un artículo de estas revistas sería muy favorable. Complementario a esto se pueden entregar folletos y tarjetas de presentación, que ayudan a que potenciales clientes nos contacten. 


\subsubsection{Análisis de precios}

En este acápite se procede a detallar tanto la tendencia de precios históricos como precios actuales.

\subsubsection{Tendencia histórica de los precios}

Según información proporcionada por los gerentes de Gexim y Poliempaq, los precios a nivel local se han mantenido relativamente constantes en los últimos 5 años (comunicación personal, 6 de junio, 2016). En cuanto al nivel internacional, la información de la web brinda precios referenciales de la actualidad los cuales se mencionan a continuación.

Esto se traduce a los siguientes precios, por kilogramo:

- Materia prima, basura hecha a base de polipropileno, comprada a recolectores: $\mathrm{S} / 0,85$

- Escamas de polipropileno reciclado de color surtido producidas localmente (y tampoco $100 \%$ diferenciadas por polímero): S/ 1,80

- Escamas de polipropileno reciclado de color surtido importadas del exterior: entre S/ 1,63 (Quiminet, 2017) y S/ 1,73 (Solo stocks, 2016), precios que escalan hasta 1,84 y 1,95 soles respectivamente al considerar los gastos de importación

- Escamas de polipropileno reciclado diferenciadas por polímero y color producidas localmente: S/ 2,40

- Escamas de polipropileno reciclado diferenciadas por polímero y color importadas del exterior: S/ 2,23 (Solo stocks, 2017), precio que se eleva hasta 2,52 soles al considerar los gastos de importación 
Figura 2.4

Tendencia histórica de precios

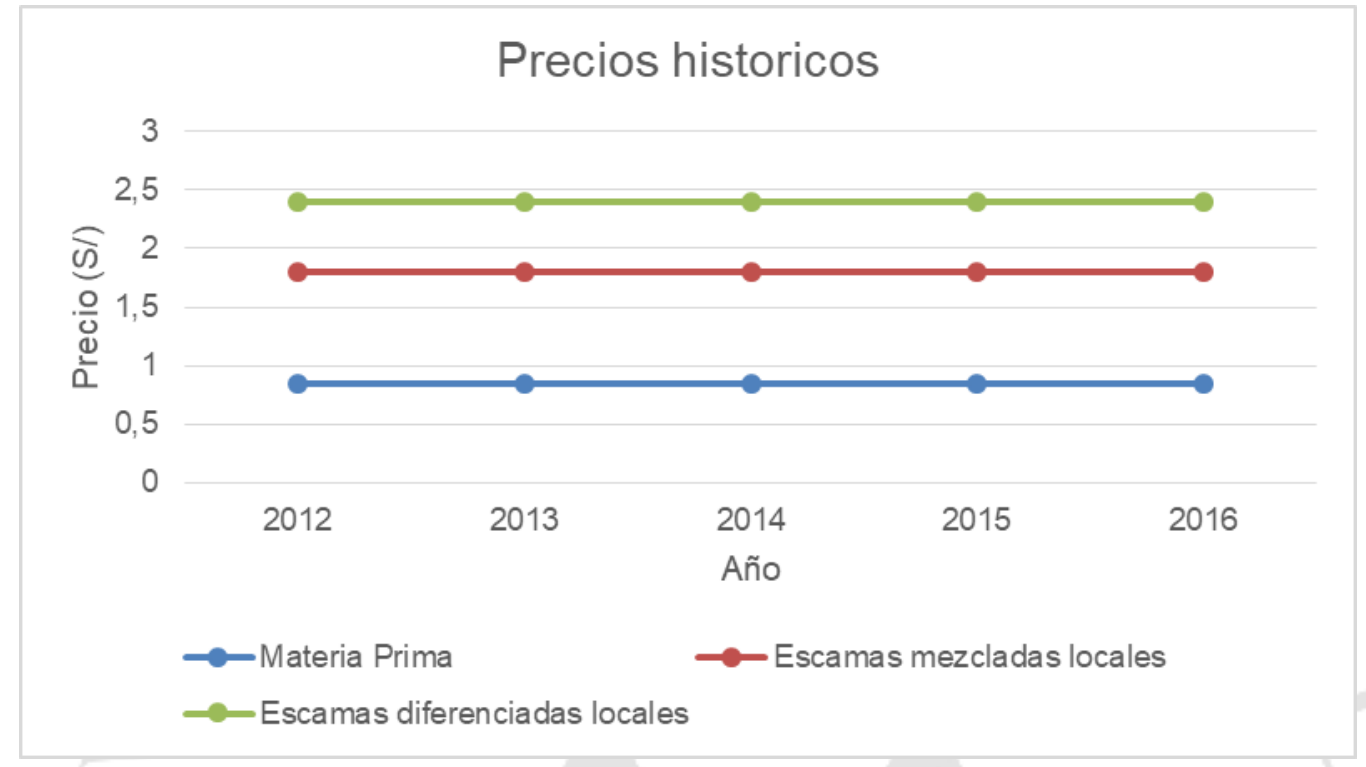

Elaboración propia

\subsubsection{Precios actuales}

Como se mencionó previamente, los precios no han sufrido variaciones importantes en los últimos 5 años. La figura a continuación nos ayudará a comprender mejor el excelente margen del producto terminado en comparación a materia prima que se maneja: 
Figura 2.5

Comparación de precios actuales

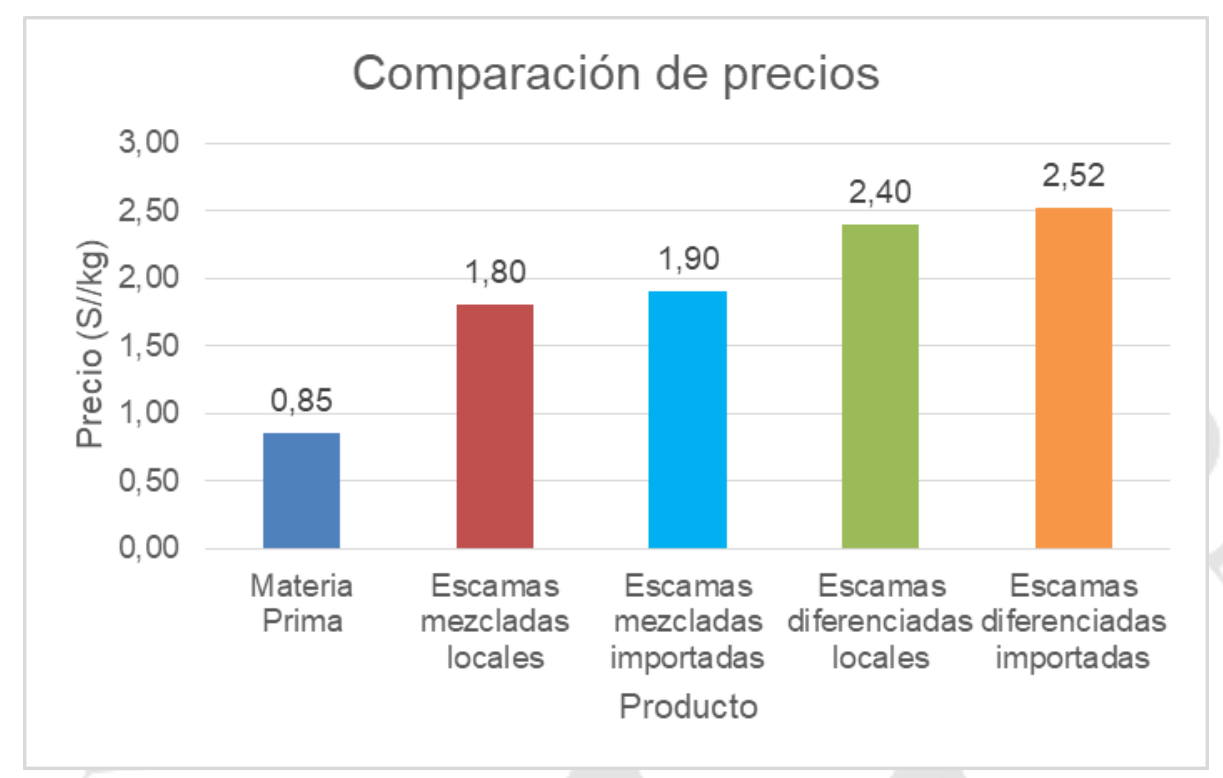

Elaboración propia

Como se puede ver, en base a los precios, hay una alta rentabilidad por kilogramo de nuestro producto. Comparado con las escamas mezcladas que es lo que ofrece el mercado actualmente, hay una diferencia de $\mathrm{S} / 0,60$ soles que equivalen a una diferencia de $33 \%$ del precio actual. Si se compara con el precio de la materia prima, tenemos un margen del $180 \%$ que es aún más sorprendente. En cuanto a los precios en el mercado exterior para la importación de escamas recicladas similares a nuestro producto, estos son superiores debido a factores como el transporte, impuestos y demás elementos que deben ser añadidos al precio de compra en el país proveedor. Por lo tanto, la importación de escamas de polipropileno reciclado no es rentable en comparación con efectuar la compra a un fabricante local como nuestra empresa.

\subsection{Análisis de disponibilidad de los insumos principales}

En este acápite se procede a detallar las características principales, disponibilidad y costos de la materia prima. 


\subsubsection{Características principales de la materia prima}

Se obtendrá de los residuos sólidos generados por la población de Lima Metropolitana y el Perú. El requisito principal es que sea polipropileno y que sea puro. Otro requisito, más por conveniencia en este caso, es que este separado previamente de otro tipo de residuos. Cuanto mayor sea el grado de clasificado previo (en términos de pureza, limpieza, humedad y color) más eficiente será el proceso en el aspecto de tiempo y de costos. Por último, debe ser un plástico que no haya sido reciclado previamente en numerosas ocasiones, ya que al reciclarse pierde sus cualidades gradualmente. Esta barrera no es tan crítica en Perú ya que recién se está inculcando la cultura de reciclar, por lo tanto, aun no circula tanta materia que ya haya pasado por un proceso de reciclaje.

\subsubsection{Disponibilidad de la materia prima}

Con el apoyo de diversas fuentes incluidas en las referencias (entre ellas Compendio Estadístico de INEI, UDEP y Nefco), se realizó un análisis para determinar la cantidad neta de materia prima disponible. Partiendo del total de residuos sólidos generados, 3146 030,76 toneladas anuales en Lima Metropolitana (Ambiente, 2016), se determinó el porcentaje que pertenecía a plásticos duros en general lo cual equivalía a $2 \%$ y ya dentro de esta porción, un $55 \%$ era netamente polipropileno. El número final es de 34 606,34 toneladas disponibles al año, este cálculo se ve más a detalle en el acápite 4.2.

\subsubsection{Costos de la materia prima}

En base al estudio de mercado realizado y los contactos del medio, se determinó que el costo promedio de un kilogramo de materia prima era de 85 centavos por kilo. Este es un precio estándar en todo el mercado. No hay variación de un proveedor a otro ya que la materia prima, en este caso residuos sólidos, no tiene mayor diferenciación ni valor agregado. 


\section{CAPÍTULO III: LOCALIZACIÓN DE PLANTA}

\subsection{Identificación y análisis detallado de los factores de localización}

a) Cercanía a materias primas: Este primer factor solo influenciará el aspecto macro del análisis, y se medirá en base a la producción de residuos sólidos en cada departamento. Ya que esta viene a ser la materia prima del proyecto podremos evaluar así a qué cantidad tiene acceso cada departamento. De cierta manera, se planteará el escenario como si cada departamento fuera autosuficiente. Por lo tanto, se obtuvo los departamentos donde las municipalidades reportaron las mayores cantidades diarias de recojo de basura.

\section{Tabla 3.1}

Kilogramos de residuos sólidos recolectados de forma diaria por departamento en el año 2016

\begin{tabular}{c|c}
\hline Provincia & $\begin{array}{c}\text { Cantidad de residuos } \\
\text { recogidos }(\mathbf{k g})\end{array}$ \\
\hline Lima & 9293294 \\
La Libertad & 1568780 \\
Lambayeque & 1099228 \\
Piura & 1061496 \\
Arequipa & 1035741 \\
Cusco & 959871 \\
Prov. Constit del Callao & 843275 \\
Áncash & 758339 \\
Junín & 688937 \\
Cajamarca & 644402 \\
Puno & 606672 \\
Ica & 598986 \\
Loreto & 542505 \\
\hline
\end{tabular}

Fuente: Ministerio del Ambiente (2016)

b) Cercanía al mercado: Este factor también se observará solo desde el nivel macro de la localización. El mercado se definió en base a la opinión de expertos, lo investigado, y la 
manera en que funciona el país en el sentido de que todo se encuentra centralizado en Lima. El mercado de plásticos está basado principalmente en Lima (Metropolitana), por lo tanto, se definió esta ubicación como el mercado en sí. Para el análisis, se obtuvieron las distancias de cada departamento hasta Lima siendo en el caso de Lima $0 \mathrm{~km}$.

Tabla 3.2

Distancias entre capitales y Lima

\begin{tabular}{c|c}
\hline Capi tal / departamento & Distancia a Lima (km) \\
\hline Lima & - \\
Ica & 303,21 \\
Trujillo (La Libertad) & 557,20 \\
Chiclayo (Lambayeque) & 763,35 \\
Cajamarca & 850,66 \\
Arequipa & 966,89 \\
Piura & 972,85 \\
Tacna & 1293,00 \\
\hline
\end{tabular}

Fuente: Adonde.com (2016)

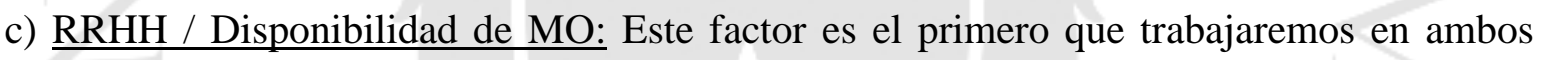
aspectos, macro y micro. Esto es por el hecho de que la cifra de población importa tanto para los departamentos como para los distritos posteriores. En adicional, se agregó el dato de cuantos años de estudio en el colegio (entre educación primaria y secundaria) en promedio había en cada departamento. Esto es muy relevante, ya que si puede ser necesario una mano de obra especializada y es importante saber si estaría disponible. En el caso de este proyecto, se consideró que el personal de la planta mínimo debería tener una educación secundaria finalizada, y aunque se haría un trabajo mayormente operativo (al trabajar con máquinas semiautomáticas) si es importante que tengan un nivel de formación adecuado para las responsabilidades que tendrán. En el caso de la Población Económica Activa (PEA) por distrito, se estimó en base a la proporción de PEA de Lima respecto a la población total. 


\section{Tabla 3.3}

PEA del año 2015 y promedio de años de estudio del 2014 por departamento

\begin{tabular}{c|cc}
\hline Departamento & PEA & Años de estudio \\
\hline Lima & 5231070 & 11,1 \\
La Libertad & 952574 & 9,7 \\
Piura & 913143 & 9,2 \\
Cajamarca & 823260 & 8,3 \\
Arequipa & 693128 & 10,7 \\
Lambayeque & 635728 & 9,9 \\
Ica & 400850 & 10,9 \\
Tacna & 180231 & 10,5 \\
\hline
\end{tabular}

Fuente: Instituto Nacional de Estadística e Informática (2015)

Tabla 3.4

Población total y PEA estimada de distritos potenciales en Lima del año 2015

\begin{tabular}{c|cc}
\hline Distrito & Población Total & PEA Estimada \\
\hline San Juan de Lurigancho & 1091303 & 578391 \\
Ate & 630085 & 333945 \\
Villa El Salvador & 463014 & 245397 \\
Santa Anita & 228422 & 121064 \\
Lurin & 85132 & 45120 \\
\hline
\end{tabular}

Fuente: Instituto Nacional de Estadística e Informática (2015)

d) Energía y recursos eléctricos: Este factor macro es muy importante, ya que es vital determinar si la planta podrá funcionar en la localización que elijamos y si existe un suministro suficiente de potencia de energía para accionar todas las máquinas y las instalaciones en general de forma óptima. 
Tabla 3.5

Producción de Gigawatts/hora por departamento

\begin{tabular}{c|c}
\hline Departamento & Producción \\
\hline Lima & 24987,52 \\
Arequipa & 1011,47 \\
Ica & 909,53 \\
La Libertad & 454,09 \\
\hline
\end{tabular}

Fuente: Instituto Nacional de Estadística e Informática (2015)

e) Servicios de transporte y red vial: El transporte para las redes de acopio y distribución en una empresa es vital en el mundo que vivimos, y sobre todo en un país como Perú y un departamento como Lima, donde la congestión automovilística es un problema ascendente en los últimos años. La perspectiva a analizar en el nivel macro, es el porcentaje de redes viales asfaltadas y en buen estado, y el acceso a vías de transporte (sea terrestre, marítimo o incluso aéreo). En el nivel micro, el cual se manejará de forma subjetiva está relacionado con la congestión vehicular en el distrito particular y las distancias que puedan haber hasta los recolectores de materia prima y hacia los clientes.

Tabla 3.6

Porcentaje de la red vial Nacional asfaltada por departamento al 2014

\begin{tabular}{c|c}
\hline Departamento & Porcentaje asfal tado \\
\hline Ica & $90 \%$ \\
Arequipa & $75 \%$ \\
Lima & $67 \%$ \\
La Libertad & $50 \%$ \\
\hline
\end{tabular}

Fuente: Instituto Nacional de Estadística e Informática,INEI (2015)

f) Recursos Hídricos: El agua, al igual que la energía eléctrica es otro recurso básico vital para que la planta funcione. Este recurso forma parte elemental de procesos como el lavado y la separación por flotación, y es importante determinar que tendremos acceso a la misma de manera estable. 
Tabla 3.7

Cobertura de agua potable y producción de agua potable por empresa

\begin{tabular}{c|cccc}
\hline Empresa & Departamento & $\begin{array}{c}\text { Tamaño de } \\
\text { empresa }\end{array}$ & Cobertura (\%) & $\begin{array}{c}\text { Producción (en } \\
\text { miles de m3) }\end{array}$ \\
\hline Sedapal S.A. & Todo el Perú & Sedapal & 97 & 683525 \\
Sedapar S.A. & Arequipa & Grande & 94 & 66283 \\
Emapica S.A. & Ica & Grande & 91 & 20792 \\
Semapach S.A. & Ica & Grande & 95 & 17090 \\
Emapa Cañete S.A. & Lima & Mediana & 73 & 12240 \\
Emapa Pisco S.A. & Ica & Mediana & 99 & 10077 \\
Semapa Barranca S.A. & Lima & Mediana & 85 & 9066 \\
Emapa Huacho S.A. & Lima & Mediana & 94 & 7725 \\
Emapa Huaral S.A. & Lima & Mediana & 81 & 6883 \\
Emapavigs S.A.C. & Ica & Pequeña & 89 & 2694 \\
\hline
\end{tabular}

Fuente: Instituto Nacional de Estadística e Informática,INEI (2015)

g) Clima: El último factor macro a tener en cuenta es el clima, factor relevante debido a la estacionalidad analizada en el acápite de factores de consumo. Al ser un producto de consumo masivo (las botellas de agua, gaseosa, entre otros), los que nos van a dar gran parte de nuestra materia prima, una región con mayores temperaturas en el transcurso del año es probable que incentive mayor consumo a lo largo del año.

Tabla 3.8

Temperatura promedio anual por departamento

\begin{tabular}{c|c}
\hline Departamento & $\begin{array}{c}\text { Temperatura } \\
\text { promedio }\left({ }^{\circ} \mathbf{C}\right)\end{array}$ \\
\hline Ica & 21,0 \\
Lima & 19,5 \\
Arequipa & 16,1 \\
\hline
\end{tabular}

Fuente: Instituto Nacional de Estadística e Informática, INEI (2015)

h) Acceso a residuos sólidos inmediatos: Este factor micro es muy parecido al primero de cercanía de materias primas, pero es relevante ya que puede haber distritos donde hay una mayor producción de desechos sólidos y es fácil hacer una alianza con las municipalidades para tener acceso privilegiado a los mismos. 
Tabla 3.9

Generación de residuos sólidos por persona y en total del año 2013

\begin{tabular}{c|cc}
\hline Distrito & $\begin{array}{c}\text { Generacion per capita } \\
\text { diaria (kg/habitante) }\end{array}$ & $\begin{array}{c}\text { Generacion total por } \\
\text { dia (toneladas) }\end{array}$ \\
\hline Santa Anita & 0,96 & 204 \\
Lurín & 0,92 & 71 \\
Ate & 0,73 & 417 \\
Villa El Salvador & 0,68 & 295 \\
San Juan de Lurigancho & 0,66 & 675 \\
\hline
\end{tabular}

Fuente: Instituto Nacional de Estadística e Informática,INEI (2015)

i) Seguridad ciudadana: Otro de los factores micro relevantes es la seguridad, aunque de todas maneras se contratará vigilantes y se tendrá un sistema de cámaras y otros, es importante ver si el sitio que elijamos es realmente seguro. Aparte de la propia empresa, es importante cuidar a nuestros trabajadores, socios y nuestra imagen también en el día a día.

Tabla 3.10

Cantidad de delitos cometidos registrados por distrito del año 2014

\begin{tabular}{c|c}
\hline Distrito & $\begin{array}{c}\text { \# de denuncias } \\
\text { registradas }\end{array}$ \\
\hline Lurín & 390 \\
Santa Anita & 2415 \\
Villa El Salvador & 3346 \\
Ate - Vitarte & 7259 \\
San Juan de Lurigancho & 10603 \\
\hline
\end{tabular}

Fuente: Instituto Nacional de Estadística e Informática, INEI (2015)

j) Precio del terreno: El último factor micro es el precio del terreno. Este puede ser realmente determinante a la hora de analizar la inversión y tener restricciones de capital. Para esto se obtuvo el precio aproximado de un metro cuadrado en cada distrito con la asesoría de un corredor inmobiliario (comunicación personal, 26 de junio, 2016), y el apoyo de la base de datos utilizada para agentes inmobiliarios, House Online. 
Tabla 3.11

Precios promedios de propiedad por distrito del año 2016

\begin{tabular}{c|c}
\hline Distrito & Precio $\mathbf{( \$ \mathbf { m } 2 )}$ \\
\hline Ate & 1000 \\
Santa Anita & 950 \\
Villa El Salvador & 500 \\
Lurin & 300 \\
San Juan de Lurigancho & 250 \\
\hline
\end{tabular}

Nota: En el caso de Santa Anita no se tenía un valor exacto, por lo que se sacó un aproximado en base a Ate que es su distrito aledaño y muy similar en el aspecto industrial.

Fuente: House Online (2016)

\subsection{Identificación y descripción de las alternativas de localización}

Los departamentos finales por evaluar tras el análisis preliminar del acápite 3.1 son Lima, Arequipa e Ica, todos departamentos de la Costa donde se encuentra el foco del proyecto. Estos son los que mostraron mejores resultados en los factores identificados para la localización de la planta, a continuación, daremos una breve reseña de cada uno, con el apoyo de data de la página EnPeru.org la cual contiene información variada del país y todos sus departamentos:

- Lima: Es la capital del Perú y "en la actualidad se le considera el centro comercial, financiero, cultural y político del país” (EnPerú, 2015). Por esta misma razón, es casi imperativo que fuera considerado como una de las opciones finales para la localización. El único factor que le juega en contra es la densidad poblacional excesiva que hay en este departamento, esto perjudica por factores como la alta cantidad de congestión vehicular.

- Arequipa: Este departamento es uno de los más importantes en el Perú, tanto histórica como culturalmente. Está ubicado en la Costa al igual que Lima, con acceso al Océano Pacifico y es ahí donde desembocan sus principales ríos. Uno de los factores que más relevancia le da es el alto nivel de desarrollo interno que hay, lo cual se refleja en la educación de su población, el alto porcentaje de red vial asfaltada que tienen y el acceso a energía eléctrica, entre otros. 
- Ica: Este último también se encuentra en la Costa y es una potencial ubicación muy estratégica. Se encuentra muy cerca de Lima y es uno de los departamentos con más acceso a materia prima. Eso se puede ver de dos maneras, ya que no es bueno que se produzca muchos desechos, pero al mismo tiempo presenta una excelente oportunidad de hacer un cambio positivo en la comunidad. Por último, tiene el clima más cálido que es un impulsador del consumo de bebidas.

\subsection{Evaluación y selección de la localización}

Para el análisis de localización, se utilizará el método de ranking de factores. Este consiste en determinar los factores relevantes para la decisión de donde ubicar la planta desde el punto de vista macro (departamento) y micro (distrito). Este es un método semi cualitativo donde enfrentaremos los diversos factores para darles ponderaciones. Para estos enfrentamientos entre factores se asignará un puntaje de 1 si gana o empata y 0 si pierde para reflejar claramente la importancia de cada factor. Tras esto, asignaremos puntajes a cada ubicación en base a los factores para obtener un puntaje total. Por último, la localización con el puntaje más alto será la elegida.

\subsubsection{Evaluación y selección de la macro localización}

Se realizó el análisis de ranking de factores obteniendo los resultados a continuación: los dos factores que resultan determinante para este resultado son la cercanía tanto a las materias primas (a) como al mercado (b). Si hubiera que hacer un orden de prioridades, estas dos son igualmente importantes. Después, les siguen en orden de importancia RRHH (c), Energía (d) y Transporte (e), esto es debido a que es todo lo elemental para que la planta funcione y se pueda tener comunicación tanto con clientes como con proveedores. Por último, los recursos hídricos (f) y el clima (g) fueron los menos determinantes acorde a la tabla de enfrentamiento. 
Tabla 3.12

Tabla de enfrentamiento macro localización

\begin{tabular}{c|ccccccccc}
\hline Factores & $\mathbf{a}$ & $\mathbf{b}$ & $\mathbf{c}$ & $\mathbf{d}$ & $\mathbf{e}$ & $\mathbf{f}$ & $\mathbf{g}$ & Conteo & Ponderación \\
\hline $\mathbf{a}$ & & 1 & 1 & 1 & 1 & 1 & 1 & 6 & 23 \\
$\mathbf{b}$ & 1 & & 1 & 1 & 1 & 1 & 1 & 6 & 23 \\
$\mathbf{c}$ & 0 & 0 & & 1 & 1 & 1 & 1 & 4 & 15 \\
$\mathbf{d}$ & 0 & 0 & 1 & & 1 & 1 & 1 & 4 & 15 \\
$\mathbf{e}$ & 0 & 0 & 1 & 1 & & 1 & 1 & 4 & 15 \\
$\mathbf{f}$ & 0 & 0 & 0 & 0 & 0 & & 1 & 1 & 4 \\
$\mathbf{g}$ & 0 & 0 & 0 & 0 & 0 & 1 & & 1 & 4 \\
Total & & & & & & & & $\mathbf{2 6}$ & $\mathbf{1 0 0}$ \\
\hline
\end{tabular}

Elaboración propia

Tabla 3.13

Ranking de Factores macro localización

\begin{tabular}{c|cccccc}
\cline { 2 - 7 } & \multicolumn{2}{c}{ Lima } & \multicolumn{2}{c}{ Arequipa } & \multicolumn{2}{c}{ Ica } \\
\hline Factores & Calificacion & Puntaje & Calificacion & Puntaje & Calificacion & Calificacion \\
\hline a & 10 & 231 & 4 & 92 & 8 & 185 \\
b & 10 & 231 & 6 & 138 & 8 & 185 \\
c & 10 & 154 & 10 & 154 & 10 & 154 \\
d & 10 & 154 & 4 & 62 & 4 & 62 \\
e & 6 & 92 & 8 & 123 & 10 & 154 \\
f & 10 & 38 & 8 & 31 & 6 & 23 \\
g & 8 & 31 & 6 & 23 & 10 & 38 \\
Total & & $\mathbf{9 3 1}$ & & $\mathbf{6 2 3}$ & & $\mathbf{8 0 0}$ \\
\hline
\end{tabular}

Elaboración propia

\subsubsection{Evaluación y selección de la micro localización}

Los distritos seleccionados del departamento ganador (Lima) para la evaluación final de micro localización son Lurín, Ate y Santa Anita. San Juan de Lurigancho se descartó por ser una zona más residencial que industrial y por sus altos niveles de delincuencia, mientras que Villa El Salvador era muy parecido a Lurín, pero este último era una opción más económica. El detalle de las 3 opciones a continuación: 
- Lurín: Este distrito es el más económico de todos los analizados, lo cual es un punto clave en cualquier proyecto que se guía de la rentabilidad. Es el que más alejado se encuentra del centro de Lima Metropolitana de las tres opciones finales, pero no es crítico gracias al acceso de la Panamericana Sur. Tiene baja densidad poblacional y es el distrito con mayor seguridad ciudadana.

- $\quad$ Ate: Este es un distrito industrial ya consolidado, y su gran punto a favor es la cantidad de movimiento industrial que se presenta en este distrito. Se tiene acceso inmediato a gran cantidad de materias primas y se puede contactar a otras empresas con facilidad. El factor que le puede jugar en contra son los precios altos que se manejan, al ser un distrito cotizado de Lima.

- Santa Anita: Es un distrito aledaño a Ate con características muy similares. Una de las principales razones por la que se seleccionó es debido a los antecedentes industriales, es decir, porque se encuentra cerca a empresas del rubro como Gexim, Poliempaq y SGM las cuales han aportado a este estudio con información muy valiosa del medio y del mercado. Aunque al igual que Ate tiene precios de terreno bastante elevados, lo compensa con el acceso a materia prima y la seguridad ciudadana.

Se realizó el análisis de micro localización con 3 distritos, en este escenario, el factor más importante fue el precio del terreno (e) ya que representa la inversión más fuerte en activos fijos, en este caso la planta en sí. Luego, se determinó el transporte (b) y la seguridad (d) como factores de segundo nivel de importancia, esto es debido a que en Lima actualmente el tráfico representa un auténtico problema en términos de tiempo, ergo, de eficiencia. Por último, se encuentran el acceso inmediato a residuos (c) y RRHH (a) ya que ambos factores, a fin de cuentas, se puede acceder sea cual sea el distrito.

Cabe remarcar, que en el factor (b) de transporte fue donde se realizó un análisis un tanto más subjetivo, se redujo un poco el puntaje de Lurín por la distancia, y de Ate y Santa Anita por la congestión vehicular. 
Tabla 3.14

Tabla de enfrentamiento micro localización

\begin{tabular}{c|ccccccc}
\hline Factores & $\mathbf{a}$ & $\mathbf{b}$ & $\mathbf{c}$ & $\mathbf{d}$ & $\mathbf{e}$ & Conteo & Ponderación \\
\hline $\mathbf{a}$ & & 0 & 1 & 0 & 0 & 1 & 8.3 \\
$\mathbf{b}$ & 1 & & 1 & 1 & 0 & 3 & 25 \\
$\mathbf{c}$ & 1 & 0 & & 0 & 0 & 1 & 8.3 \\
$\mathbf{d}$ & 1 & 1 & 1 & & 0 & 3 & 25 \\
$\mathbf{e}$ & 1 & 1 & 1 & 1 & & 4 & 33.3 \\
Total & & & & & & $\mathbf{1 2}$ & $\mathbf{1 0 0}$ \\
\hline
\end{tabular}

Elaboración propia

Tabla 3.15

Ranking de factores micro localización

\begin{tabular}{c|cccccc}
\cline { 2 - 7 } \multicolumn{2}{c}{} & \multicolumn{2}{c}{ Lurin } & \multicolumn{2}{c}{ Ate } & \multicolumn{2}{c}{ Santa Anita } \\
\hline Factores & Calificacion & Puntaje & Calificacion & Puntaje & Calificacion & Calificacion \\
\hline a & 2 & 17 & 10 & 83 & 6 & 50 \\
b & 6 & 150 & 8 & 200 & 8 & 200 \\
c & 2 & 17 & 10 & 83 & 6 & 50 \\
d & 10 & 250 & 2 & 50 & 6 & 150 \\
e & 10 & 333 & 4 & 133 & 4 & 133 \\
Total & & $\mathbf{7 6 7}$ & & $\mathbf{5 5 0}$ & & $\mathbf{5 8 3}$ \\
\hline
\end{tabular}

Elaboración propia

Tras el análisis presentado a lo largo de este capítulo, se determinó que la planta se instalaría en el departamento de Lima, en el distrito de Lurín siendo esta la combinación de localización óptima. 


\section{CAPÍTULO IV: TAMAÑO DE PLANTA}

\subsection{Relación tamaño-mercado}

Para el cálculo de la relación tamaño mercado se hace uso de la demanda del proyecto proyectada para el quinto año, la cual se muestra en la tabla a continuación. Al dividir este dato entre el precio de venta (S/ 2,4 por kilogramo) se obtiene que el tamaño-mercado es de 4321,8 toneladas/año.

Tabla 4.1

Proyección de la DIA para los próximos cinco años

\begin{tabular}{|c|c|c|c|c|c|c|c|}
\hline \multirow[t]{2}{*}{ Año } & \multirow[t]{2}{*}{$\begin{array}{c}\text { DIA (en } \\
\text { toneladas) }\end{array}$} & $\begin{array}{c}\text { Empresas } \\
\text { grandes, } \\
\text { medianas y } \\
\text { pequeñas }\end{array}$ & $\begin{array}{l}\text { Empresas } \\
\text { en rubros } \\
\text { relevantes }\end{array}$ & $\begin{array}{c}\text { Porcentaje } \\
\text { de mezcla }\end{array}$ & $\begin{array}{l}\text { Intencion e } \\
\text { intensidad }\end{array}$ & \multirow{2}{*}{$\begin{array}{c}\text { Demanda } \\
\text { del } \\
\text { Proyecto } \\
\text { (en } \\
\text { toneladas) }\end{array}$} & \multirow[t]{2}{*}{$\begin{array}{c}\text { Demanda del } \\
\text { Proyecto (en } \\
\text { soles) }\end{array}$} \\
\hline & & $22,20 \%$ & $13,97 \%$ & $50,00 \%$ & $80,00 \%$ & & \\
\hline 2016 & 274740,06 & 60992,29 & 8519,84 & 4259,92 & 3407,94 & 3407,94 & 8179048,24 \\
\hline 2017 & 291551,85 & 64724,51 & 9041,18 & 4520,59 & 3616,47 & 3616,47 & 8679537,51 \\
\hline 2018 & 309392,39 & 68685,11 & 9594,43 & 4797,21 & 3837,77 & 3837,77 & 9210652,54 \\
\hline 2019 & 328324,61 & 72888,06 & 10181,53 & 5090,76 & 4072,61 & 4072,61 & 9774267,36 \\
\hline 2020 & 348415,33 & 77348,20 & 10804,55 & 5402,28 & 4321,82 & 4321,82 & 10372370,69 \\
\hline
\end{tabular}

Nota: Asumiendo que cada kilogramo se vende a S/ 2,4

Elaboración propia

\subsection{Relación tamaño-recursos productivos}

Tomando como referencia información del INEI y del Ministerio del Ambiente se sabe que, aproximadamente, se generaban 3146 030,76 toneladas de residuos sólidos al año 2015 en Lima Metropolitana (Ambiente, 2016) de las cuáles 2\% corresponde a plásticos duros como el PVC, ABS y polipropileno, y a su vez el 54,98\% corresponde específicamente a polipropileno, finalmente de todo ese polipropileno el $93 \%$ tiene como destino final los botaderos municipales o rellenos sanitarios. Realizando la proyección respectiva de la data histórica y las conversiones respectivas, proceso que se muestra en las tablas a continuación, se obtiene una disponibilidad de materia prima de 36651,93 toneladas al quinto año 
proyectado, que transformadas en producto terminado (Por cada kilogramo de insumo, se obtiene 0,84 kilogramos de producto terminado) se convierten en 30 787,62 toneladas/año.

\section{Tabla 4.2}

Datos históricos de residuos sólidos generados en Lima Metropolitana 2011-2015

\begin{tabular}{l|ccccc}
\hline $\begin{array}{l}\text { Residuos solidos en } \\
\text { Lima Metropolitana }\end{array}$ & $\mathbf{2 0 1 1}$ & $\mathbf{2 0 1 2}$ & $\mathbf{2 0 1 3}$ & $\mathbf{2 0 1 4}$ & $\mathbf{2 0 1 5}$ \\
\hline Toneladas & 2761713,05 & 2907961,05 & 2980952,76 & 3049379,76 & 3146030,76 \\
\hline
\end{tabular}

Fuente: Instituto Nacional de Estadística e Informática,INEI (2015)

Tabla 4.3

Proyección de residuos sólidos generados en Lima Metropolitana 2016-2020

\begin{tabular}{l|ccccc}
\hline $\begin{array}{l}\text { Residuos solidos en } \\
\text { Lima Metropolitana }\end{array}$ & $\mathbf{2 0 1 6}$ & $\mathbf{2 0 1 7}$ & $\mathbf{2 0 1 8}$ & $\mathbf{2 0 1 9}$ & $\mathbf{2 0 2 0}$ \\
\hline Toneladas & 3444424,87 & 3485606,15 & 3521676,77 & 3553803,02 & 3582789,19 \\
\hline
\end{tabular}

Elaboración propia

Tabla 4.4

Disponibilidad de materia prima al 2020

\begin{tabular}{l|cccc}
\hline Materia Prima & Residuos solidos al & PP, PVC y & PP & Enviado a rellenos \\
Disponible & $\mathbf{2 0 2 0}$ & ABS & & sanitarios y botaderos \\
& $\mathbf{1 0 0 \%}$ & $\mathbf{2 \%}$ & $\mathbf{5 5 \%}$ & $\mathbf{9 3 \%}$ \\
\hline Toneladas & 3582789,19 & 71655,78 & 39410,68 & 36651,93 \\
\hline
\end{tabular}

Nota: Para el proyecto se utilizarán 5150 toneladas de materia prima en el año 2020

Elaboración propia

\subsection{Relación tamaño tecnología}

En base a la secuencia de operaciones necesaria para la producción del polipropileno reciclado, las capacidades o ritmos de producción de las máquinas utilizadas y el know how propio del negocio, no existe propiamente dicho un cuello de botella dentro de la línea de 
producción; sin embargo, la capacidad promedio de las líneas de producción accesibles como las ofrecidas por Pagani (Pagani, 2017), empresa Mexicana, y Floplastics (Floplastics, 2017), empresa Norteamericana, es de $1000 \mathrm{~kg} /$ hora, lo cual se traduce en una producción máxima anual de 7430 toneladas de producto terminado.

\section{Tabla 4.5}

Alternativas de líneas de producción con capacidad de producción de $1000 \mathrm{~kg} / \mathrm{h}$

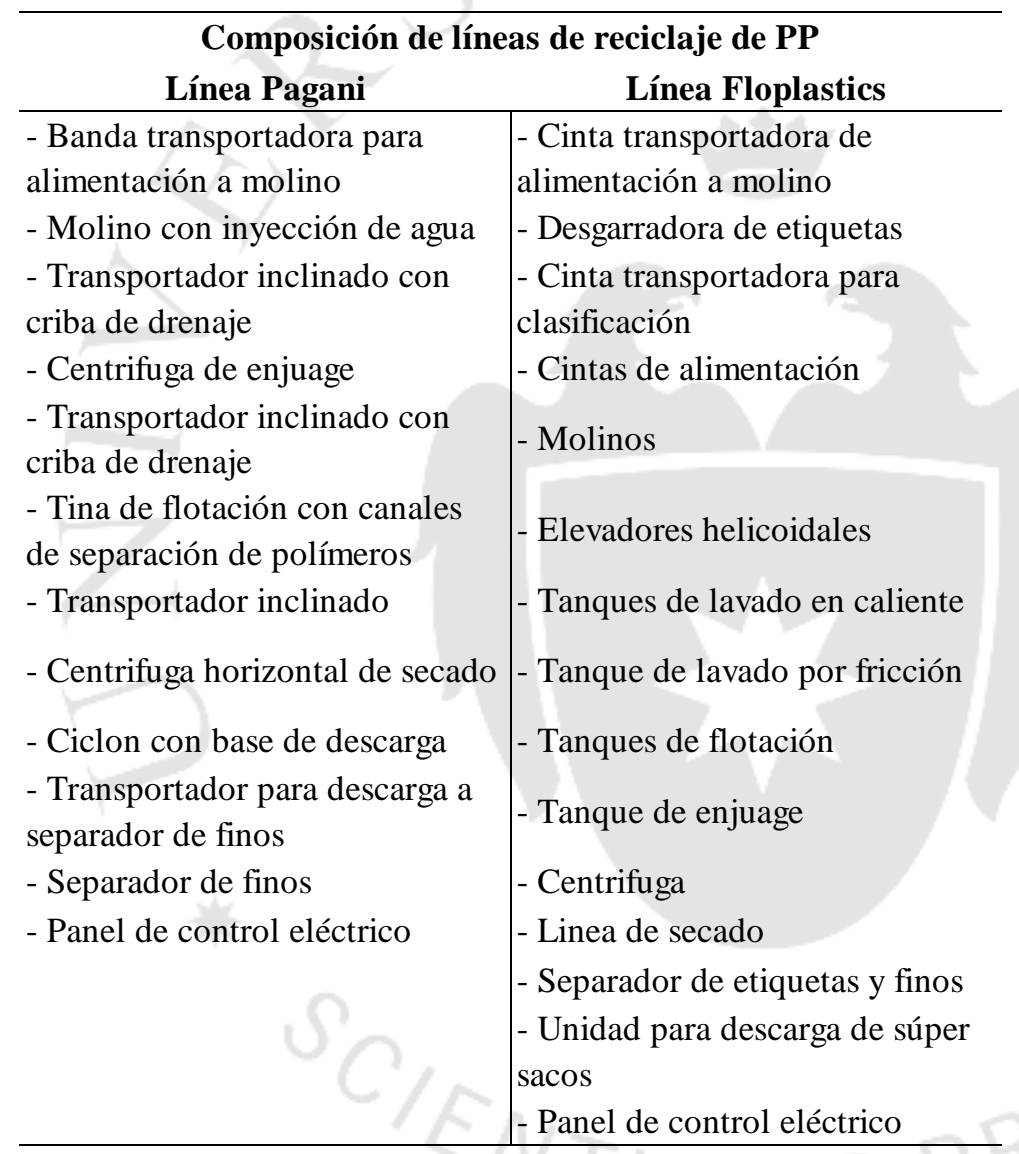

Elaboración propia

\subsection{Relación tamaño-inversión}

Con respecto a la inversión, está no representa una limitante ya que se encuentra dividida en una proporción Deuda/Capital social equilibrada, es decir, la porción correspondiente a la 
deuda es factible de ser pagada en un periodo menor a la vida útil del proyecto gracias a las ventas pronosticadas e ingresos que generan las mismas, por lo que no representa un inconveniente. Por otro lado, el porcentaje de la inversión correspondiente a capital social es factible de obtener mediante un aporte un tanto importante por parte de los dos socios y dueños de la compañía, además como se observa en los acápites posteriores, esta cantidad será recuperada en un periodo menor al tiempo de vida útil del proyecto por lo que tampoco representa una limitante para el tamaño de las operaciones.

\subsection{Relación tamaño-punto de equilibrio}

Para la determinación de este quinto tamaño se necesita tomar en cuenta la estructura de costos de la compañía. Todos los elementos que componen dicha estructura dan como resultado los costos y gastos fijos y variables y el punto de equilibrio que se muestran a continuación.

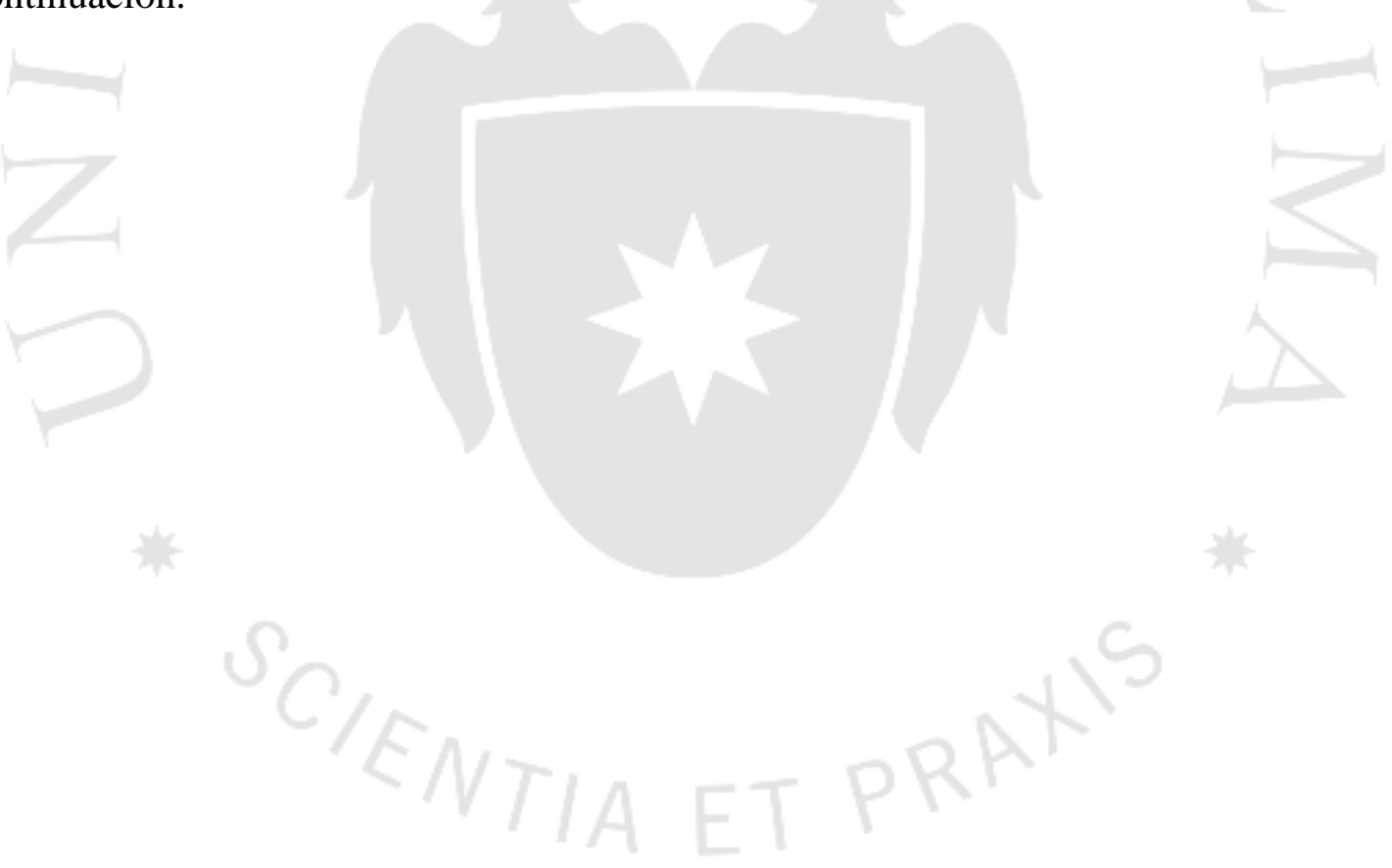


Tabla 4.6

Costos y gastos fijos y variables

\begin{tabular}{|c|c|c|c|}
\hline \multicolumn{2}{|c|}{ Costos y gastos fijos } & \multicolumn{2}{|l|}{ Costos y gastos variables } \\
\hline Mano de obra & 837540,00 & Luz & \\
\hline Mantenimiento & 48000,00 & Agua & 0,0366 \\
\hline Administración & 48000,00 & Materia prima & 1,0119 \\
\hline Depreciación & 135169,48 & Insumos & 0,1369 \\
\hline Amortización & 925,15 & Transporte MP & 0,0833 \\
\hline Vigilancia & 69795,00 & Transporte PT & 0,0700 \\
\hline Sueldos gerenciales & 244800,00 & Energía & 0,2563 \\
\hline Repuestos & 66720,00 & Bolsas & 0,0260 \\
\hline $\operatorname{cascos}$ & 910,00 & & \\
\hline mascarillas & 2080,00 & $n+3$ & \\
\hline lentes & 650,00 & & \\
\hline guantes & 208,00 & & \\
\hline tapones & 468,00 & & \\
\hline botas & 910,00 & & \\
\hline Muestras a clientes & 120,00 & & - \\
\hline Agua & 58,63 & & 5 \\
\hline Energía & 39543,75 & & \\
\hline TOTAL & 1495898,02 & TOTAL & 1,62 \\
\hline
\end{tabular}

Elaboración propia

Tabla 4.7

Cálculo del punto de equilibrio

\begin{tabular}{l|l}
\hline Criterio & Resul tado \\
\hline Costos y gastos fijos anuales & 1495898,02 soles \\
Costos y Gastos variables anuales por kg & 1,62 soles/kg \\
Punto de equilibrio en unidades & 1920,29 ton/año \\
\hline
\end{tabular}

Nota: Precio de venta 2,4 soles por kilogramo

Elaboración propia

\subsection{Selección del tamaño de planta}

Tras el análisis de los diversos tamaños de planta, el tamaño-mercado es el limitante ya que es mayor que el punto de equilibrio, sin embargo, es menor que los demás tamaños encontrados. Finalmente, el tamaño de planta adecuado es de 4 321,8 toneladas por año. 


\section{Tabla 4.8}

Cuadro resumen de tamaños de planta

\begin{tabular}{l|c}
\hline Tamaños de planta & Toneladas/año \\
\hline Tamaño-mercado & 4321,80 \\
Tamaño-recursos productivos & 30787,62 \\
Tamaño-tecnología & 7430,00 \\
Tamaño-punto de equilibrio & 1920,29 \\
\hline
\end{tabular}

Elaboración propia

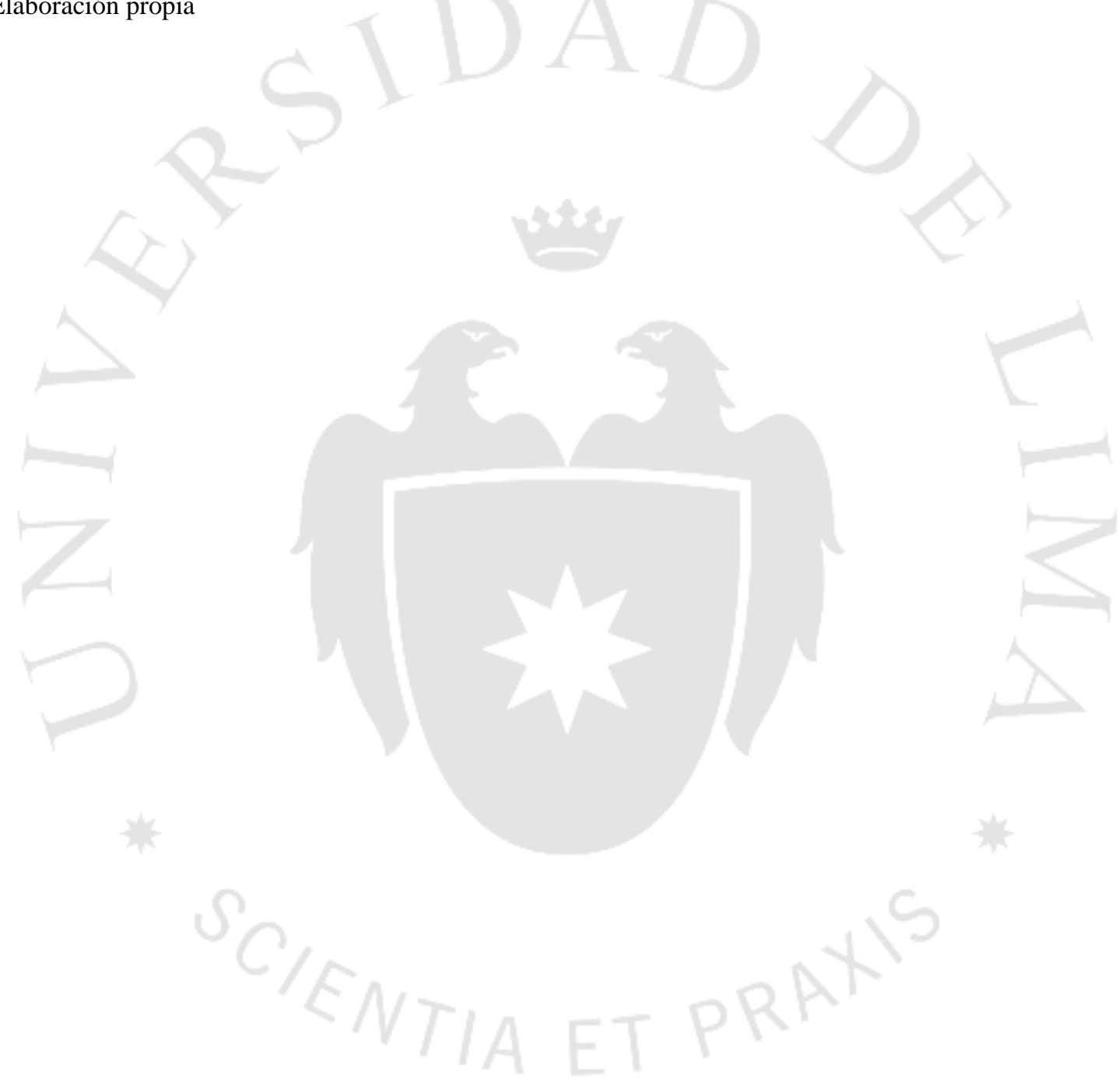




\section{CAPÍTULO V: INGENIERÍA DEL PROYECTO}

\subsection{Definición técnica del producto}

El polipropileno es uno de los polímeros más utilizados y populares en variados sectores de la industria, debido a sus propiedades físicas y accesibilidad económica. Se obtiene a partir de la polimerización del monómero propileno.

El polipropileno es un termoplástico, lo cual significa que puede ser calentado para alterar sus propiedades mecánicas y que sea más fácil trabajarlo, luego al enfriarse recupera sus propiedades originales. Entre otras cualidades se encuentran su dureza, resistencia a la corrosión y mayor resistencia al calor en comparación al polietileno. Es por ello, que las escamas de polipropileno reciclado, el producto en cuestión, pueden adquirir múltiples formas y tener múltiples usos.

\subsubsection{Especificaciones técnicas del producto}

El producto a producir y comercializar son escamas de polipropileno reciclado en un formato de sacos de 25 kilogramos. Este es un producto de carácter industrial, ya que es dirigido a empresas como materia prima, no para consumo final.

Las características que lo diferencian de otros polímeros reciclados son su pureza, color y humedad. Estos tres factores reflejan la calidad del producto. Para entrar un poco más al detalle, la pureza se refiere a que no sea un polímero contaminado, es decir con presencia de polietileno o PET, y debe tener una cantidad mínima de partes por millón (ppm) de dichos contaminantes, se busca una proporción menor a 10000 ppm de contaminantes dentro del producto a ofrecer. El color se refiere a que el producto se comercializa por familias de color diferenciadas, es decir, se ofrecerán las gamas de colores rojos, amarillos, azules, negros, etc.; que permitan al consumidor producir productos finales de una amplia gama de colores y la humedad consiste en que el material se encuentra totalmente seco, ya que este factor es 
crítico para trabajar el material correctamente (Galvis Gutierrez, 2014), el valor recomendado y que se busca ofrecer para dicho factor es de $0,5 \%$ (Reciclaje de plásticos).

\subsubsection{Composición del producto}

La composición del producto es casi homogénea, es decir, está compuesto por polipropileno en un porcentaje mayor a $99 \%$, el porcentaje restante puede estar compuesto de otros polímeros que puedan no haber sido retirados del proceso durante el proceso de clasificación. Como se mencionó anteriormente está característica permite que pueda ser combinado con el producto virgen en mayor proporción dentro de las mezclas que los clientes utilizan para fabricar sus respectivos productos terminados.

\subsubsection{Diseño gráfico del producto}

Figura 5.1

Representación del producto

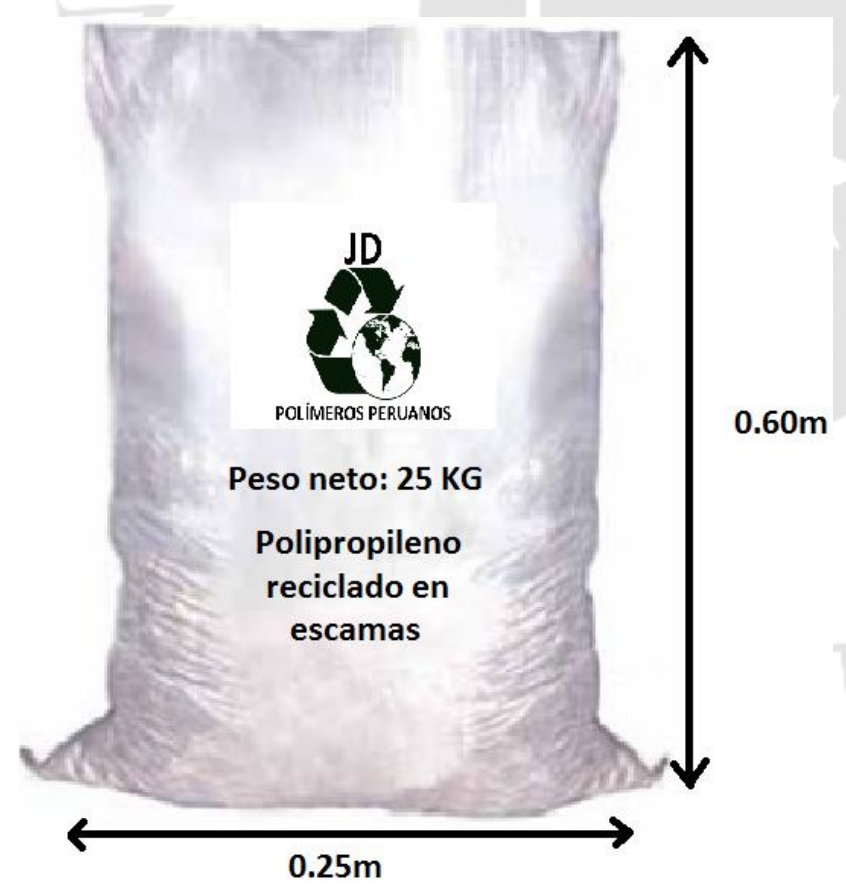

Elaboración propia 


\section{Figura 5.2}

Foto del producto
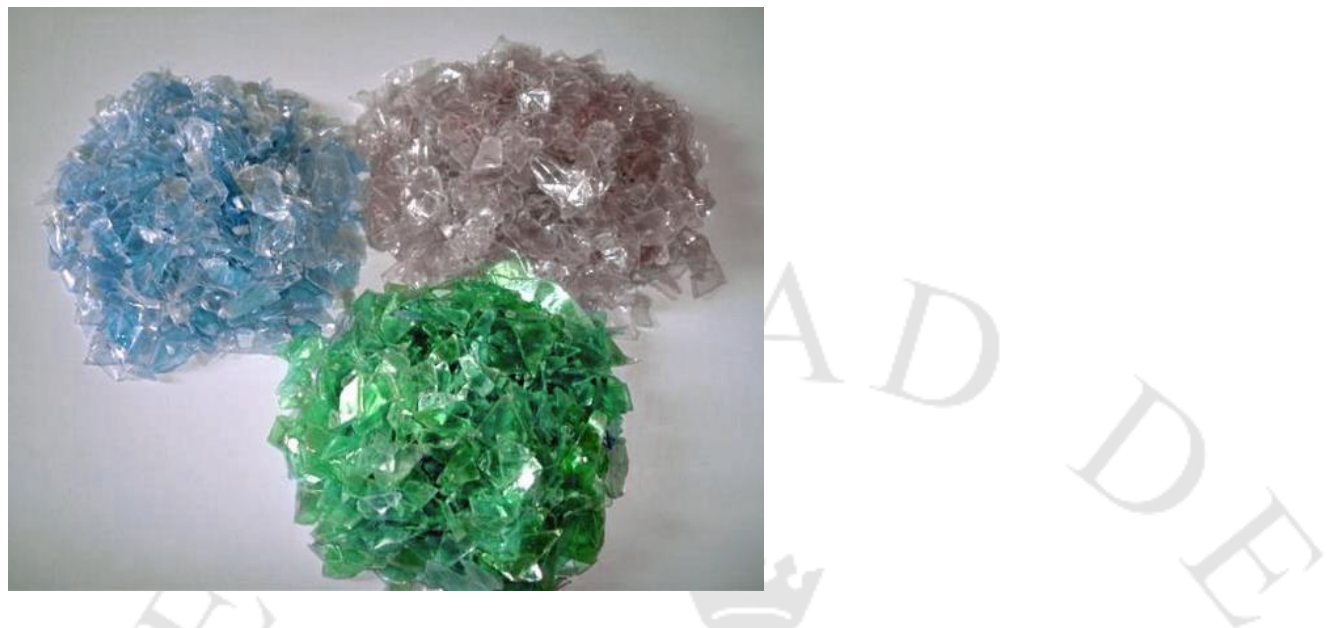

Fuente: petysolopet.com (2014)

\subsubsection{Regulaciones técnicas al producto}

Actualmente en nuestro país no existe una norma que sirva como marco regulatorio estrictamente para el producto que se ofrece. Esto es debido a que seguimos muy retrasados en el rubro del reciclaje a nivel internacional en general por dos razones, falta de tecnología y conciencia.

Con referencia a la tesis de Rivera Távara de la Universidad de Piura (UDEP), a nivel mundial, cada continente y cada país a su vez manejan el reciclaje a su manera. También, revisando el "Informe: Diagnóstico de los Residuos Sólidos en el Perú" publicado por NEFCO y el Ministerio del Ambiente, se puede complementar el detalle a nivel del Perú, identificándose algunas de las regulaciones que existen como:

- Ley General de Residuos Sólidos (Ley Nº 27314 del 21 de Julio del 2000): Es la principal ley a nivel nacional y básicamente le otorga una responsabilidad a la sociedad respecto al manejo de los residuos sólidos que generen. Esto puede ser de diversas maneras, como minimización, segregación en la fuente, almacenamiento, entre otros, siendo el reaprovechamiento, lo cual incluye el reciclaje, solo uno de los métodos posibles. También, se cuenta con una autoridad para asegurar el cumplimiento de esta Ley, el Consejo Nacional del Ambiente (o CONAM). 
- Ley que Regula la Actividad de los Recicladores (Ley N 29419 del 7 de octubre del 2009): Junto a su respectivo reglamento, buscan la protección, formación y capacitación de los recicladores al contribuir tanto de forma social como laboral, incentivando la formalización.

- Código de Medio Ambiente y los Recursos Naturales (DL No 613 -08/09/90): En uno de sus artículos (el $\left.\mathrm{N}^{\circ} 106\right)$ estipula que el Estado fomenta el reciclaje lo cual es positivo. El problema es que, aunque está por escrito, la mayoría de veces no se refleja en la práctica.

- Ley Orgánica de Municipalidades (Ley No 23853): Pone a cargo de las municipalidades todas las actividades que involucren el saneamiento ambiental por medio del servicio de limpieza pública.

Las regulaciones previamente mencionadas junto a algunas más, ya menos relevantes, son las que le dan un contexto al reciclaje en Perú. Aunque un punto que es importante notar, es que solo una de estas se enfoca específicamente en el reciclaje desde la perspectiva de los recicladores, el resto solamente lo mencionan de forma indirecta o lo presentan como una opción.

Las principales autoridades son DIGESA y DIRESA (Dirección General/Regionales de Salud Ambiental), junto con el Gobierno y las municipalidades.

En resumen, el marco regulatorio con el que actualmente cuenta el país promueve de cierta manera a reciclar, pero aún no se habla del reciclaje como una prioridad en el Perú. Ese sería el siguiente paso para complementar estas normas e implementar una cultura de conciencia a nivel nacional.

\subsection{Tecnologías existentes y procesos de producción}

En este acápite se procede a detallar la tecnología requerida y el proceso de producción maquina por máquina. 


\subsubsection{Naturaleza de la tecnología requerida}

En este acápite se procede a detallar las tecnologías o tipos de reciclaje existentes y el porqué de la selección de la tecnología con la que se trabajará.

\subsubsection{Descripción de las tecnologías existentes}

Actualmente, en lo que respecta al rubro de reciclaje de plásticos se presentan dos tipos de tecnología, denominadas reciclaje mecánico y reciclaje químico. Ambos se explican a continuación, con el apoyo de la información del "Manual de Valorización de los Residuos Plásticos" de EcoPlas, del artículo "El reciclado de plásticos" de la página web ecojoven.com, la guía Taller de plásticos de la profesora Goicovic y de las tesis de Olazar Oviedo y Lopez, y Rivera Távara:

- Reciclaje mecánico: Es un proceso físico - mecánico por medio del cual se puede recuperar el plástico, tanto post consumo como industrial, para darle un uso nuevamente y por lo tanto un valor para la sociedad. Una nota importante, es que dicha tecnología solo aplica para los termoplásticos, debido a que estos plásticos se pueden trabajar a calor y a presión para darles nuevas formas. Este es el tipo de tecnología que se aplicará debido a que el foco de esta investigación es un termoplástico, el polipropileno.

Este tipo de reciclaje puede repetirse varias veces, pero no de forma ilimitada ya que cada vez que se aplica los plásticos pierden sus propiedades mecánicas (como viscosidad o resistencia al impacto) en un rango entre 5 y $10 \%$. Aquí es donde entran en juego los aditivos, como por ejemplo los plastificantes o estabilizantes, que ayudan a que el plástico sea más trabajable nuevamente.

Un punto vital del proceso es la separación por polímero ya que los polímeros suelen ser incompatibles entre sí. Por esto, el proceso genérico consiste en clasificación, cortado y molido, lavado (con la ayuda de detergente y soda cáustica, o por fricción), secado, y finaliza con el pelletizado por medio de extrusión. 
En la siguiente figura, se muestra como es el proceso de reciclaje mecánico, el cual se detallará a profundidad en el acápite 5.2.2.1.

\section{Figura 5.3}

Diagrama de flujo simple del reciclaje mecánico

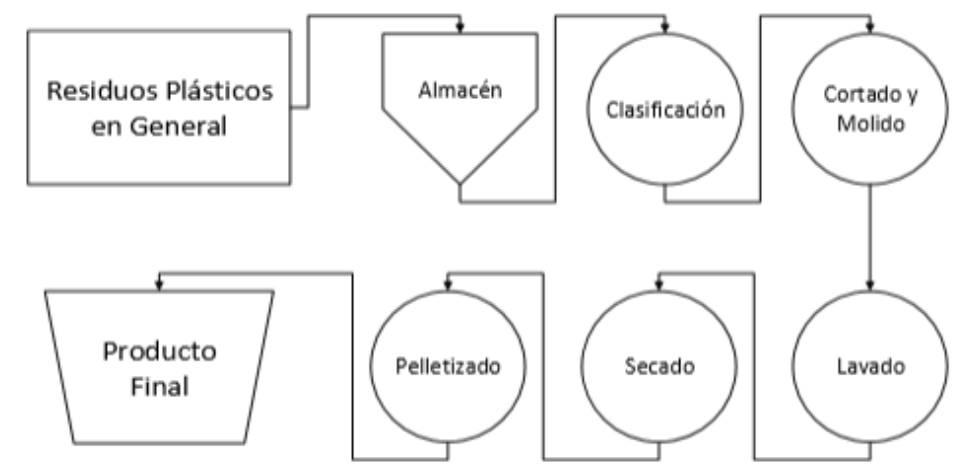

Fuente: Olazar, S. y López, G. (2016)

Una última consideración a la hora de determinar el detalle del proceso de producción con reciclaje mecánico es tanto el origen del residuo a reciclar como el destino final para el cual se utilizará. El origen puede ser:

- Merma/scrap industrial tras un proceso de producción de la industria petroquímica. Este residuo es más fácil de reciclar ya que es más limpio y homogéneo.

- Residuo de consumo doméstico que puede ser simple (ya clasificado), mixto (mezclados entre plásticos) o mixtos con otros residuos (como madera, metal, papel, entre otros).

Esto es debido a que si, por ejemplo, se piensa envasar alimentos o bebidas de consumo final debe cumplir con estándares de lavado mucho más exigentes que si es una materia prima para reutilizar en otro proceso industrial.

- Reciclaje químico: La gran diferencia respecto al mecánico, es que este método involucra una descomposición y reestructuración a nivel molecular de los plásticos, mientras que el 
primero es tan solo a un nivel físico. Con esto, pueden mezclarse plásticos para producir nuevos polímeros o generar el mismo polímero como "virgen".

Dentro del reciclaje químico hay dos ramas principales, la termólisis y la quimiólisis que profundizaremos a continuación:

- Termólisis: Se aplica para polímeros de adición por medio del efecto del calor. Esto significa que los monómeros pueden formar el respectivo polímero sin la perdida de átomos (a diferencia de cuando se realiza por condensación donde se generan subproductos).

- Pirólisis: Significa que se craquean o rompen las moléculas por calentamiento en vacío. Con esto se generan hidrocarburos sólidos o líquidos que pueden ser utilizados en calderas, refinerías o en plantas de vidrio o ladrillos.

\section{Figura 5.4}

Representación de usos de reciclaje por pirólisis

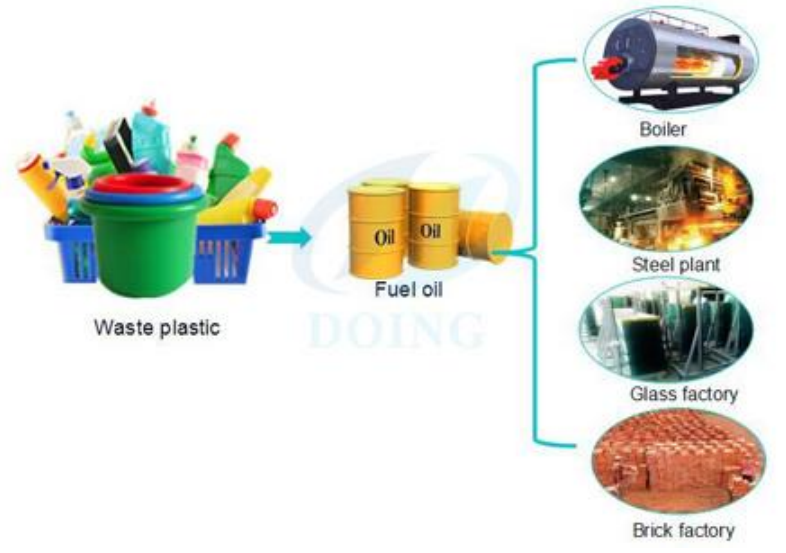

Fuente: wastetireoil.com (2015)

- Quimiólisis: Se aplica para despolimerizar totalmente cualquier polímero por medio del efecto de reactivos químicos. Este método tiene la gran ventaja de que puede crear 
polímeros completamente distintos al utilizado como materia prima. Por lo tanto, facilita el proceso de clasificación y separación que se aplica en cualquier otro proceso de reciclaje.

- Hidrogenación: Se trabaja el plástico con hidrogeno y calor para romper las cadenas poliméricas y producir petróleo sintético. Se puede usar en refinerías o plantas químicas

- Gasificación: Se trabaja el plástico con aire u oxigeno con el objetivo de conseguir los gases de síntesis monóxido de carbono e hidrogeno. Por ejemplo, se utiliza para producir metanol o amoniaco.

- Chemolysis: Se trabaja el plástico por medio de procesos solvolíticos o de separación como hidrólisis, glicólisis o alcohólisis. De esta forma se logra alcanzar los monómeros básicos y luego re polimerizar. Este método aplica para los poliésteres, poliuretanos, poliacetales y poliamidas.

En resumen, el reciclaje químico se desarrolló como una alternativa al reciclaje mecánico, ya que este por sí solo no era suficiente para abastecer todo el material que se necesita reciclar, y se está desarrollando cada vez más a nivel mundial.

\subsubsection{Selección de la tecnología}

Respecto a las tecnologías existentes identificadas, se trabajará con la mecánica. Esto es debido a tres motivos principales que son:

- El escaso conocimiento del método químico, ya que el reciclaje químico apareció luego del mecánico y se ha ido desarrollando en los últimos años aun no es el método más conocido. Esto conlleva a que tampoco se puede conseguir "asesoría" de expertos del medio, ya que en Perú toda la tecnología que se utiliza actualmente es la mecánica. 
- Los costos más elevados que implica este tipo de reciclaje según la opinión de expertos encontradas en la web Azul Ambientalistas y la información de investigaciones previas (Oviedo, 2014)

- La tecnología química es enfocada en plásticos termoestables, por lo tanto, no podemos aplicarlo en el polímero considerado en el presente proyecto, que es polipropileno.

Aunque el reciclaje químico es mucho más efectivo en términos de que puede volver a crear un plástico virgen a partir del reciclado, es un proceso distinto y que representaría otra investigación e inversión totalmente diferentes. A su vez, ya que es un proceso más elaborado se requieren insumos y maquinaria mucho más caros que no son tan comunes.

De igual manera, no se descarta que se pueda llevar a cabo en el futuro como una extensión del portafolio de producción cuando la empresa ya esté asentada en el mercado local.

\subsubsection{Proceso de producción}

En este acápite se procede a detallar todo el proceso de producción con las especificaciones técnicas de cada máquina, el diagrama de proceso y balance de materia y energía.

\subsubsection{Descripción del proceso}

El proceso productivo comienza recibiendo la materia prima obtenida a través de la red de acopio. Dicha red está conformada principalmente de recolectores formales, empresas tercerizadas que se encargan de obtener el material de otras empresas para luego venderlo a compradores potenciales como nuestra empresa, y de socios estratégicos como municipalidades a quienes se les comprará sus desechos recolectados periódicamente.

Una vez que llega el material a la planta, lo primero es pesarlo por dos razones: para pagar lo correspondiente por la cantidad obtenida y para registrar cuanto material entra a la línea de producción. Tras esta primera inspección de pesado, comienza el proceso de clasificación. Este es manual y es donde se acumulará la mayor parte de operarios de la 
planta, ya que es un proceso que involucra mucho nivel de detalle y es riguroso. Tras está separación se tiene la materia prima dividida por color y por polímero, la cual se mantiene en un "almacén" provisional por lotes. En esta etapa se pueden retirar todos los metales que pueden estar presentes junto con la materia prima y polímeros como polietileno que no necesitamos y que se puede identificar a simple vista.

\section{Figura 5.5}

Códigos de identificación de los polímeros

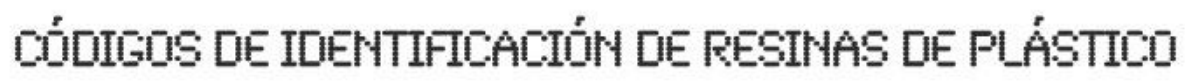

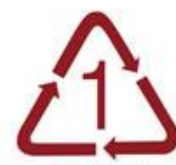

PETE

POLIETLENO TEREFTALATO

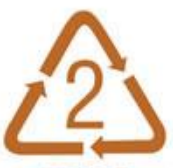

HDPE

POLIETLENO DE ALTA DENSIDAD

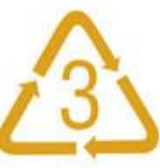

V

POLICLORURO DE

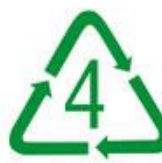

LDPE

POLIETLENO DE BAJA DENSIDAD

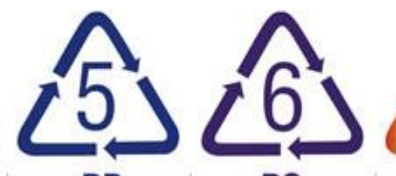

PS

POLIPROPILEMO POLIESTIREMO

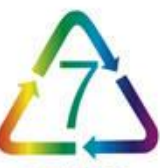

OTHER

OTROS

Fuente: tecnologiadelosplasticos.blogspot.com (2011)

Posteriormente, se procede a cargar el lote de material seleccionado a la faja transportadora que lo cargará a la primera máquina de la línea, la cual es el molino. 
Figura 5.6

Molino Pagani

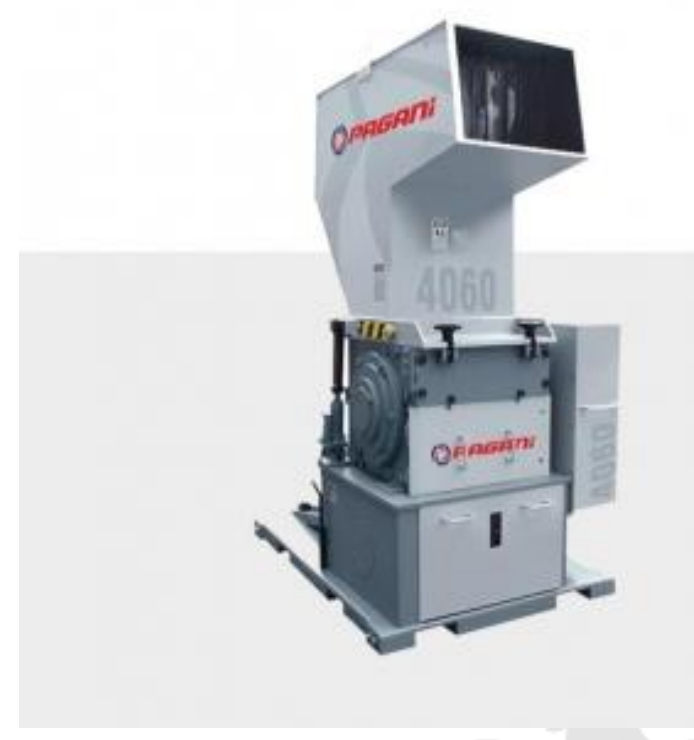

\begin{tabular}{l|r}
\hline Característica & Descripción \\
\hline Modelo & Molino 40120-CH \\
Motor HP & 103 \\
Boca de alimentación & $400 \times 1200$ \\
Tipo de rotor & Abierto \\
Dimensiones $(\mathrm{mm})$ & $2492 \times 1900 \times 2613$ \\
Producción $\mathrm{Kg} / \mathrm{hr}$ & 1200 \\
\hline
\end{tabular}

Fuente: pagani.com.mx (2017)

En el transcurso de la faja transportadora, se lleva a cabo una segunda inspección preventiva con el detector de metales incorporado en la faja. Este paso es sumamente importante ya que de llegar algún metal al molino podría malograrlo al interactuar con las cuchillas. Con esto, se retiran todos los metales que se hayan podido filtrar con la materia prima en la clasificación previa.

Luego, el material es triturado en el molino, por lo tanto, quedan solo partículas pequeñas del plástico. Estas se juntan con agua, detergente y soda caustica para el proceso de lavado y para de esta manera eliminar el polvo, residuos o cualquier elemento patógeno que pueda haber presente de su uso previo. En el molino también se utiliza agua, aunque en menor medida, a modo de pre lavado. 


\section{Figura 5.7}

Centrifuga de lavado

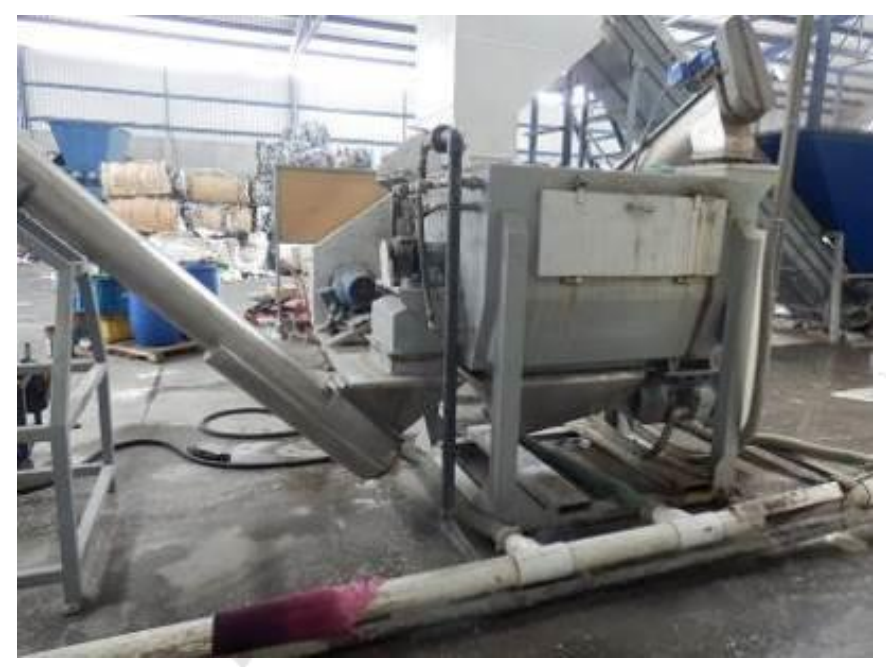

\begin{tabular}{l|r}
\hline Característica & Descripción \\
\hline Modelo & Centrifuga GTC \\
Motor HP & 30 \\
Tipo de rotor & De paletas \\
Dimensiones $(\mathrm{mm})$ & $1644 \times 1700 \times 2927$ \\
Producción $\mathrm{Kg} / \mathrm{hr}$ & 5000 \\
\hline
\end{tabular}

Fuente: pagani.com.mx (2017)

En este momento empieza la primera parte crítica del proceso para asegurar la pureza del producto que es la separación por flotación para retirar el PET o PVC que pueda haber presente en la mezcla.

\section{Figura 5.8}

Tina de flotación

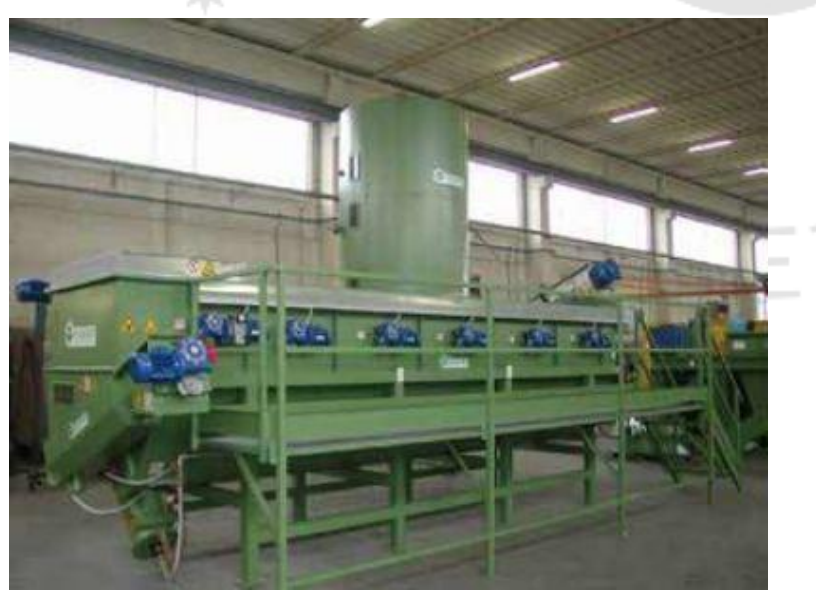

\begin{tabular}{l|r}
\hline Característica & \multicolumn{1}{|l}{ Descripción } \\
\hline Modelo & Acero inoxidable \\
Motor HP & 10 \\
Dimensiones (mm) & $1246 \times 5900 \times 1045$ \\
Producción Kg/hr & 1500 \\
\hline
\end{tabular}

Fuente: pagani.com.mx (2017) 
Una vez realizada dicha separación, queda solo polipropileno puro en nuestra mezcla, el cual pasa por los procesos de centrifugado y secado para retirar toda la humedad presente en el producto, segundo punto crítico para garantizar la calidad.

\section{Figura 5.9}

Centrifuga horizontal de secado

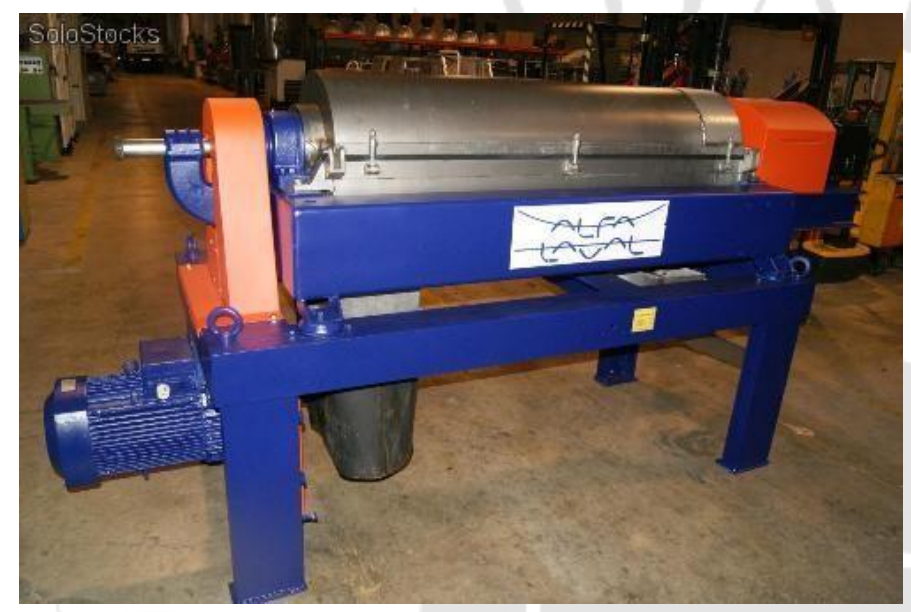

\begin{tabular}{l|r}
\hline Característica & \multicolumn{2}{|c}{ Descripción } \\
\hline Modelo & Spin 1000 \\
Motor HP & 50 \\
Dimensiones $(\mathrm{mm})$ & $1246 \times 2730 \times 1672$ \\
Producción $\mathrm{Kg} / \mathrm{hr}$ & 1000 \\
\hline
\end{tabular}

Fuente: pagani.com.mx (2017)

Ya con el material seco, se procede a introducirlo en el ciclón, que funciona como separador para las etiquetas que tienen una composición diferente que las escamas de polipropileno. Estas etiquetas pueden venderse como materia prima a un tercero de manera que se puede recuperar algo del dinero invertido en la compra de la materia prima. 


\section{Figura 5.10}

\section{Ciclón}

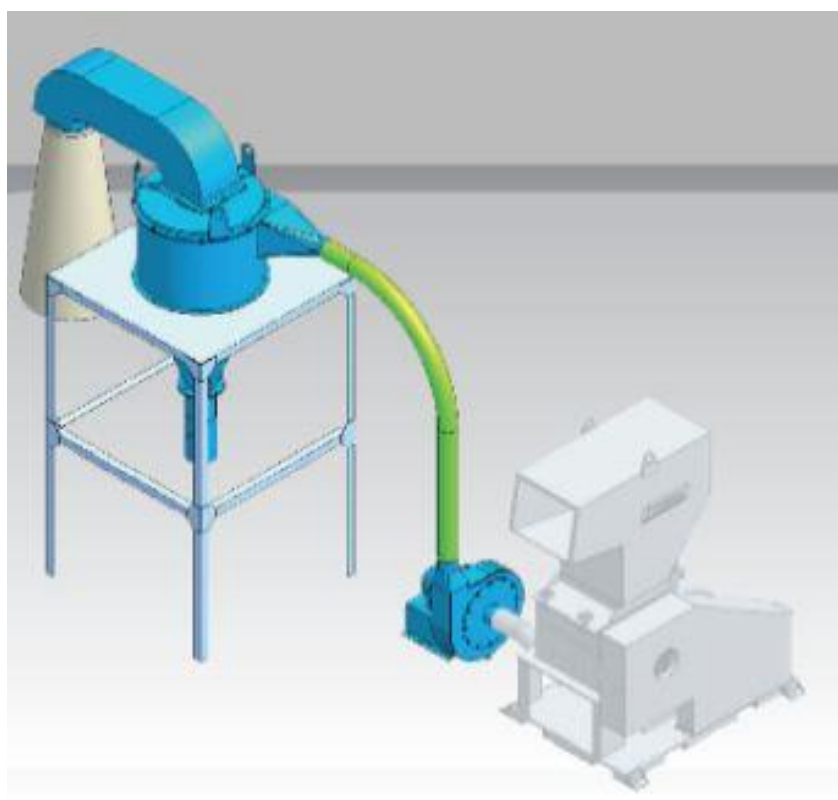

\begin{tabular}{l|r}
\hline Característica & Descripción \\
\hline Modelo & Ciclón con base de \\
descarga \\
Motor HP & 0 \\
Dimensiones (mm) & $498 \times 600 \times 2620$ \\
Producción Kg/hr & 1000 \\
\hline
\end{tabular}

Fuente: pagani.com.mx (2017)

Para finalizar, se realiza una última separación en el separador de finos con el objetivo de retirar todos los polvos que puedan haber quedado. Las escamas limpias, secas y puras de polipropileno se pesan y embolsan en sacos de 25 kilogramos para obtener el producto final, listo para comercializar. 
Figura 5.11

Separador de finos

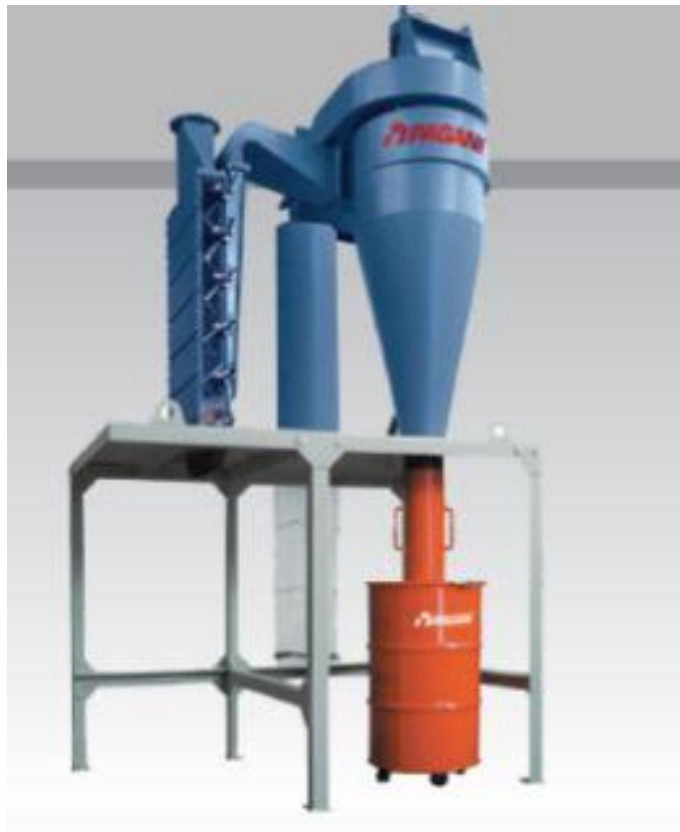

\begin{tabular}{l|r}
\hline Característica & Descripción \\
\hline Modelo & SEP-10 \\
Motor HP & 7,5 \\
Dimensiones (mm) & $2400 \times 1300 \times 4300$ \\
Producción Kg/hr & 1000 \\
\hline
\end{tabular}

Fuente: pagani.com.mx (2017)

Cabe considerar que de cada 1000 kilogramos de escamas que salen del separador de finos, se retira 1 kilogramo de producto terminado para realizar dos pruebas de calidad que permitirán alcanzar los estándares esperados por los clientes y ofrecidos por la compañía. La primera de ellas es una prueba asociada a la pureza del producto terminado y busca asegurar que la selección y separación realizadas durante los primeros pasos del proceso productivo han sido efectivas. Esta consiste en poner 990 gramos del kilogramo de producto terminado antes mencionado en una cubeta transparente llena de agua y observar la proporción de escamas flotantes en comparación con aquellas que se hunden. A mayor proporción de escamas flotantes con respecto a las que se hunden, se puede concluir que la calidad del producto es mayor ya que existe una menor cantidad de impurezas dentro del producto terminado. La segunda prueba consiste en colocar los 10 gramos restantes del kilogramo retirado en un equipo de medición de humedad, durante aproximadamente 2 a 3 minutos, para asegurar que esta no supere el límite de 0,5\% previamente establecido como estándar de calidad para nuestro producto. 


\section{Figura 5.12}

Medidor de humedad

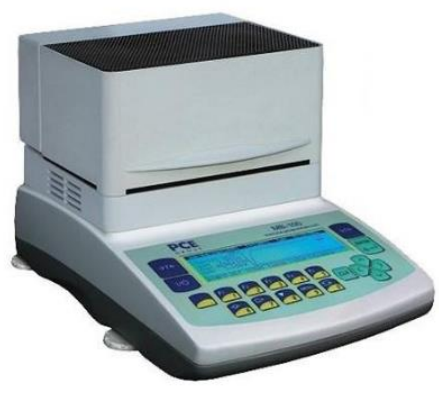

\begin{tabular}{l|r}
\hline Característica & Descripción \\
\hline Modelo & Macide Scorp \\
Motor HP & 0 \\
Dimensiones $(\mathrm{mm})$ & $200 \times 300 \times 600$ \\
Producción Kg/hr & 0,2 \\
\hline
\end{tabular}

Fuente: interempresas.net (2016)

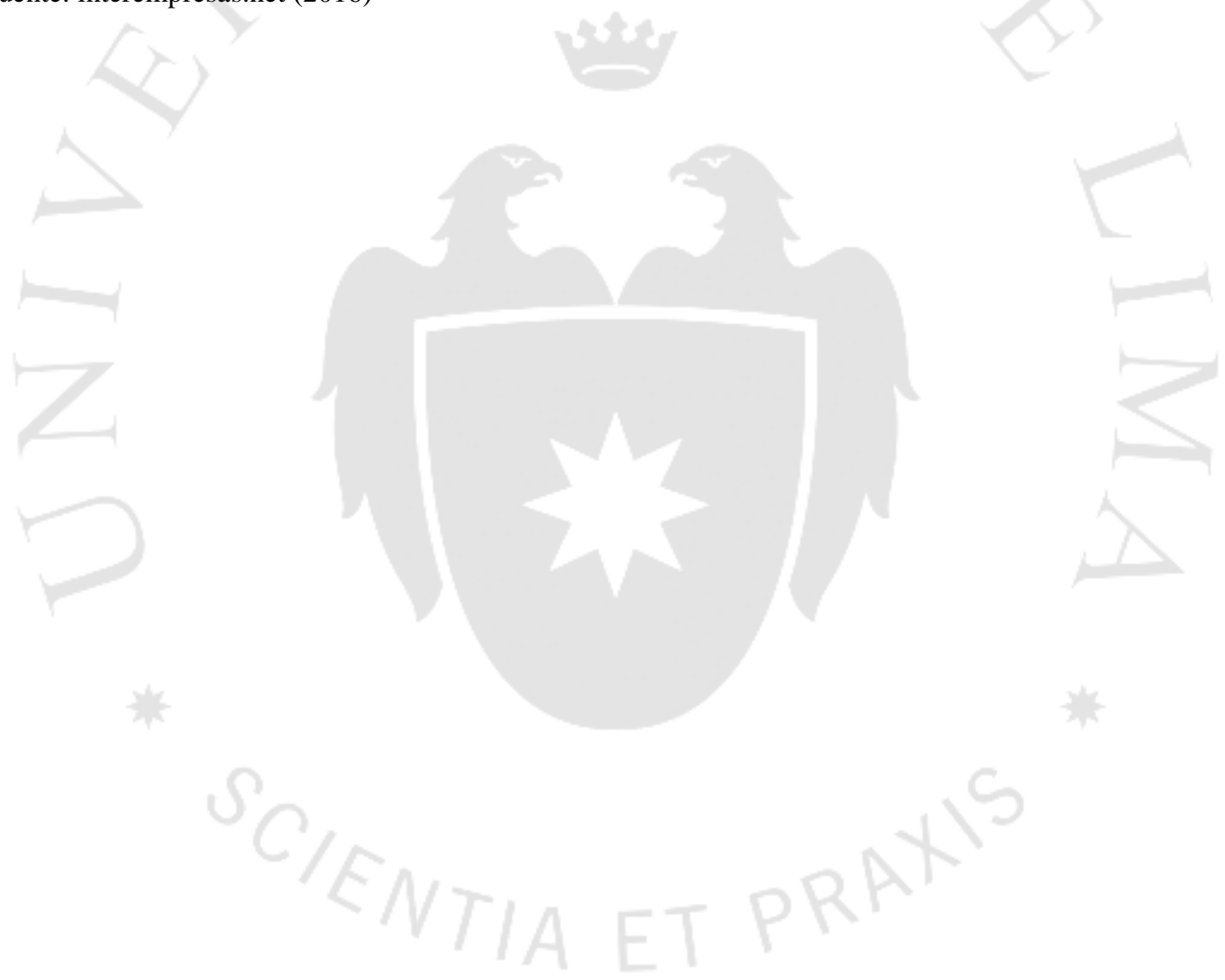




\subsubsection{Diagrama del proceso}

Figura 5.13

Diagrama de operaciones del proceso

DIAGRAMA DE OPERACIONES PARA LA PRODUCCIÓN DE POLIPROPILENO RECICLADO

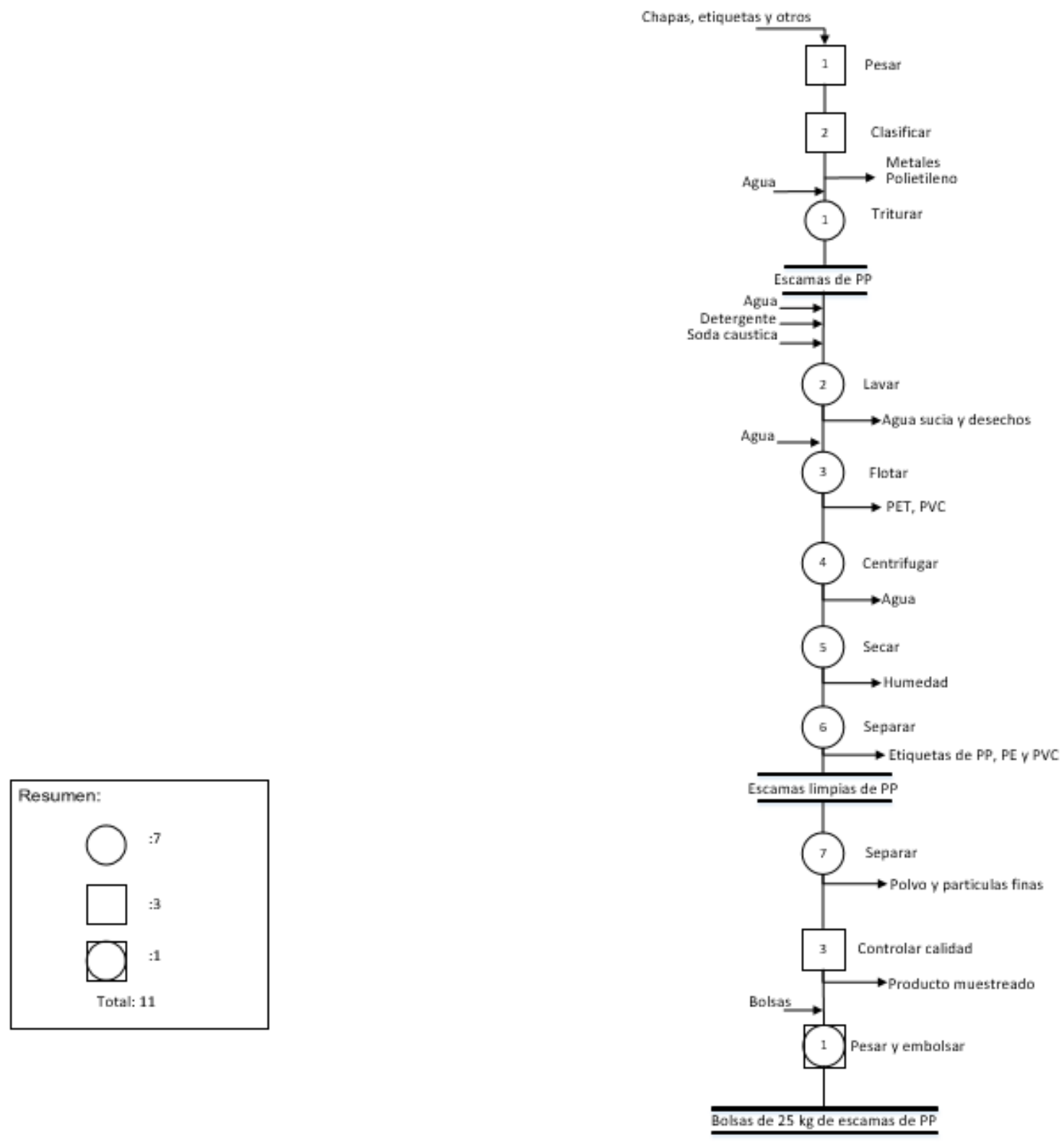

Elaboración propia 


\subsubsection{Balance de materia y energía}

Figura 5.14

Balance de materia para producción de polipropileno reciclado

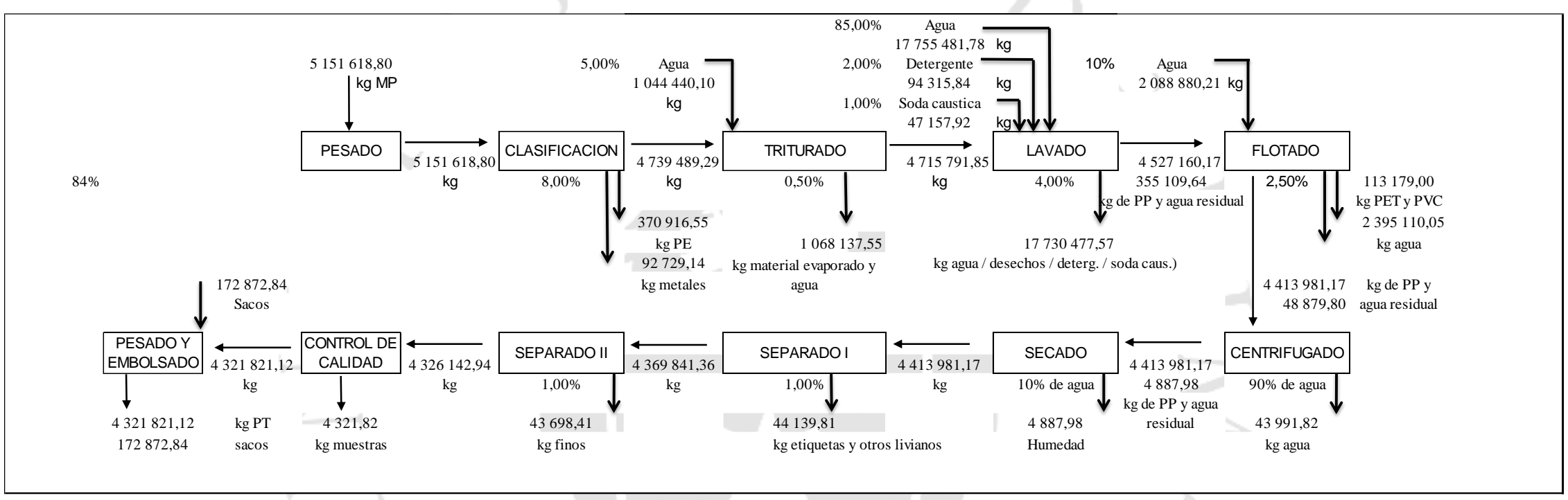

Elaboración propia 
En todo el proceso se maneja aproximadamente un 16\% de mermas, esto quiere decir que por cada 1 kilogramo de materia prima se obtiene 0,84 kilogramos de producto terminado. El grueso de las mermas se origina en los procesos de clasificación y lavado (aproximadamente 12\%), por la naturaleza de la materia prima con la que se trabaja. Al ser prácticamente basura originada del consumo o merma industrial lamentablemente muchas veces viene mezclada con otros materiales que no se pueden utilizar. Otro aspecto importante es que el proceso diagramado en la figura anterior consume grandes volúmenes de agua, siendo la mayoría de dicho consumo destinado al lavado, operación crítica ya que al tratar con productos que podrían estar contaminados, estos deben ser desinfectados antes de poder reutilizarse.

\subsection{Características de las instalaciones y equipos}

En este acápite se procede a detallar la selección de maquinaria y equipos, y las especificaciones de las mismas.

\subsubsection{Selección de la maquinaria y equipos}

Dentro de la gran variedad de máquinas y equipos que se ofrecen en el mercado, las cuales han sido mencionadas en el acápite 4.3, la maquinaria seleccionada consiste en una línea de producción integrada proveniente de una empresa mexicana llamada Pagani, la cual es altamente reconocida por la calidad de sus productos desde 1966. El principal motivo por el cual se selecciona dicha tecnología en vez de la ofrecida por Floplastics es la alta calidad de la maquinaria Pagani y el reconocimiento de la misma a lo largo de la historia, lo cual da lugar a una producción más eficiente y más rentable. Algunas empresas que pueden evidenciar este primer punto son Gexim y Poliempac, ya que utilizan la maquinaria Pagani. El segundo y tercer motivo se interrelacionan y son la cercanía del lugar de adquisición de la máquina y el idioma manejado por los vendedores y expertos de dichas máquinas. La maquinaria Pagani se fabrica en México país más cercano al Perú que los Estados Unidos, lugar de donde se tendría que importar la maquinaria de Floplastics; este factor es relevante ya que una mayor cercanía se traduce en menores costos de transporte al comprar la maquinaria. Por otro lado, los técnicos y expertos de Pagani manejan ampliamente el idioma 
español, al ser su lengua materna, por lo que se facilita la comunicación con técnicos y usuarios de la maquinaria en el Perú; mientras que el personal de Floplastics se rige principalmente por el inglés, idioma con bajo nivel y poco utilizado en el Perú. (Gestión, 2016)

En cuanto al equipo para la prueba de calidad de humedad, se cotizaron dos proveedores españoles, Metrotec (Metrotec) y Scorp (Scorp), ambos cuentan con máquinas de alta tecnología; sin embargo por cuestiones de la inversión asociada, 13500 dólares versus 2500 dólares, se selecciona la tecnología brindada por la compañía Scorp ya que cumple con los requisitos necesarios para la operativa requerida por la prueba que se busca realizar, es decir, tiene un espectro de medición lo suficientemente preciso.

\subsubsection{Especificaciones de la maquinaria}

Se puso especial enfoque en conseguir ciertas características de las maquinas:

- Costo unitario por máquina

- Dimensiones con el plano

- Consumo de energía

- Consumo hídrico

- Capacidad de producción 
Tabla 5.1

Especificaciones de línea de producción Pagani de $1000 \mathrm{~kg} / \mathrm{h}$

\begin{tabular}{|c|c|c|c|}
\hline NO & EQUIPOS & $\underline{\mathrm{HP}}$ & PRECIO US\$ \\
\hline 1 & $\begin{array}{l}\text { BANDA TRANSPORTADORA INCLINADA PARA ALIMENTACION DEL MOLINO, } \\
\text { ESTRUCTURA DE ACERO AL CARBON Y LIGA DE PVC CON EMPUJADORES } \\
\text { VULCANIZADOS. }\end{array}$ & 5 & 10800 \\
\hline 2 & $\begin{array}{l}\text { MOLINO } 40120-C H \text { CON INYECCION DE AGUA, } 3 \text { CUCHILLAS DE ROTOR Y } 2 \text { DE CAJA, } \\
\text { ROTOR DE } 400 \mathrm{~mm} \text { DE DIAMETRO Y } 1,200 \mathrm{~mm} \text { DE LARGO. CRIBA CON BARRENOS DE } \\
1 / 2^{m} \text { DE DIAMETRO. } \\
\text { MOLINO CON AUGER EN EL FONDO PARA DESCARGA DEL MATERIAL. DE ACERO } \\
\text { INOXIDABLE. }\end{array}$ & 103 & 66850 \\
\hline 3 & $\begin{array}{l}\text { TRANSPORTADOR AUGER INCLINADO DE 6" DE DIAMETRO Y DE ACERO } \\
\text { INOXIDABLE CON CRIBA DE DRENAJE. }\end{array}$ & 5 & 7950 \\
\hline 4 & $\begin{array}{l}\text { CENTRIFUGA GTC DE ENJUAGUE, CRIBA DE ACERO INOXIDABLE, ROTOR DE } \\
\text { PALETAS Y BASTIDOR FABRICADOS DE ACERO AL CARBON. }\end{array}$ & 30 & 24650 \\
\hline 5 & $\begin{array}{l}\text { TRANSPORTADOR AUGER INCLINADO DE 6" DE DIAMETRO Y DE ACERO } \\
\text { INOXIDABLE CON CRIBA DE DRENAJE. }\end{array}$ & 5 & 8100 \\
\hline 6 & $\begin{array}{l}\text { TINA DE FLOTACION AUGER DE ALIMENTACION, AGITADORES, HUSILLO DE FONDO, } \\
\text { AUGER DE SALIDA DE PET Y AUGER DE SALIDA DE MATERIALES FLOTABLES. } \\
\text { FABRICADA EN ACERO INOXIDABLE CON BASTIDOR DE ACERO AL CARBON. }\end{array}$ & 10 & 32950 \\
\hline 7 & TRANSPORTADOR AUGER INCLINADO DE 6" DE DIAMETRO DE ACERO INOXIDABLE & 2 & 8100 \\
\hline 8 & $\begin{array}{l}\text { CENTRIFUGA TURBO HORIZONTAL DE SECADO, SPIN 1000,CRIBA DE ACERO } \\
\text { INOXIDABLE, INTERIOR DE LAMINA DE ACERO INOXIDABLE, ROTOR Y BASTIDOR DE } \\
\text { ACERO AL CARBON. }\end{array}$ & 50 & 64650 \\
\hline 9 & CICLON CON BASE DE DESCARGA. & 0 & 750 \\
\hline 10 & $\begin{array}{l}\text { TRANSPORTADOR AUGER DE } 6^{\prime \prime} \text { DE DIAMETRO Y DE ACERO AL CARBON.PARA } \\
\text { DESCARGA A SEPARADOR DE FINOS. }\end{array}$ & 5 & 10350 \\
\hline \multirow[t]{4}{*}{11} & SEPARADOR DE FINOS SEP -10 & 7.5 & 14250 \\
\hline & TUBERIA Y CONEXIONES & 0 & 2200 \\
\hline & $\begin{array}{l}\text { PANEL DE CONTROL CON SECUENCIA DE ARRANQUE-PARO, SEṄALIZACION } \\
\text { LUMINOSA Y ALARMA SONORA. }\end{array}$ & 0 & 25800 \\
\hline & TOTAL HP & 223 & 277400 \\
\hline
\end{tabular}

Nota: El consumo hídrico estimado es de 4,83 litros de agua por kilogramo de producto terminado. El equipo para la medición de humedad es adquirido con otra empresa Scorp y tiene un costo de 2500 dólares.

Fuente: pagani.com.mx (2017)

Estos son vitales para determinar la inversión total inicial a realizar, los costos que representaría importar la maquinaria, la disposición de la planta, el porcentaje del suelo que necesita ser asfaltado, los costos fijos que podría representar la producción, entre otros.

A continuación, se presenta la maquinaria que se evalúa utilizar: 


\section{Figura 5.15}

Bosquejo de la línea de producción

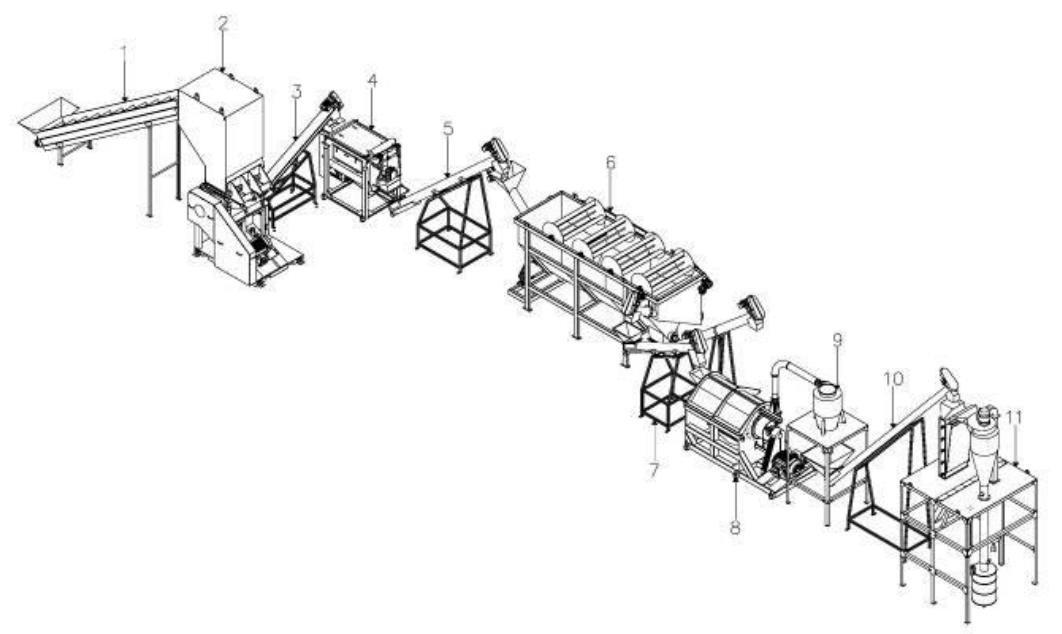

Nota: La leyenda de cada una de las máquinas se presenta en la tabla 5.1

Fuente: pagani.com.mx (2017)

\section{Figura 5.16}

Bosquejo de la línea de producción con dimensiones totales

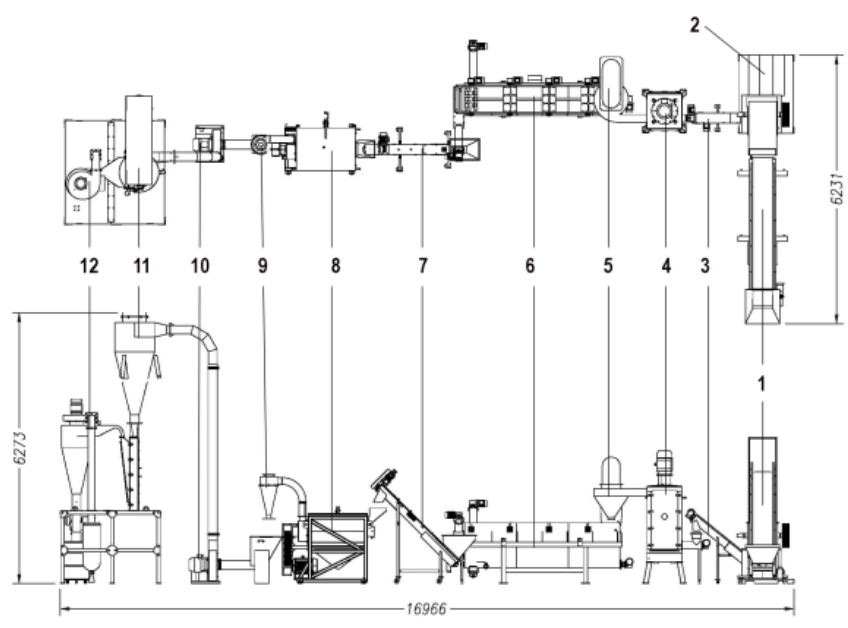

Nota: Las dimensiones disgregadas se pueden hallar en las especificaciones técnicas de cada máquina

Fuente: pagani.com.mx (2017) 


\section{Figura 5.17}

Foto referencial 1 de la línea de producción completa Pagani

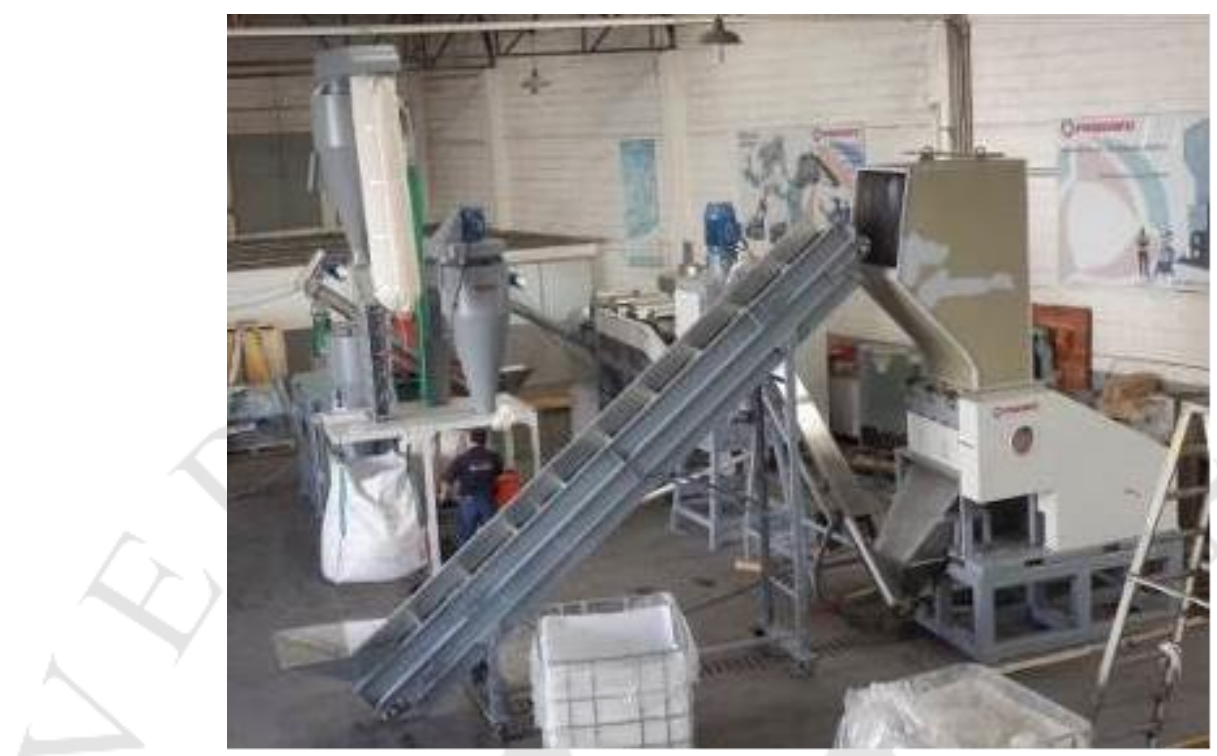

Fuente: pagani.com.mx (2017)

\section{Figura 5.18}

Foto referencial 2 de la línea de producción completa Pagani

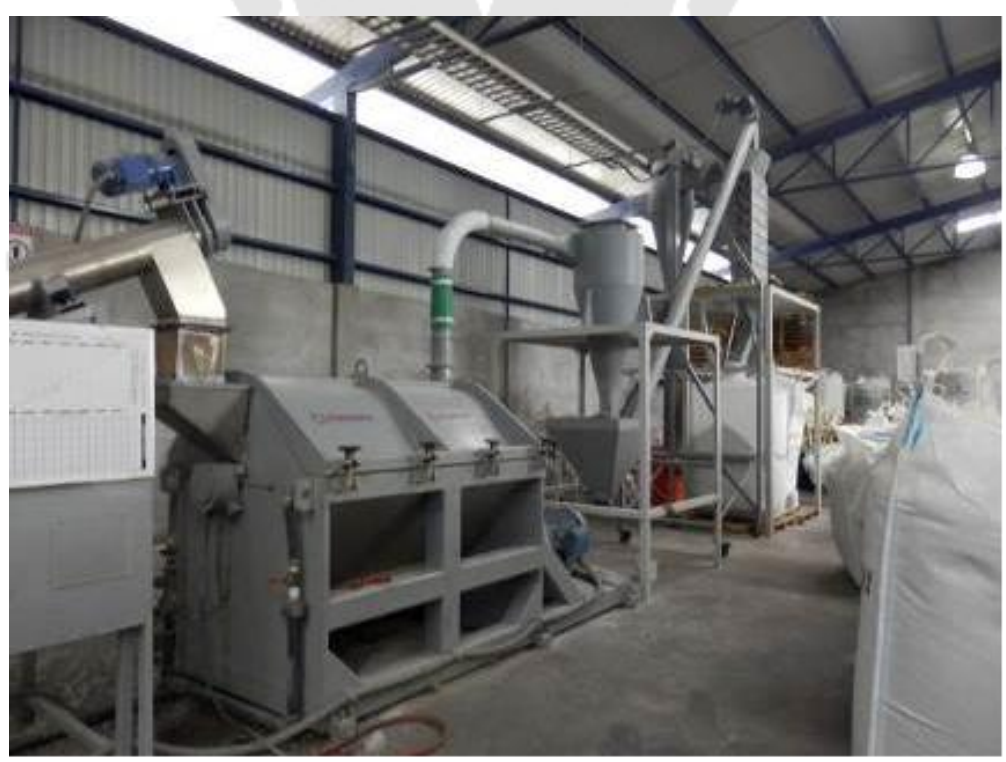

Fuente: pagani.com.mx (2017) 
Como se puede observar, la opción de una línea integrada conlleva ciertas ventajas, como la garantía de que todas las maquinas funcionan juntas y a un ritmo uniforme. En este caso, dicho ritmo es de 1000 kilogramos/hora ya que es preferible tener capacidad en exceso y proyección de crecimiento como se verá en el siguiente capítulo de capacidad instalada.

\subsection{Capacidad instalada}

En este acápite se procede a detallar el cálculo de la capacidad instalada alineado con el número de máquinas y operarios requeridos.

\subsubsection{Cálculo de la capacidad instalada}

Tabla 5.2

Cálculo de la capacidad instalada

\begin{tabular}{c|cccc}
\hline AÑO & $\begin{array}{c}\text { Demanda } \\
\text { especifica }\end{array}$ & $\begin{array}{c}\text { \% uso cap. } \\
\text { Instalada }\end{array}$ & $\begin{array}{c}\text { Cap. instal ada } \\
\text { usada (kg) }\end{array}$ & CIO \\
\hline 2016 & 3407936,77 & $65 \%$ & 3861030,89 & 2079016,63 \\
2017 & 3616473,96 & $70 \%$ & 4158033,26 & 1782014,26 \\
2018 & 3837771,89 & $80 \%$ & 4752038,02 & 1188009,50 \\
2019 & 4072611,40 & $85 \%$ & 5049040,39 & 891007,13 \\
2020 & 4321821,12 & $90 \%$ & 5346042,77 & 594004,75 \\
\hline
\end{tabular}

Elaboración propia

Se obtuvo la capacidad instalada total en función al ritmo de producción de 1000 kilogramos/hora, el total de horas de producción anual, equivalente a 7430,4, los coeficientes de utilización (U) y eficiencia (E) y factor de conversión que funciona la planta en el transcurso del año. Este detalle se observa en el balance de materia efectuado, donde se determina el cuello de botella del proceso que es un empate entre el centrifugado, secado y separado I y por ende, la capacidad instalada máxima real de la línea de $5940048 \mathrm{~kg}$. 
Tabla 5.3

Cálculo de la capacidad productiva y operativa

\begin{tabular}{|c|c|c|c|c|c|c|c|c|c|c|c|c|c|c|c|c|c|}
\hline \multirow{2}{*}{ Operación } & \multicolumn{2}{|c|}{$\mathbf{Q E}$} & \multicolumn{2}{|l|}{ QS } & \multirow{2}{*}{$\begin{array}{c}\text { P } \\
\text { Prod (kg/h) }\end{array}$} & \multirow{2}{*}{ \# Maq } & \multirow{2}{*}{$\begin{array}{c}\text { H/T } \\
\text { Hreal/turno }\end{array}$} & \multirow{2}{*}{$\begin{array}{c}\text { T/D } \\
\text { turno/dia }\end{array}$} & \multirow{2}{*}{$\begin{array}{c}\mathrm{D} / \mathrm{S} \\
\text { dias/semana }\end{array}$} & \multirow{2}{*}{$\begin{array}{c}\mathrm{S} / \mathrm{M} \\
\text { semana/mes }\end{array}$} & \multirow{2}{*}{$\begin{array}{l}\text { M/AÑO } \\
\text { mes/año }\end{array}$} & \multirow{2}{*}{$\begin{array}{c}\mathbf{U} \\
\text { Util. }\end{array}$} & \multirow{2}{*}{$\begin{array}{c}\text { E } \\
\text { Efic. }\end{array}$} & \multirow{2}{*}{$\begin{array}{c}\text { CO } \\
\text { Cap. Proces. }\end{array}$} & \multirow{2}{*}{$\begin{array}{c}\text { CO } \\
\text { Cap. Produc. } \\
\end{array}$} & \multirow{2}{*}{$\begin{array}{c}\text { FC } \\
\text { Factor conv. }\end{array}$} & \multirow{2}{*}{$\begin{array}{c}\text { COPT } \\
\text { Cap. Operat. } \\
\end{array}$} \\
\hline & Cantidad & Unidades & Cantidad & Unidades & & & & & & & & & & & & & \\
\hline Triturado & 4739489,29 & $\mathrm{~kg}$ & 4715791,85 & $\mathrm{~kg}$ & 1200 & 1 & 12 & 2 & 6 & 4,3 & 12 & 0,95 & 0,85 & 7200057,60 & 7164057,31 & 0,04 & 262622,06 \\
\hline Lavado & 715791,85 & $\mathrm{~kg}$ & 4527160,17 & $\mathrm{~kg}$ & 5000 & 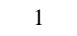 & 12 & 2 & 6 & 4,3 & 12 & 0,95 & 0,85 & 30000240,00 & 28800230,40 & 0,04 & 1099757,37 \\
\hline Flotado & 4527160,17 & $\mathrm{~kg}$ & 4413981,17 & $\mathrm{~kg}$ & 1500 & 1 & 12 & 2 & 6 & 4,3 & 12 & 0,95 & 0,85 & 9000072,00 & 8775070,20 & 0,04 & 343674,18 \\
\hline Centrifugado & 4413981,17 & $\mathrm{~kg}$ & 4413981,17 & $\mathrm{~kg}$ & 1000 & 1 & 12 & 2 & 6 & 4,3 & 12 & 0,95 & 0,85 & 6000048,00 & 6000048,00 & 0,04 & 234990,89 \\
\hline Secado & 4413981,17 & $\mathrm{~kg}$ & 4413981,17 & $\mathrm{~kg}$ & 1000 & 1 & 12 & 2 & 6 & 4,3 & 12 & 0,95 & 0,85 & 6000048,00 & 6000048,00 & 0,04 & 234990,89 \\
\hline Separado I & 4413981,17 & $\mathrm{~kg}$ & 4369841,36 & $\mathrm{~kg}$ & 1000 & 1 & 12 & 2 & 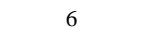 & 4,3 & 12 & 0,95 & 0,85 & 6000048,00 & 5940047,52 & 0,04 & 234990,89 \\
\hline Separado II & 4369841,36 & $\mathrm{~kg}$ & 4326142,94 & $\mathrm{~kg}$ & 1000 & 1 & 12 & 2 & 6 & 4,3 & 12 & 0,95 & 0,85 & 6000048,00 & 5940047,52 & 0,04 & 237364,54 \\
\hline Embolsado & 4326142,94 & $\mathrm{~kg}$ & 4321821,12 & $\mathrm{~kg}$ & 1000 & 1 & 12 & 2 & 6 & 4,3 & 12 & 0,95 & 0,85 & 6000048,00 & 6000048,00 & 0,04 & 240001,92 \\
\hline
\end{tabular}

Elaboración propia

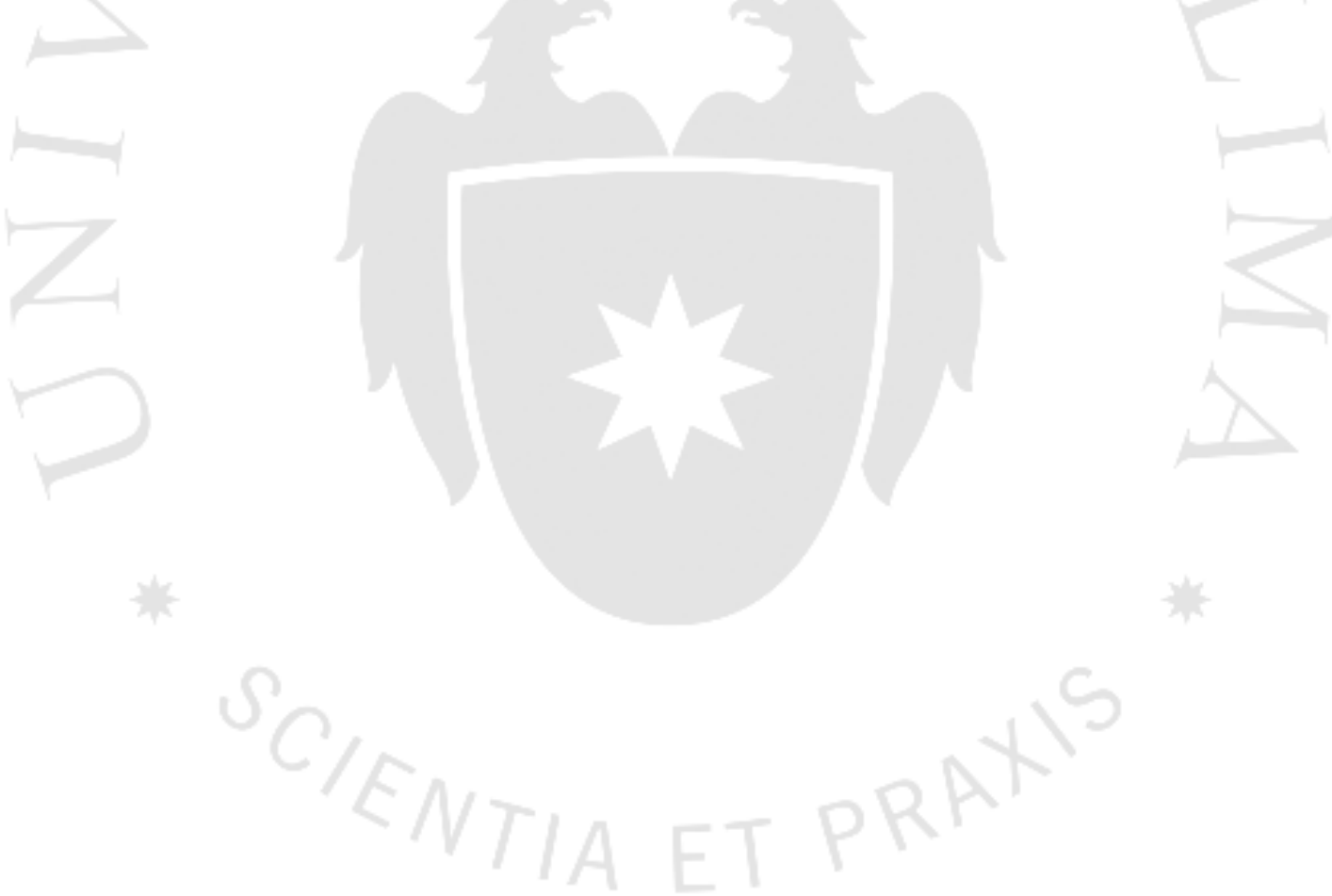


Otro detalle contemplado para los cálculos es la "curva de aprendizaje" para el porcentaje de uso de la capacidad instalada en la planta, el cual evoluciona desde un 65\% hasta un $90 \%$ de uso de la capacidad total en un periodo de 5 años. Al principio la capacidad instalada ociosa (CIO) es elevada, pero va reduciéndose año a año, y al ser siempre mayor a cero significa que no se tendrá problemas de capacidad en ninguno de los periodos trabajados.

\subsubsection{Cálculo detallado del número de máquinas y operarios requeridos}

El cálculo de operarios, tomando en cuenta un factor de eficiencia de 0.85 , un factor de utilización de 0.9375 , dos turnos diarios de doce horas cada uno y seis días de trabajo a la semana; se muestra a continuación.

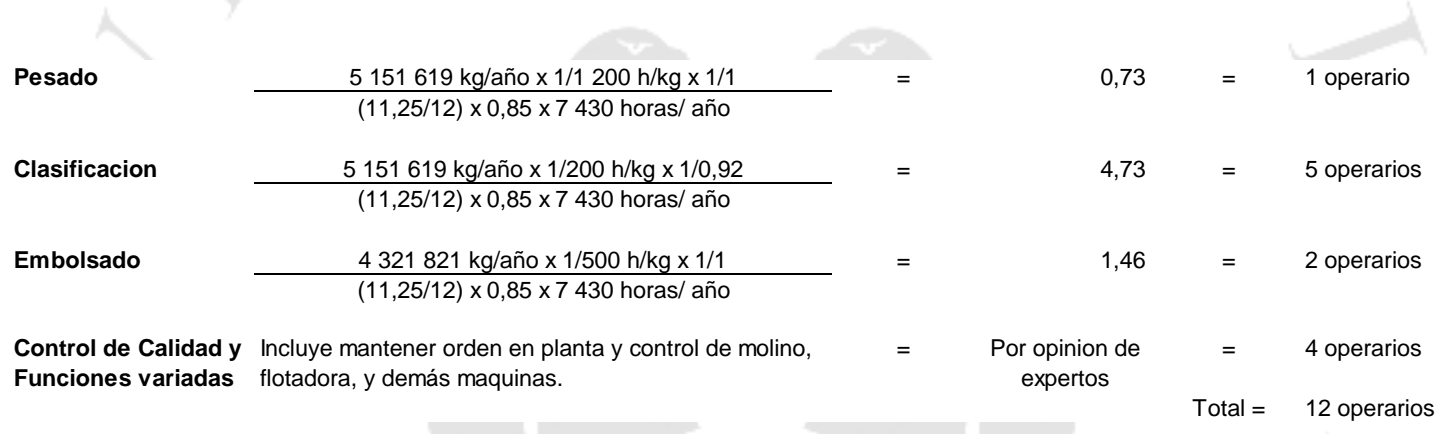

Tomando en cuenta las mismas condiciones mencionadas anteriormente, se muestra a continuación el número de máquinas necesarias.

\begin{tabular}{|c|c|c|c|c|c|}
\hline Molino: & $\frac{(4739489+1044440) \mathrm{kg} / \text { año } \times 1 / 1200 \mathrm{~h} / \mathrm{kg} \times 1 / 0,995}{0,95 \times 0,85 \times 7430 \text { horas } / \text { año }}$ & $=$ & 0,81 & $=$ & 1 máquina \\
\hline Lavadora: & $\frac{(4715792+17896956) \mathrm{kg} / \text { año } \times 1 / 5000 \mathrm{~h} / \mathrm{kg} \times 1 / 0,96}{0,95 \times 0,85 \times 7430 \text { horas } / \text { año }}$ & $=$ & 0,79 & $=$ & 1 máquina \\
\hline Flotadora: & $\frac{(4527160+2443990) \mathrm{kg} / \text { año } \times 1 / 1500 \mathrm{~h} / \mathrm{kg} \times 1 / 0,975}{0,95 \times 0,85 \times 7430 \text { horas/ año }}$ & $=$ & 0,79 & $=$ & 1 máquina \\
\hline Centrifugadora: & $\frac{(4413981+48880) \mathrm{kg} / \mathrm{año} \times 1 / 1000 \mathrm{~h} / \mathrm{kg} \times 1 / 1}{0,95 \times 0,85 \times 7430 \text { horas/ año }}$ & $=$ & 0,74 & $=$ & 1 máquina \\
\hline Secadora: & $\frac{(4413981+4888) \mathrm{kg} / \text { año } \times 1 / 1000 \mathrm{~h} / \mathrm{kg} \times 1 / 1}{0,95 \times 0,85 \times 7430 \text { horas } / \text { año }}$ & $=$ & 0,74 & $=$ & 1 máquina \\
\hline Separacion I: & $\frac{(4413981) \mathrm{kg} / \mathrm{año} \times 1 / 1000 \mathrm{~h} / \mathrm{kg} \times 1 / 0,99}{0,95 \times 0,85 \times 7430 \text { horas } / \text { año }}$ & $=$ & 0,74 & $=$ & 1 máquina \\
\hline Separacion II: & $\frac{(4369841) \mathrm{kg} / \mathrm{año} \times 1 / 1000 \mathrm{~h} / \mathrm{kg} \times 1 / 0,99}{0,95 \times 0,85 \times 7430 \text { horas } / \text { año }}$ & $=$ & 0,74 & $=$ & 1 máquina \\
\hline Embolsado: & (4 321821$) \mathrm{kg} / \mathrm{año} \times 1 / 1000 \mathrm{~h} / \mathrm{kg} \times 1 / 1$ & $=$ & 0,72 & $=$ & 1 máquina \\
\hline
\end{tabular}


Tabla 5.4

Resumen del cálculo del número de operarios requeridos

\begin{tabular}{c|cccccc}
\hline Actividad & Pesado & Clasificacion & Embolsado & $\begin{array}{c}\text { Funciones } \\
\text { variadas }\end{array}$ & $\begin{array}{c}\text { Total por } \\
\text { turno }\end{array}$ & Total para rotación \\
\hline Operarios & 1 & 5 & 2 & 4 & 12 & 24 \\
\hline
\end{tabular}

Elaboración propia

Para el cálculo de operarios previo, se determinaron diferentes ritmos de producción en base a la asesoría de expertos. Por ejemplo, el proceso que menor ritmo de producción tiene es el de clasificación con solo 200 kilogramos/hora por la naturaleza de la tarea. Es muy importante clasificar con exactitud los diferentes polímeros que se reciben. Por otro lado, el pesado se puede realizar con mayor velocidad ya que simplemente se recibe el material, se sube a la balanza y se registra el peso obtenido.

Adicional a los 8 operarios calculados previamente, se designan 4 operarios encargados de funciones variadas. Esto se hace en función al juicio de expertos, en este caso los gerentes de Gexim y Poliempaq, ya que se considera importante tener personal con tareas flexibles que puedan apoyar donde se requiera a lo largo de la jornada laboral. Como se menciona en el cálculo, esto incluye mantener orden de la planta, realizar limpieza, apoyar con el manejo de las maquinas semiautomáticas, traslado de herramientas, también pueden dar soporte a sus compañeros si hubiera alguna urgencia y por último realizar los controles de calidad de pureza y humedad. Esta última actividad toma 2 a 3 minutos por lote de 1000 $\mathrm{kg}$, por lo cual en un día se tendrían que invertir entre 10 a 15 minutos finalmente, cosa que es fácilmente distribuible entre los 4 operarios.

Tomando en cuenta dichas consideraciones, se obtuvo un total de 12 operarios requeridos por turno, lo cual se traduce en 24 operarios al día debido a los dos turnos de trabajo diarios que se mencionaron al inicio del acápite.

\subsection{Resguardo de la calidad o inocuidad del producto}

En este acápite se procede a detallar los estándares de calidad que se necesitan manejar y como se propone usar estrategias de mejora. 


\subsubsection{Calidad de la materia prima, de los insumos, del proceso y del producto}

Con respecto al primero de los ítems, la materia prima, la calidad no es un factor crítico del proceso porque se puede utilizar materia prima de casi todas las calidades, sin afectar el producto final.

Los insumos, principalmente el detergente y la soda caustica, deben ser de buena calidad para permitir la correcta remoción de todos los contaminantes que acompañan a la materia prima; por ello se adquieren de proveedores autorizados para garantizar así que el producto sea el adecuado.

Por otro lado, con respecto al proceso productivo, su calidad se asegura a través del uso de maquinaria de última tecnología, acompañada de un monitoreo constante de variables críticas para el desempeño de dichas máquinas y de un adecuado plan de mantenimiento para garantizar un funcionamiento adecuado de las mismas, lo que finalmente se traduce en un producto de calidad.

Finalmente, la calidad del producto se asegura mediante dos pruebas realizadas cada cierto tiempo de producción. La primera prueba consiste en retirar 990 gramos de producto terminado y colocarlos en una cubeta llena de agua contra la luz y observar y calcular, pasado un tiempo razonable, el porcentaje de escamas que se hunden con respecto a las que flotan, buscando siempre que, dicho porcentaje no sea mayor a las 10000 partes por millón, cifra estipulada como meta de calidad para el producto terminado. La segunda prueba consiste en colocar 10 gramos en una máquina medidora de humedad, durante 2 a 3 minutos, para asegurar que el porcentaje de humedad en el producto terminado no supere el límite recomendado de $0,5 \%$.

\subsubsection{Estrategias de mejora}

El abastecimiento de la materia prima en las cantidades adecuadas es un factor de suma relevancia. Con la finalidad de mejorar y asegurar dicho abastecimiento al igual que el de los insumos utilizados en el proceso productivo, se cuenta con un plan de desarrollo de socios estratégicos del cual son actores principales los dueños de las diversas compañías 
involucradas. El objetivo final de la formación de socios estratégicos es un resultado winwin para ambas partes.

Por otro lado, como se menciona en el punto anterior la maquinaria de alta tecnología se encuentra contemplada dentro de la inversión del proyecto, al igual que el gasto asociado a un plan de mantenimiento el cuál asegurará el desempeño de dichas máquinas según el estándar deseado.

Finalmente, la curva de aprendizaje permitirá afinar el factor humano involucrado dentro del proceso de manera que se pueda lograr un mejor producto de manera conjunta con una producción más eficiente y eficaz.

\subsection{Estudio de impacto ambiental}

El estudio de impacto ambiental se muestra en la tabla a continuación, la cual se encuentra conformada por las entradas y salidas a cada actividad al proceso y los aspectos, impactos y componentes ambientales que afectan dichas actividades. Es importante recalcar que a pesar de que se producen efectos dañinos para el medio ambiente a través de este proceso, se optimiza este último para reducir los impactos, a su vez el proceso por sí mismo colabora con el medio ambiente al reutilizar diversos productos de polipropileno cuyo destino intencional era la basura. 
Tabla 5.5

Matriz de impacto ambiental

\begin{tabular}{|c|c|c|c|c|c|}
\hline Entradas & Etapas del proceso & Salidas & Aspectos ambientales & Impactos ambientales & $\begin{array}{l}\text { afectado } \\
\text { - Medio } \\
\text { ambiente } \\
\text { - Tierra }\end{array}$ \\
\hline - Productos plásticos & Pesado & - Productos plásticos & - Utilización de recursos & \multirow{4}{*}{$\begin{array}{l}\text { - Contaminación por } \\
\text { consumo eléctrico } \\
\text { - Contaminación de suelos }\end{array}$} & \multirow{4}{*}{$\begin{array}{l}\text { - Medio } \\
\text { ambiente } \\
\text { - Tierra }\end{array}$} \\
\hline - Productos plásticos & \multirow{3}{*}{$\begin{array}{c}\Downarrow \\
\text { Selección }\end{array}$} & $\begin{array}{l}\text { pesados } \\
\text { - PP }\end{array}$ & \multirow{4}{*}{$\begin{array}{l}\text { - Utilización de recursos } \\
\text { - Generación de residuos } \\
\text { sólidos }\end{array}$} & & \\
\hline \multirow{3}{*}{ pesados } & & -PET & & & \\
\hline & & $-\mathrm{PVC}$ & & & \\
\hline & & $-\mathrm{PE}$ & & & \\
\hline - PP y delta de PE, PET, PVC & $\downarrow$ & - Plástico molído & - Genereación de efluentes & - Contaminación del recurso & - Agua \\
\hline - Desperdicios & Molido & - Agua sucia & - Utilización de recursos & hídrico & -Ambiente de \\
\hline - Agua & & - Desperdicios remanentes & - Volatilización de partículas & - Contaminación del ambiente & trabajo \\
\hline - Electricidad & & & $\begin{array}{l}\text { sólidas } \\
\text { - Generación de ruido }\end{array}$ & $\begin{array}{l}\text { de trabajo } \\
\text { - Contaminación del aire }\end{array}$ & - Aire \\
\hline - Plástico molido & $\downarrow$ & - Plástico limpio & - Generación de efluentes & - Contaminación del recurso & - Agua \\
\hline -Agua y detergente & $\frac{\Downarrow}{\text { Lavado }}$ & - Agua sucia & - Utilización de recursos & hídrico & - Ambiente de \\
\hline - Soda caústica & & & - Generación de ruido & - Contaminación del ambiente & trabajo \\
\hline - Electricidad & & 128 & & de trabajo & \\
\hline - Plástico limpio & $\downarrow$ & - PP húmedo & - Utilización de recursos & - Contaminación del ambiente & -Ambiente de \\
\hline - Agua & Flotación & - Agua con PET y PVC & - Generación de ruido & de trabajo & trabajo \\
\hline - Electricidad & & & & & \\
\hline - PP húmedo & & - PP semi seco & - Generación de efluentes & - Contaminación del recurso & - Agua \\
\hline - Electricidad & Centrifugado & - Agua & - Utilización de recursos & hídrico & - Ambiente de \\
\hline & & & - Genereación de ruido & $\begin{array}{l}\text { - Contaminación del ambiente } \\
\text { de trabajo }\end{array}$ & trabajo \\
\hline - PP semi seco & $\downarrow$ & - PP seco & - Generación de vapores & - Contaminación del aire & - Aire \\
\hline - Electricidad & Secado & - Aire húmedo & - Utilización de recursos & - Contaminación del ambiente & -Ambiente de \\
\hline - Aire caliente & & & - Generación de ruido & de trabajo & trabajo \\
\hline - PP seco & $\downarrow$ & - PP seco & - Utilización de recursos & - Contaminación del aire & -Aire \\
\hline - Electricidad & Separación al vacío & - Etiquetas & - Generación de vapores & - Contaminación del ambiente & - Ambiente de \\
\hline -Aire & & - Aire & - Generación de ruido & de trabajo & trabajo \\
\hline - PP seco & $\downarrow$ & - PP seco & - Generación de particulas en & - Contaminación del aire & - Aire \\
\hline - Aire & Separación de finos & - Polvillo de PP & suspensión & - Contaminación del ambiente & - Ambiente de \\
\hline - Electricidad & & - Aire & & de trabajo & trabajo \\
\hline - PP seco & $\frac{\Downarrow}{\text { Pesado y embolsado }}$ & - PP ensacado & - Generación de residuos & - Contaminación de suelos & - Suelo \\
\hline - Bolsas & & - Merma de PP y bolsas & sólidos & & \\
\hline
\end{tabular}

Elaboración propia

\subsection{Seguridad y salud ocupacional}

El análisis de este punto, crítico para el buen desempeño de una organización manufacturera, se hará en dos etapas, una inicial de identificación de peligros y riesgos por actividades realizadas en la compañía y una segunda de proposición de medidas de control para disminución de la exposición y severidad de dichos riesgos.

El listado de las actividades, sus respectivos peligros y riesgos y las medidas de control respectivas se muestran en la tabla a continuación. 
Tabla 5.6

Matriz de identificación de peligros, evaluación de riesgos y control

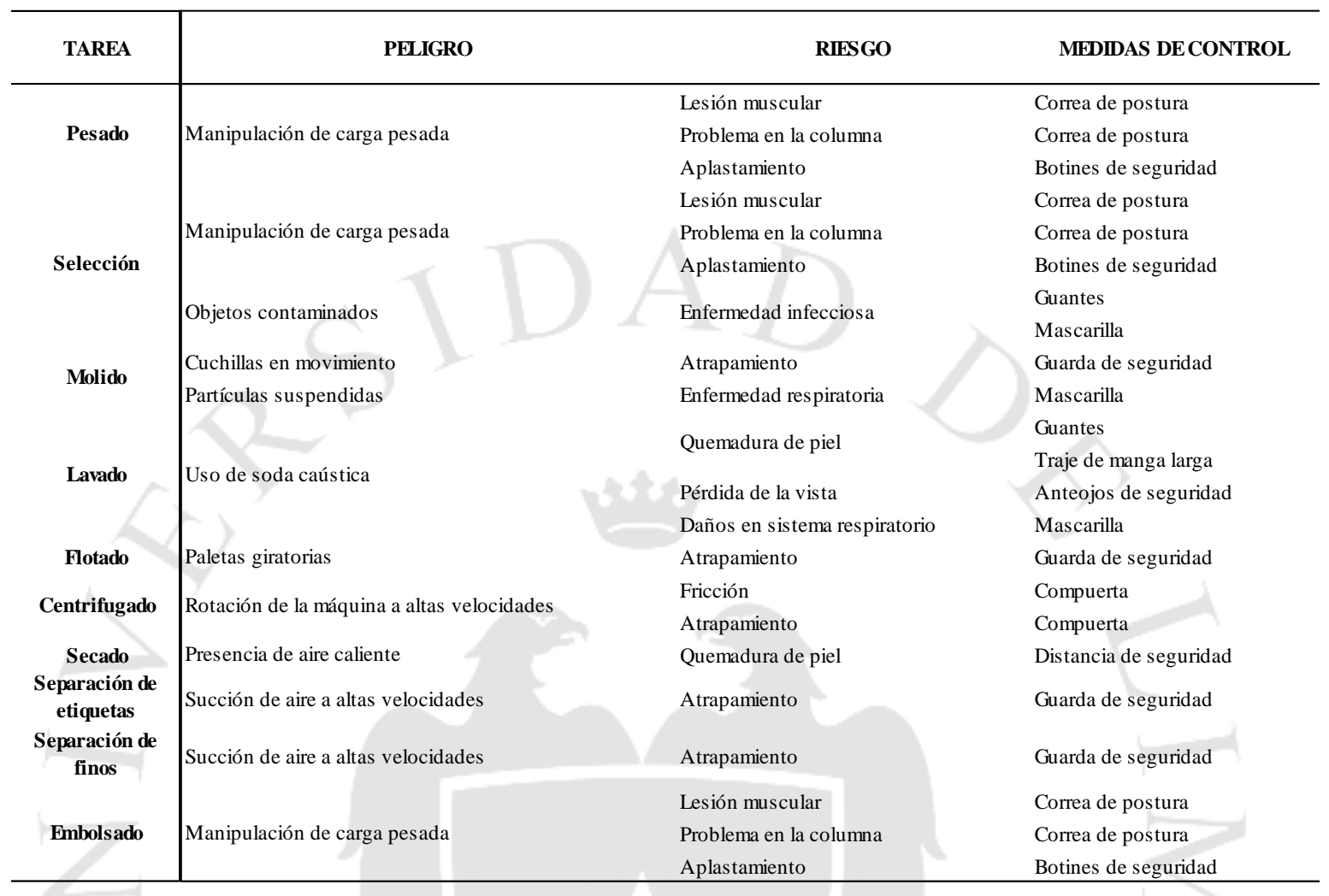

Elaboración propia

\subsection{Sistema de mantenimiento}

Dentro de la planta se contemplan dos principales tipos de mantenimiento. El primero de ellos, de carácter planificado, es el mantenimiento preventivo que consiste en ejecutar un cronograma de mantenimiento que se realiza en base a las especificaciones de periodicidad de mantenimiento de cada máquina según lo especificado por el fabricante.

Por otro lado, y debido a que ninguna máquina se encuentra libre de una avería se contempla el uso de un mantenimiento reactivo, de carácter no programado, el cual tiene lugar cuando de manera súbita e imprevista una máquina deja de funcionar, tratando siempre de mantener su incidencia en el menor nivel posible. Su principal finalidad es corregir la avería y colocar la máquina en operación en la brevedad posible. 
De manera complementaria a los dos mantenimientos mencionados previamente, se lleva a cabo mantenimiento predictivo, pero con una escasa frecuencia, principalmente debido al elevado costo y la complejidad que involucra su ejecución.

Finalmente, todos y cada uno de estos tipos de mantenimiento se desarrollan por terceros especialistas en la temática, ya que permite ahorro de costos y mayor eficiencia en la tarea.

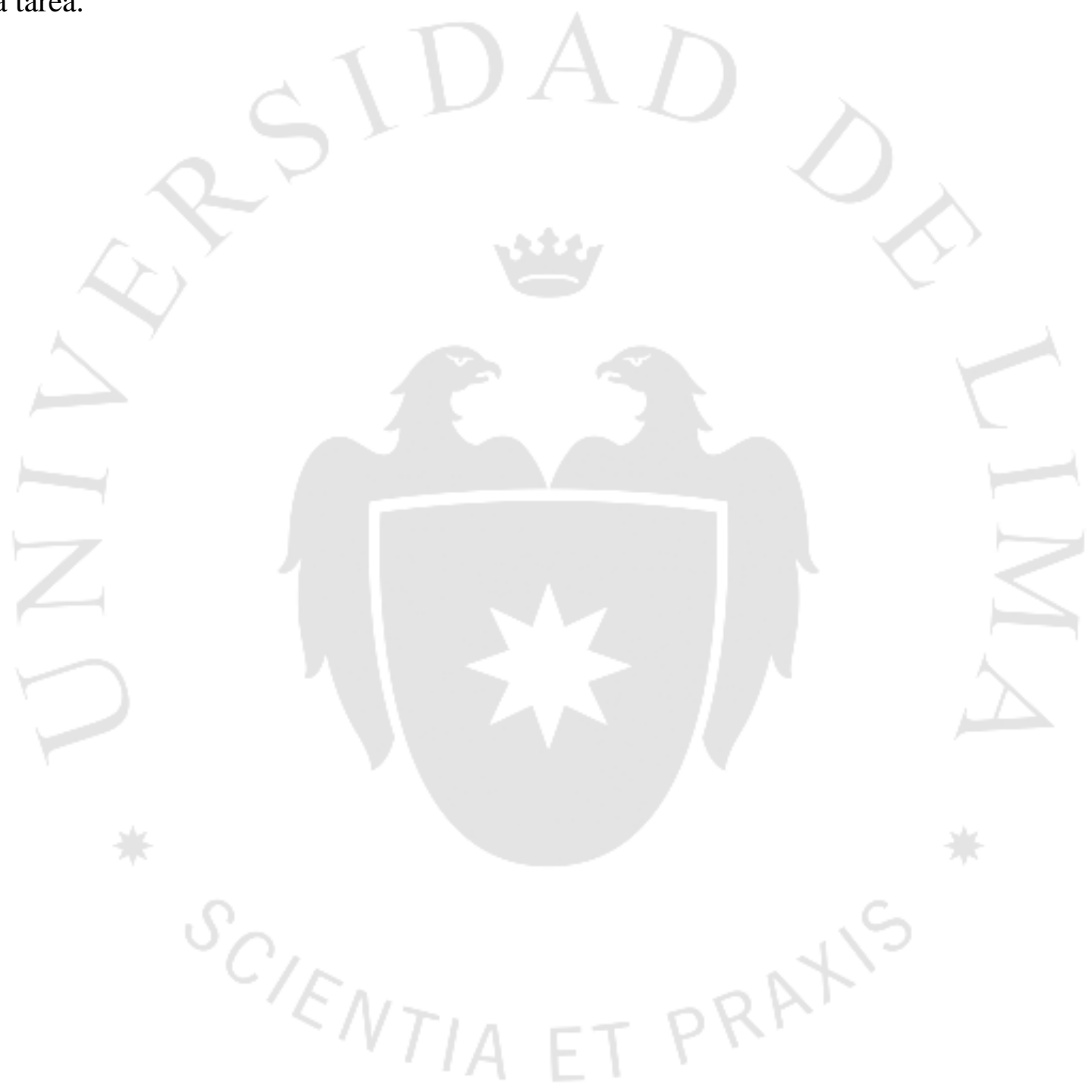


Tabla 5.7

Plan de mantenimiento

\begin{tabular}{|c|c|c|c|c|c|c|c|c|c|c|c|c|c|c|c|c|}
\hline Máquina & Actividad & Frecuencia & ENE & _ & FEB & 3 & MAR & ABR & MAY & JUN & JUL & AGO & SEP & OCT & NOV & DIC \\
\hline Balanza & Calibración de la balanza & $1 \mathrm{mes}$ & $\mathrm{x}$ & zet & $\mathrm{x}$ & & $\mathrm{x}$ & $\mathrm{x}$ & $\mathrm{x}$ & $\mathrm{x}$ & $\mathrm{x}$ & $\mathrm{x}$ & $\mathrm{x}$ & $\mathrm{x}$ & $\mathrm{x}$ & $\mathrm{x}$ \\
\hline Faja transportadora & Calibración de la faja & $1 \mathrm{mes}$ & $\mathrm{x}$ & & $\mathrm{x}$ & & $\mathrm{x}$ & $\mathrm{x}$ & $\mathrm{x}$ & $\mathrm{x}$ & $\mathrm{x}$ & $\mathrm{x}$ & $\mathrm{x}$ & $\mathrm{x}$ & $\mathrm{x}$ & $\mathrm{x}$ \\
\hline \multirow[t]{2}{*}{ Molino } & Cambio de cuchillas & 1 día & $x \times x \times$ & $x \quad x$ & $x \times x$ & $x \times x$ & $\mathrm{x} \times \mathrm{x}$ & $\mathrm{x} \times \mathrm{x}$ & $x \quad x \quad x \quad x$ & $x \times x$ & $x \times x$ & $x \times x$ & $x \quad x \quad x$ & $x \times x$ & $\mathrm{x} \times \mathrm{x}$ & $x \quad x \quad x \quad x$ \\
\hline & Afilado de cuchillas & 1 día & $x \times x \times$ & $\mathrm{x} \quad \mathrm{x}$ & $x \times x$ & $x \times x$ & $\mathrm{x} \times \mathrm{x}$ & $\mathrm{x}$ & $x \times x \times$ & $x \quad x \quad x$ & & $\mathrm{x} \times \mathrm{x}$ & $x \quad x \quad x$ & $x \times x$ & $\mathrm{x} \times \mathrm{x}$ & $\mathrm{x} \times \mathrm{x} \times \mathrm{x}$ \\
\hline Lavadora & Inspección del rotor & 10 meses & & & & & -2 & & & & & & & $\mathrm{x}$ & & \\
\hline Flotadora & Inspección del tornillo sinfín & 1 año & & & & & & & & & & & & & & $\mathrm{x}$ \\
\hline Centrifuga & Inspección de canastilla & 1 año & & & & & & & & & & & & & & $\mathrm{x}$ \\
\hline Secadora & Inspección del flujo térmico y motor & 1 año & & & & & & & & & & & & & & $\mathrm{x}$ \\
\hline Ciclón & Inspección del motor & 1 año & & & & & & & & & & & & & & $\mathrm{x}$ \\
\hline Embolsadora & Inspección del motor & 1 año & & & & & & & & & & & & & & $\mathrm{x}$ \\
\hline Bomba & Inspección del mecanismo & 6 meses & & & & & & & 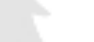 & $\mathrm{x}$ & & & & & & $\mathrm{x}$ \\
\hline Medidor de humedad & Calibración del equipo & 1 año & & & & 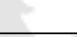 & & & L & & & 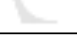 & & & & $\mathrm{x}$ \\
\hline
\end{tabular}

Elaboración propia

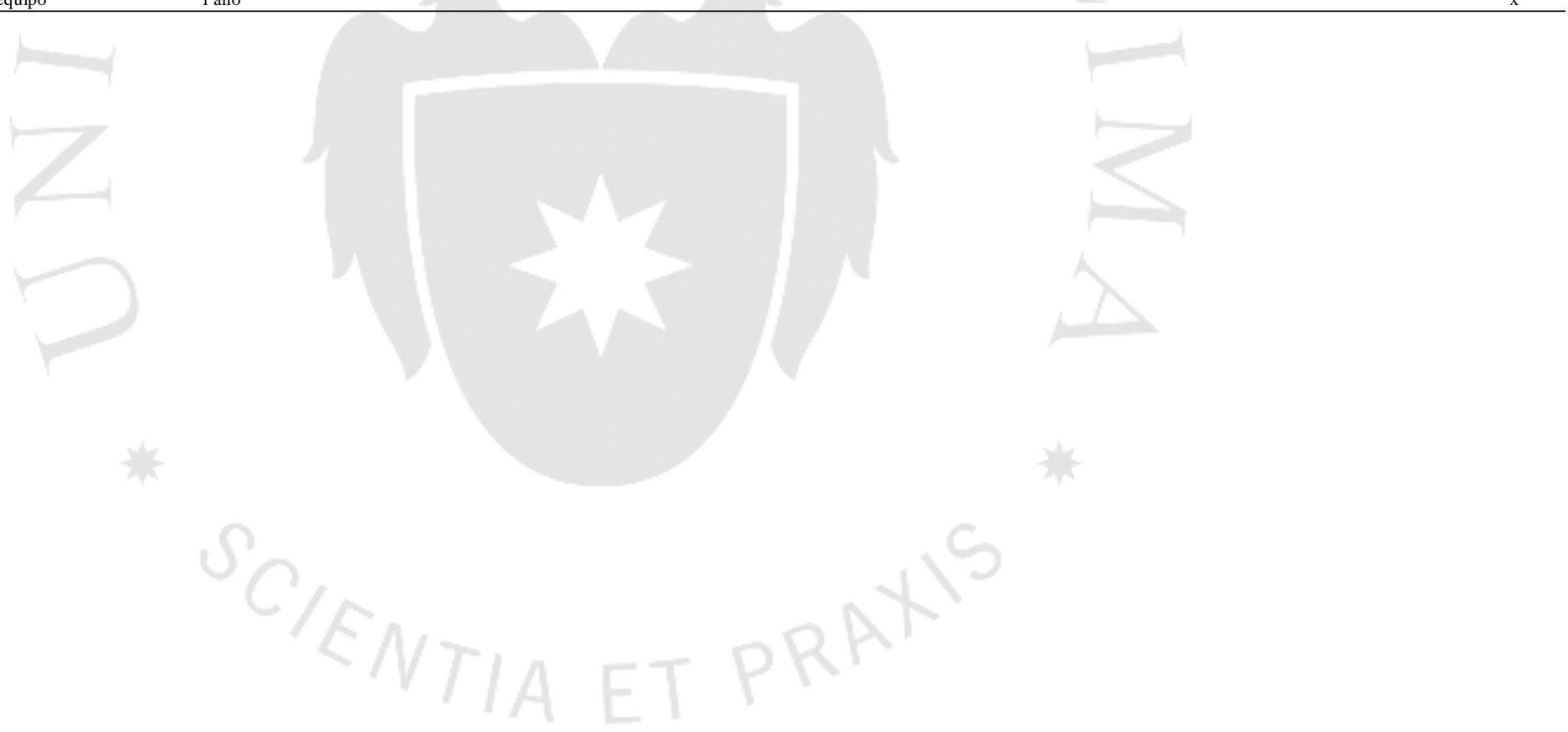




\subsection{Programa de producción}

En este acápite se procede a detallar los factores para la programación de producción y el programa proyectado a 5 años.

\subsubsection{Factores para la programación de la producción}

Al momento de realizar la programación fue necesario tomar en cuenta los siguientes factores, y estos se analizan en el transcurso de todo el capítulo 5:

- Factor material: Detallado en acápite 5.10.1

- Factor máquina: Detallado en acápite 5.3 con la línea integrada de producción

- Factor hombre: Detallado en acápite 5.4

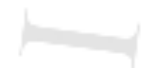

- Factor movimiento: Es analizado en el acápite 5.11.2, 5.11.3 y 5.11.5 con la designación de las áreas físicas requeridas, los m2 de cada una y las adyacencias para garantizar un flujo y movimiento óptimo.

- Factor espera: Se considera como parte del análisis previo en el acápite 5.11.3 y con el método de Guerchet en el 5.11.6.

- Factor servicio: Detallado en acápite 5.10.2. 5.10.4 y 5.11.1.

- Factor edificio: Detallado en acápite 5.11.1.

- Factor cambio: Se consideró un terreno grande para contar con cierto grado de flexibilidad en caso se realicen cambios en el transcurso del proyecto en el futuro. 


\subsubsection{Programa de producción}

La producción necesaria por año se obtiene en base a la siguiente fórmula:

Ventas = Inventario Inicial + Producción - Inventario Final

Tabla 5.8

Programa de producción en kilogramos

\begin{tabular}{c|ccccc}
\hline Año/ criterio & $\mathbf{2 0 1 6}$ & $\mathbf{2 0 1 7}$ & $\mathbf{2 0 1 8}$ & $\mathbf{2 0 1 9}$ & $\mathbf{2 0 2 0}$ \\
\hline Demanda & 3407936,77 & 3616473,96 & 3837771,89 & 4072611,40 & 4321821,12 \\
Inv. Inicial & 0 & 340793,68 & 361647,40 & 383777,19 & 407261,14 \\
Produccion & 3748730,44 & 3637327,68 & 3859901,69 & 4096095,35 & 4346742,09 \\
Inv. Final & 340793,68 & 361647,40 & 383777,19 & 407261,14 & 432182,11 \\
\hline
\end{tabular}

Elaboración propia

El dato de las ventas se obtiene en base a la demanda del proyecto, y para los inventarios se determinó tener un equivalente al 10\% de las ventas respectivas del año. Esto se debe a las fluctuaciones que existen en la práctica y es importante que la compañía esté cubierta frente a las mismas, sea tanto por factores internos (fallas de máquinas y caída de productividad) o externos (problemas de proveedores para suministro). Con dichos datos, se desarrolla el programa de producción, el cual posee un inventario inicial inexistente.

\subsection{Requerimiento de insumos, servicios y personal indirecto}

En este acápite se procede a detallar todos los requerimientos de materia prima, insumos, servicios, operarios indirectos y terceros para el éxito de la operación.

\subsubsection{Materia prima, insumos y otros materiales}

La materia prima que requerimos para el presente proyecto se obtiene de diversas fuentes. Según EcoPlas, pueden ser de origen domiciliario, comercial, institucional o industrial. 
Tabla 5.9

Resumen de consumo de recursos 2016 - 2020

\begin{tabular}{|c|c|c|c|c|c|c|}
\hline Año/criterio & 2016 & 2017 & 2018 & 2019 & 2020 & $\begin{array}{c}\text { Factor } \\
\text { requerimiento }\end{array}$ \\
\hline Produccion $(\mathrm{kg})$ & 3748730,44 & 3637327,68 & 3859901,69 & 4096095,35 & 4346742,09 & \\
\hline $\begin{array}{l}\text { MP (polimeros } \\
\text { recuperados) }\end{array}$ & 4468493,64 & 4335701,35 & 4601009,97 & 4882553,26 & 5181324,64 & $\begin{array}{c}1,19 \mathrm{~kg} \mathrm{MP} / \mathrm{kg} \\
\mathrm{PT}\end{array}$ \\
\hline Agua (lt) & 18118863,81 & 17580417,14 & 18656191,48 & 19797794,21 & 21009253,46 & 4,83 lt / kg PT \\
\hline Detergente (kg) & 81809,18 & 79378,02 & 84235,29 & 89389,79 & 94859,69 & $0,02 \mathrm{~kg} / \mathrm{kg} \mathrm{PT}$ \\
\hline Soda caustica (kg) & 40904,59 & 39689,01 & 42117,65 & 44694,89 & 47429,85 & $0,01 \mathrm{~kg} / \mathrm{kg} \mathrm{PT}$ \\
\hline Sacos (unds.) & 149949,22 & 145493,11 & 154396,07 & 163843,81 & 173869,68 & $\begin{array}{c}0,04 \operatorname{sacos} / \mathrm{kg} \\
\mathrm{PT}\end{array}$ \\
\hline
\end{tabular}

Elaboración propia

En base al programa de producción elaborado, se determina el requerimiento tanto de materia prima como de insumos. Para ello se utiliza un factor de requerimiento, es decir con cuantos kilogramos/litros/sacos de cada insumo se obtiene un kilogramo de producto terminado. Este dato es derivado del balance de materia en base a las cantidades de entrada y salida al flujo para poder determinar con exactitud cada cantidad.

\subsubsection{Servicios}

Se contará con dos servicios principales, los cuales son:

- Agua: Para este servicio, se recurrirá a Sedapal, que es la empresa más grande a nivel nacional que ofrece el servicio de agua potable y alcantarillado. Su tarifa se divide en dos aspectos: un costo fijo y uno variable. El primero es la tarifa mínima que ofrece Sedapal por el derecho a tener agua, y el segundo ya es el costo al que se incurre por cada kilogramo de producto terminado producido. 
Tabla 5.10

Resumen de costos de agua 2016 - 2020

\begin{tabular}{c|cccccc}
\hline Año/criterio & $\mathbf{2 0 1 6}$ & $\mathbf{2 0 1 7}$ & $\mathbf{2 0 1 8}$ & $\mathbf{2 0 1 9}$ & $\mathbf{2 0 2 0}$ & $\begin{array}{c}\text { Factor } \\
\text { requerimiento }\end{array}$ \\
\hline Produccion $(\mathrm{kg})$ & 3748730,44 & 3637327,68 & 3859901,69 & 4096095,35 & 4346742,09 & \\
Costo fijo agua & 59 & 59 & 59 & 59 & 59 & 58,6 soles $/$ año \\
Costo variable agua & 137203,53 & 133126,19 & 141272,40 & 149917,09 & 159090,76 & 0,0366 soles $/ \mathrm{kg}$ \\
PT & \\
Costo total agua & 137262,17 & 133184,83 & 141331,03 & 149975,72 & 159149,39 & - \\
\hline
\end{tabular}

Elaboración propia

- Luz / Energía: Al igual que el servicio previo de agua, este también se reparte en dos cuotas, una variable y una fija. En el caso de este servicio, se obtendrá de Luz del Sur que cubre el área geográfica (zona sureste de Lima) donde instalaremos la planta, es decir Lurín. En la tabla siguiente se observa los costos anuales del horizonte del proyecto:

\section{Tabla 5.11}

Resumen de costos de energía 2016 - 2020

\begin{tabular}{|c|c|c|c|c|c|c|}
\hline Año/criterio & 2016 & 2017 & 2018 & 2019 & 2020 & $\begin{array}{c}\text { Factor } \\
\text { requerimiento }\end{array}$ \\
\hline Produccion $(\mathrm{kg})$ & 3748730,44 & 3637327,68 & 3859901,69 & 4096095,35 & 4346742,09 & \\
\hline Costo fijo energía & 39543,75 & 39543,75 & 39543,75 & 39543,75 & 39543,75 & $\begin{array}{c}39543,75 \text { soles } / \\
\text { año }\end{array}$ \\
\hline Costo variable energía & 949553,42 & 921335,10 & 977713,10 & 1037540,95 & 1101029,77 & $\begin{array}{c}0,2533 \text { soles / } \mathrm{kg} \\
\mathrm{PT}\end{array}$ \\
\hline Costo total energía & 989097,17 & 960878,85 & 1017256,85 & 1077084,70 & 1140573,52 & - \\
\hline
\end{tabular}

Elaboración propia

\subsubsection{Determinación del número de operarios y trabajadores indirectos}

En lo que respecta a los trabajadores indirectos de la planta, solo se contará con dos vigilantes que trabajarán las 24 horas del día en dos turnos, uno diurno y otro nocturno.

Aunque Lurín sea un distrito inclinado a lo industrial, con baja densidad poblacional y seguro en base al dato del número de denuncias realizadas en el mismo (uno de los criterios para selección de micro localización del capítulo 3) igual es muy importante poder garantizar 
la seguridad de la planta. Lamentablemente la situación en el Perú, en términos de la delincuencia, no es buena y no se puede correr el riesgo de sufrir un robo ya que dicho hecho tendría un importante impacto en términos del bienestar de la empresa.

En resumen, se considera vital contar con un recurso humano encargado de la seguridad en todo momento.

\subsubsection{Servicios de terceros}

Los servicios que se tercerizarán son los de transporte tanto de materia prima como de producto terminado y el mantenimiento de los equipos y máquinas de la planta.

En el caso del transporte se toma esta decisión ya que la compra de un camión representa una inversión significativa que en un primer momento puede no ser posible de asumir en adicional a toda la inversión principal.

Por lo tanto, según el dato de expertos del medio, el alquiler de un camión cuesta aproximadamente 350 soles por día y puede cargar aproximadamente 2,5 toneladas por viaje, siendo posible realizar dos viajes a máxima capacidad en un día, uno por la mañana y otro por la tarde.

Cabe recalcar que esto involucrará un estudio de rutas para lograr cubrir la mayor cantidad de puntos de acopio claves y de forma eficiente, por el hecho de que se cuenta con un tiempo limitado y no es un activo propio. Los costos anuales de transporte se aprecian a continuación:

\section{Tabla 5.12}

Resumen de costos de transporte 2016 - 2020

\begin{tabular}{c|cccccc}
\hline Año/criterio & $\mathbf{2 0 1 6}$ & $\mathbf{2 0 1 7}$ & $\mathbf{2 0 1 8}$ & $\mathbf{2 0 1 9}$ & $\mathbf{2 0 2 0}$ & $\begin{array}{c}\text { Factor } \\
\text { requerimiento }\end{array}$ \\
\hline Produccion $(\mathrm{kg})$ & 3748730,44 & 3637327,68 & 3859901,69 & 4096095,35 & 4346742,09 & \\
Costo transporte MP & 312794,56 & 303499,09 & 322070,70 & 341778,73 & 362692,72 & $0,07 \mathrm{soles} / \mathrm{kg}$ \\
& & & & & $\mathrm{MP}$ & $0,07 \mathrm{soles} / \mathrm{kg}$ \\
Costo transporte PT & 262411,13 & 254612,94 & 270193,12 & 286726,67 & 304271,95 & $\mathrm{PT}$ \\
Costo total transporte & 575205,69 & 558112,03 & 592263,82 & 628505,40 & 666964,67 & - \\
\hline
\end{tabular}

Elaboración propia 
Por otro lado, la decisión de tercerizar las funciones de mantenimiento se basa en la mayor experiencia y conocimiento de terceros en la temática, lo cual permite un ahorro en costos y mayor eficiencia en la tarea. El costo asociado a este servicio es de aproximadamente 115 mil soles para cada uno de los años de operación, monto compuesto por la mano de obra, los repuestos y los insumos a utilizar.

\subsection{Disposición de la planta}

En este acápite se procede a detallar las características físicas a considerar, las zonas físicas requeridas, el cálculo de áreas en $\mathrm{m} 2$ para cada una, los dispositivos de seguridad, y finalmente la disposición con el plano elaborado y análisis de Guerchet.

\subsubsection{Características físicas del proyecto}

- Factor edificio:

- La edificación de la planta está constituida por un solo piso, el cual se encuentra asfaltado en su totalidad, estando presentes los muelles de concreto para el anclaje de las diferentes máquinas.

- La planta cuenta con una puerta tanto de entrada como de salida para vehículos (4m x 7m) y una segunda puerta más pequeña para el ingreso y salida de peatones $(1 \mathrm{~m} \mathrm{x} 7 \mathrm{~m})$.

- La circulación dentro de las instalaciones no se encuentra sujeta a mayores límites que las líneas de color amarrillo pintadas en el piso, ya que gran parte del terreno no se encuentra techado, y en la porción que si lo está no existen paredes divisorias salvo las presentes en las oficinas, comedor y servicios higiénicos.

- La porción del terreno correspondiente a la zona de producción, servicios higiénicos, comedor, oficinas, almacén de insumos y almacén de productos terminados, se encuentra 
techada con calamina alucín prepintada de un espesor de 0,35 milímetros. Por el contrario, el almacén de materias primas y el patio de maniobras no se encuentran techados.

- Además de los almacenes previamente mencionados, de materia prima y de productos terminados, se cuenta con un almacén de suministros (Soda caustica, detergente y demás materiales necesarios para la operación de la planta).

- La edificación no contará con ventanas al exterior, sin embargo, para la correcta ventilación del ambiente de trabajo, el techo cuenta con una separación de las paredes para permitir el ingreso de aire.

- Factor servicio:

- Relativos al personal:

- Cómo vías de acceso, se cuenta con las dos puertas mencionadas previamente, puerta de peatones y puerta de vehículos; además la planta posee una salida de emergencia según lo indicado por las normas respectivas.

- Se cuenta con los estacionamientos adecuados para el uso de los mismos por parte de los colaboradores de la compañía y de cualquier visita que se pueda presentar.

- Según las especificaciones de OSHA se cuenta con 4 baños correctamente acondicionados, dos para los trabajadores y dos para el personal administrativo de la compañía.

- Se encuentra implementado un comedor acondicionado con un microondas y una mesa, para el almuerzo de todos los trabajadores de la organización. 
- Para una iluminación adecuada se encuentran instalados focos fluorescentes a lo largo de toda la nave industrial, a los cuales se les da uso en aquellos momentos donde la luz solar, que ingresa por los espacios entre el techo y las paredes, deja de ser suficiente.

○ Relativos al material:

- Para el control de calidad se cuenta con cuatro operarios que dentro de sus funciones variadas incluye realizar la prueba de flotación y de humedad de un kilogramo de producto terminado como se mencionó en los acápites anteriores.

- Relativos a la maquinaria:

- La energía eléctrica necesaria para la operación es provista por la empresa Luz del Sur en los dos voltajes necesarios, 440 voltios para las máquinas y 220 voltios para la iluminación, el microondas y las oficinas.

- A modo de protección contra posibles incendios se encuentran correctamente localizados los gabinetes contra incendios, los cuales se encuentran conformados por mangueras y extintores; a su vez, todas las puertas presentes en la edificación se abren con dirección hacia afuera según lo especificado por la norma respectiva.

- Relativos al edificio:

- La planta y en general toda la instalación cuenta con la adecuada señalización de seguridad, están presentes las señales de advertencia, de prohibición, de obligatoriedad y de emergencia, según lo especificado por las normas pertinentes.

- En cuanto un adecuado ambiente de trabajo se toma como punto de referencia las 5S propuestas por la filosofía japonesa para lograr un ambiente de calidad. Esto se lleva a cabo mediante el etiquetado de los diversos elementos dentro de la fábrica (Máquinas, utensilios, materiales, etc.), la asignación de lugares fijos para cada uno de estos 
elementos, una revisión continua de los mismos para la eliminación de aquellos que no son utilizados o que no agregan valor y finalmente consistencia en dichos hábitos remarcando los beneficios de su utilización.

\subsubsection{Determinación de las zonas físicas requeridas}

Las zonas físicas requeridas dentro de las instalaciones de la planta son:

- Patio de maniobras

- Almacén de materias primas

- Almacén de productos terminados

- Almacén de insumos

- Comedor

- Servicios higiénicos

- Área de producción

- 2 oficinas administrativas

\subsubsection{Cálculo de áreas para cada zona}

En base a las zonas requeridas que se determinaron en el acápite previo se realiza el cálculo de áreas para las mismas. En el caso específicamente del área de producción se utiliza el método de Guerchet, y para otras zonas como las oficinas, comedor, servicios higiénicos, entre otros; se utiliza el material revisado en el curso de Disposición de Planta. Todo se evalúa sobre una superficie total del terreno de 1200 metros cuadrados: 
- Patio de maniobras: Se ha determinado que tenga la capacidad para que dos camiones maniobren dentro del mismo en cualquier momento. No se considera necesario más, ya que la entrada de los mismos no se da con una frecuencia mayor a dos veces al día, lo cual significa que no hay un flujo significativo de vehículos para requerir un área mayor. Por lo tanto, tendrá un área total de $121,1 \mathrm{~m} 2$.

- Almacén de materias primas: Dicho almacén tiene el espacio necesario para albergar aproximadamente dos semanas de materia prima, que equivale a 214,7 toneladas de polipropileno. En este espacio se almacena el material en cilindros por polímero y por color luego de haberse clasificado, estos se colocan en grupos de 6 cilindros por pallet y en estantes de 3 niveles. Cada nivel medirá 1,55 metros, con una altura total de 4,65 metros. Bajo estas condiciones, se requiere de un área total de 123,1 m2, considerando un 7,5\% de área de circulación. En el plano se le asigna un área mayor con un total de 129,2 $\mathrm{m} 2$.

\section{Figura 5.19}

Calculo de área para almacén de materias primas

ALMACEN DE MP

214,7 ton / MP

$214651 \mathrm{~kg} / \mathrm{MP}$

Se requieren:

Area de circulacion $=$

TOTAL
Equivalencias:

1 estante 3 niveles de pallet

1 pallet 6 cilindros

1 cilindro

$125 \mathrm{~kg}$

Elaboración propia

$\begin{array}{cr}95 \text { estantes } & \mathbf{1 1 4 , 5} \mathbf{~ m 2} \\ 7,50 \% & \mathbf{8 , 6} \mathbf{~ m 2} \\ & \mathbf{1 2 3 , 1} \mathbf{~ m 2}\end{array}$

- Almacén de insumos: Espacio destinado a almacenar los detergentes y la soda caustica necesarias para lavar el material durante el proceso productivo. Para ambos, se cuenta con el stock necesario de media semana, ya que no existe un riesgo latente de desabastecimiento en cualquier momento. Es por ello que la compra de dichos insumos se realiza con una frecuencia de dos veces por semana. Por lo tanto, se tiene un área de $6 \mathrm{~m} 2$. 
Figura 5.20

Calculo de área para almacén de insumos

\begin{tabular}{|c|c|c|c|}
\hline \multicolumn{4}{|l|}{ ALMACEN DE INSUMOS } \\
\hline 962 kg deterg. & 1 saco & $15 \mathrm{~kg}$ & 2 pallets det. \\
\hline $481 \mathrm{~kg}$ soda caus. & 1 pallet & 40 sacos & \\
\hline 226 lit. soda caus. & - 1 pallet & 80 botellas & \multirow[b]{2}{*}{2 pallets soda } \\
\hline & 1 pallet & 2 niveles & \\
\hline Se requieren: & 2 pallets det. + & 2 pallets soda & $4,8 \mathrm{~m} 2$ \\
\hline Area de circulacion $=$ & & & $0,36 \mathrm{~m} 2$ \\
\hline TOTAL & & & $5,16 \mathrm{~m} 2$ \\
\hline
\end{tabular}

Elaboración propia

- Almacén de productos terminados: Se calcula que, con la demanda del último año, se necesita almacenar aproximadamente 432,2 toneladas de producto terminado al mes para cumplir con el requerimiento de inventario provisional equivalente al $10 \%$ de la cantidad producida. Por lo tanto, se contempla un almacén capaz de contener dicho volumen en estantes de dos niveles de 2,25 metros cada uno, equivalente a una altura total de 4,5 metros. Esta altura no representa problema ya que el montacargas del que se dispone alcanza una altura total de hasta 4,7 metros. Bajo estas condiciones, se requiere un área total de 278,8m2, considerando al igual que el almacén de materias primas un área de circulación. De igual manera, tiene una dimensión un poco mayor finalmente de 324,5m2.

Figura 5.21

Calculo de área para almacén de productos terminados

\begin{tabular}{|c|c|c|}
\hline \multicolumn{3}{|l|}{ ALMACEN DE PT } \\
\hline 432,2 ton / PT & 1 saco & $25 \mathrm{~kg}$ \\
\hline \multirow[t]{2}{*}{$432182 \mathrm{~kg} / \mathrm{PT}$} & 1 estante & 2 niveles de pallet \\
\hline & 1 pallet & 40 sacos \\
\hline Se requieren: & 216,1 estantes & $259,3 \mathrm{~m} 2$ \\
\hline Area de circulacion $=$ & & $19,4 \mathrm{~m} 2$ \\
\hline TOTAL & & $278,8 \mathrm{~m} 2$ \\
\hline
\end{tabular}

Elaboración propia 
- Comedor: En el caso de la hora de refrigerio y almuerzo, se realiza una rotación, de modo que la producción no se detenga en ningún momento. Por lo tanto, nunca se dará la ocasión de tener más de 8 personas en dicho ambiente. Considerando un espacio de 1,58 $\mathrm{m} 2$ para cada persona, se requieren 12,64 m2 para esta zona. Esto se refleja en un total de $13 \mathrm{~m} 2$ en el plano.

- Servicios higiénicos: La planta cuenta con cuatro baños, dos en la zona administrativa de 3,6 m2 cada uno, el cual está conformado solamente por un retrete y un lavadero. Los otros dos baños de $8 \mathrm{~m} 2$ cada uno están destinados para el personal de producción y cuentan también con ducha y banca para vestirse. Al ser solo 13 personas, se requiere de un solo baño (ya que está dentro del rango de 1 a 15 personas). De igual manera se ha hecho un total de 4 baños, ya que por ley tiene que haber uno para hombres y otro para mujeres en ambas zonas, administrativa y de producción.

- Oficinas administrativas: Se va a considerar el espacio de dos oficinas de ejecutivo junior con un área de $15 \mathrm{~m} 2$ cada una. Ambas se comunican directamente al pasillo y están cerca a los servicios higiénicos administrativos.

- Estacionamiento: Se cuenta con espacio para tres carros, ya que solo el personal administrativo y ocasionalmente un proveedor o cliente estacionarán en la planta. Este se encuentra dispuesto de forma perpendicular para administrar el espacio óptimamente. Cada espacio es de 2,4 metros de ancho y 5 metros de largo, pero no se considera el pasillo de 7,32 metros para que los carros puedan entrar y salir sin dificultad, ya que al estar adyacente al patio de maniobras esto no representa un inconveniente. Con esto se obtiene un área de 36,1 m2 para el estacionamiento.

- Área de producción: Se realizó el análisis de Guerchet para dicha zona, el cual se detalla en la tabla del acápite 5.12.5. En resumen, se obtiene un área mínima de producción de 293,73m2. El área otorgada finalmente es $388,5 \mathrm{~m} 2$. 
En base a todo lo mencionado en este acápite, se incluye a continuación la tabla resumen de las dimensiones finales de cada área, las cuales dan un total de $1071,7 \mathrm{~m} 2$. El área total del terreno es de $1200 \mathrm{~m} 2$, pero el área restante se distribuye entre pasillos y paredes de la planta.

Tabla 5.13

Dimensiones finales de las áreas

\begin{tabular}{|c|c}
\hline Dimensiones finales de las áreas & Total en m2 \\
\hline 1. Patio de maniobras & 121,1 \\
2. Almacen de MP & 129,2 \\
3. Almacen de insumos & 6,0 \\
4. Almacen de PT & 324,5 \\
5. Comedor & 13,0 \\
6.1 Servicios higiénicos administrativos & 7,2 \\
6.2 Servicios higiénicos operativos & 16,0 \\
7. Oficinas administrativas & 30,1 \\
8. Estacionamiento & 36,1 \\
9. Area de producción & 388,5 \\
\hline TOTAL & 1071,73 \\
\hline
\end{tabular}

Elaboración propia

\subsubsection{Dispositivos de seguridad industrial y señalización}

Con respecto a los dispositivos de seguridad dentro de la planta y desde el punto de vista del riesgo de incendio, producto de la presencia de maquinarias trabajando a temperaturas elevadas y con altas cargas eléctricas, este se contrarresta con el uso de extintores y de mangueras contra incendios. Los extintores son de polvo químico seco, lo cual permite combatir fuegos de clase A (sólidos ordinarios) y clase C (energía eléctrica), fuegos que se pueden presentar en la planta debido a los materiales y equipos que se manejan en ella. La colocación de los extintores se muestra en el plano colocado posteriormente en este capítulo, para ello se toma en cuenta que se debe colocar un extintor en un radio de veinte y tres metros. Con respecto a las mangueras de agua contra incendio, estás se encuentran 
posicionadas, una cada treinta metros de radio, con una tubería de alimentación de seis pulgadas y en un gabinete de clase III, caracterizado por la presencia de dos bocas de alimentación, una de dos pulgadas y media para los bomberos y otra de una pulgada y media para la brigada que se encuentra constituida por colaboradores de la compañía correctamente capacitados.

Por otro lado, para algunos de los riesgos mecánicos que se presentan en la planta, se hace uso de guardas de seguridad y compuertas, como dispositivos de seguridad para prevenir principalmente el riesgo de atrapamiento, entre otros que ya fueron mencionados en el acápite 5.7.

En lo que respecta a la señalización, se utilizan cuatro tipos o clases de señales en la planta. El primer tipo son las señales de advertencia, cuya función es alertar sobre la presencia de peligro, estas señales son de color amarillo y de forma triangular. Como segundo tipo de señales, se encuentran las de prohibición, con forma circular, de color rojo y con una diagonal superpuesta; cuya finalidad es indicar que acciones no deben realizarse dentro de la planta. La tercera clase de señales son las de obligatoriedad, caracterizadas por ser de color azul y de forma redonda, las cuales indican que alguna acción es de carácter necesario, como por ejemplo el uso de los elementos de protección personal. Finalmente, el cuarto y último tipo de señales es el de emergencia, caracterizadas por ser de colores rojo o verde y de forma cuadrada, indicando elementos relacionados a la protección contra incendio y a la evacuación en caso de emergencia respectivamente. Algunas de estas señales se muestran en la imagen a continuación. 
Figura 5.22

Señales de seguridad

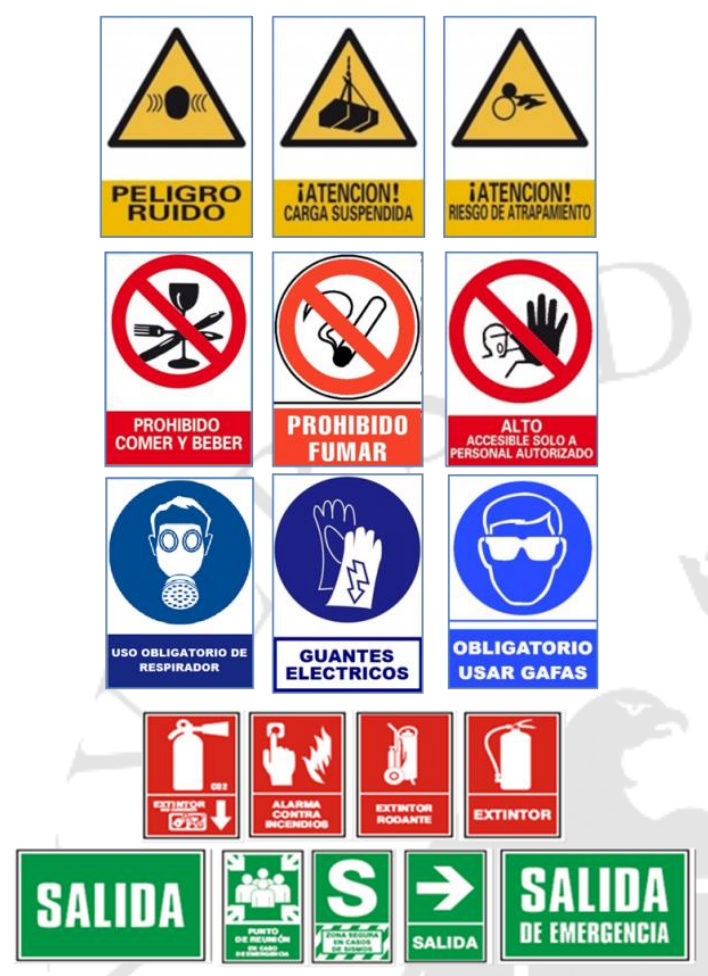

Fuente: Industrialsafety.com (2018)

\subsubsection{Disposición general}

En este acápite, se presenta un plano con el apoyo del software AutoCAD 2017 y complementa de forma total el detalle de la zona del área de producción con el resto de zonas requeridas en la planta. Para el ordenamiento de las zonas, se hace uso del análisis relacional para determinar cuáles zonas deben estar lejos o cerca respectivamente. Esto involucra determinar los valores de proximidad que van desde "Absolutamente necesario" hasta "No recomendable" y los motivos por los cuales se opta dar cada valor. Por ejemplo, es recomendable que el patio de maniobras y el almacén de materias primas estén cerca para lograr un flujo óptimo, pero no que esté cerca a las oficinas administrativas por el ruido y contaminación que se produce. 


\section{Figura 5.23}

Método de análisis relacional para distribución de las áreas

\begin{tabular}{|c|c|}
\hline Codigo & MOTIVOS \\
\hline 1 & Flujo óptimo del proceso \\
\hline 2 & Facilidad de recepción y despacho \\
\hline 3 & Ruido y contaminación \\
\hline 4 & Conveniencia y comodidad del personal \\
\hline
\end{tabular}

\begin{tabular}{|c|c|}
\hline Codigo & Valor de proximidad \\
\hline $\mathrm{A}$ & Absolutamente necesario \\
\hline $\mathrm{E}$ & Especialmente necesario \\
\hline $\mathrm{I}$ & Importante \\
\hline $\mathrm{O}$ & Normal u ordinario \\
\hline $\mathrm{X}$ & No recomendable \\
\hline
\end{tabular}

\begin{tabular}{|l} 
1. Patio de maniobras \\
2. Almacén de materias primas \\
3. Almacén de insumos \\
5. Almacén de productos terminados \\
6. Servicios higienicos \\
7. Oficinas administrativas \\
9. Área de producción
\end{tabular}

Elaboración propia 
Figura 5.24

Diagrama relacional para distribución de las áreas

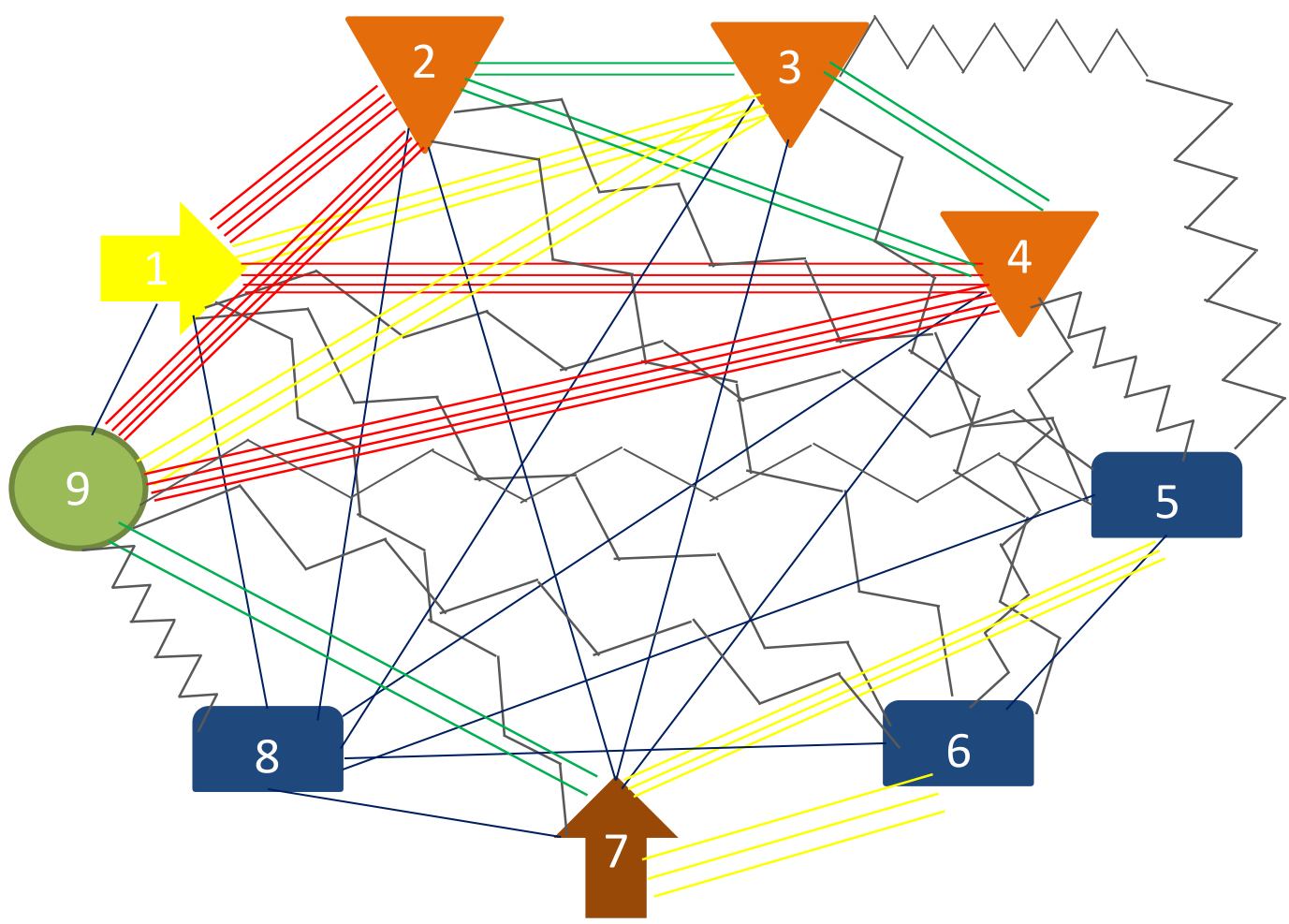

Elaboración propia

Con el análisis relacional realizado, se procede con el plano de la figura 5.24 que se muestra a continuación, tomando en consideración las áreas que son recomendables que estén juntas y las que no lo deben estar. Un punto importante a considerar es que el área de producción se encuentra "dividida" en dos partes para obtener el mejor flujo posible, ya que la etapa de pesado y clasificación son realizadas siempre en una primera instancia. Por dicha razón se cuenta con stock en el almacén de materia prima ya clasificada previamente, y cuando se desee procesar un lote, está ya estará lista para ingresar a la faja transportadora inmediatamente. 
Figura 5.25

Plano de disposición de la planta y leyenda

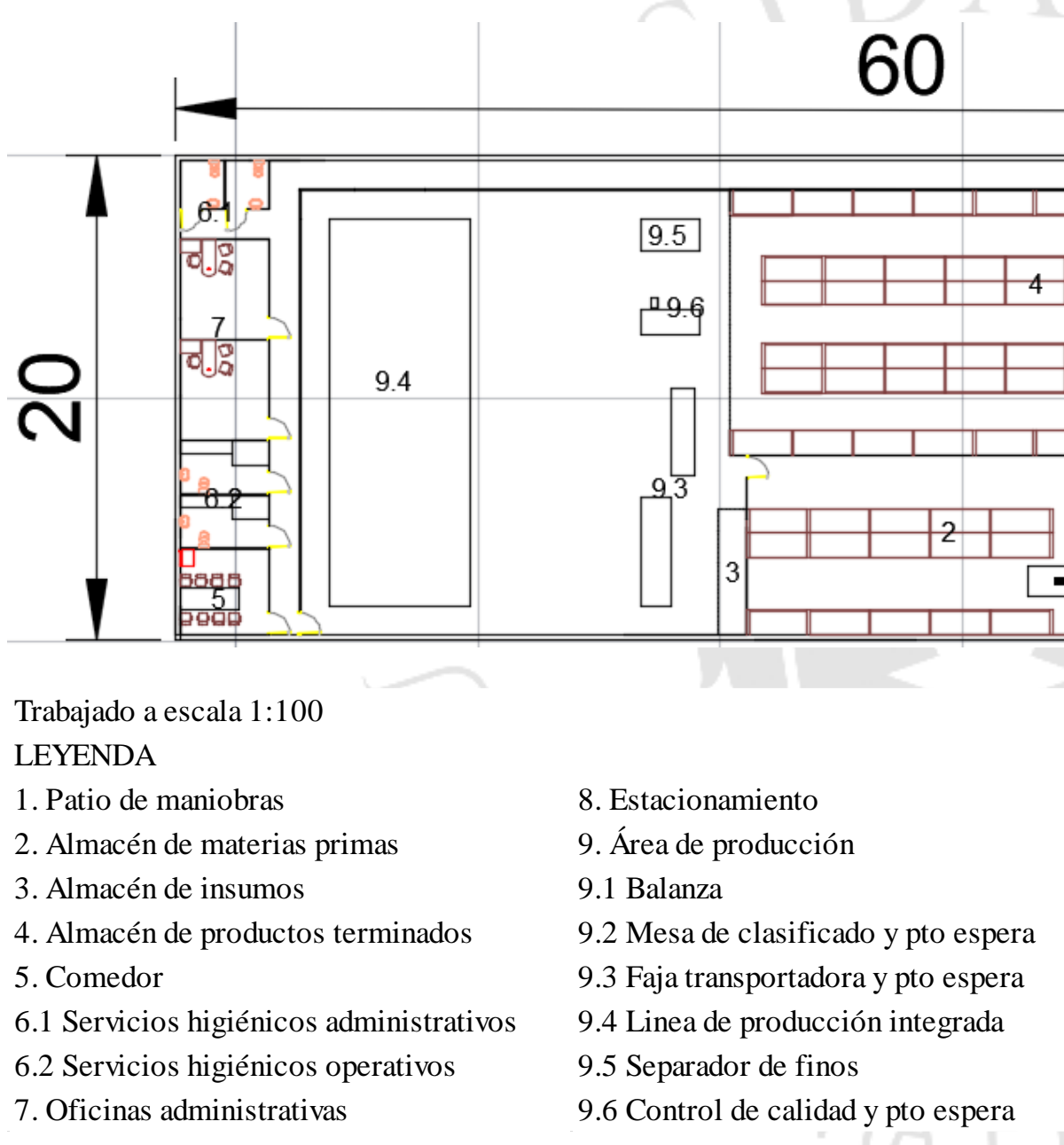

Elaboración propia 


\subsubsection{Disposición de detalle de la zona productiva}

Se realiza el método de Guerchet para obtener el área a continuación. Se identifican tres puntos de espera, que al ser mayores al 30\% del área de la estación de trabajo en la que se desenvuelven se consideran independientes. Tras obtener las superficies estáticas, gravitacionales, evolutivas y el coeficiente " $k$ " se obtiene la superficie total, o área mínima de producción que es 293,73m2.

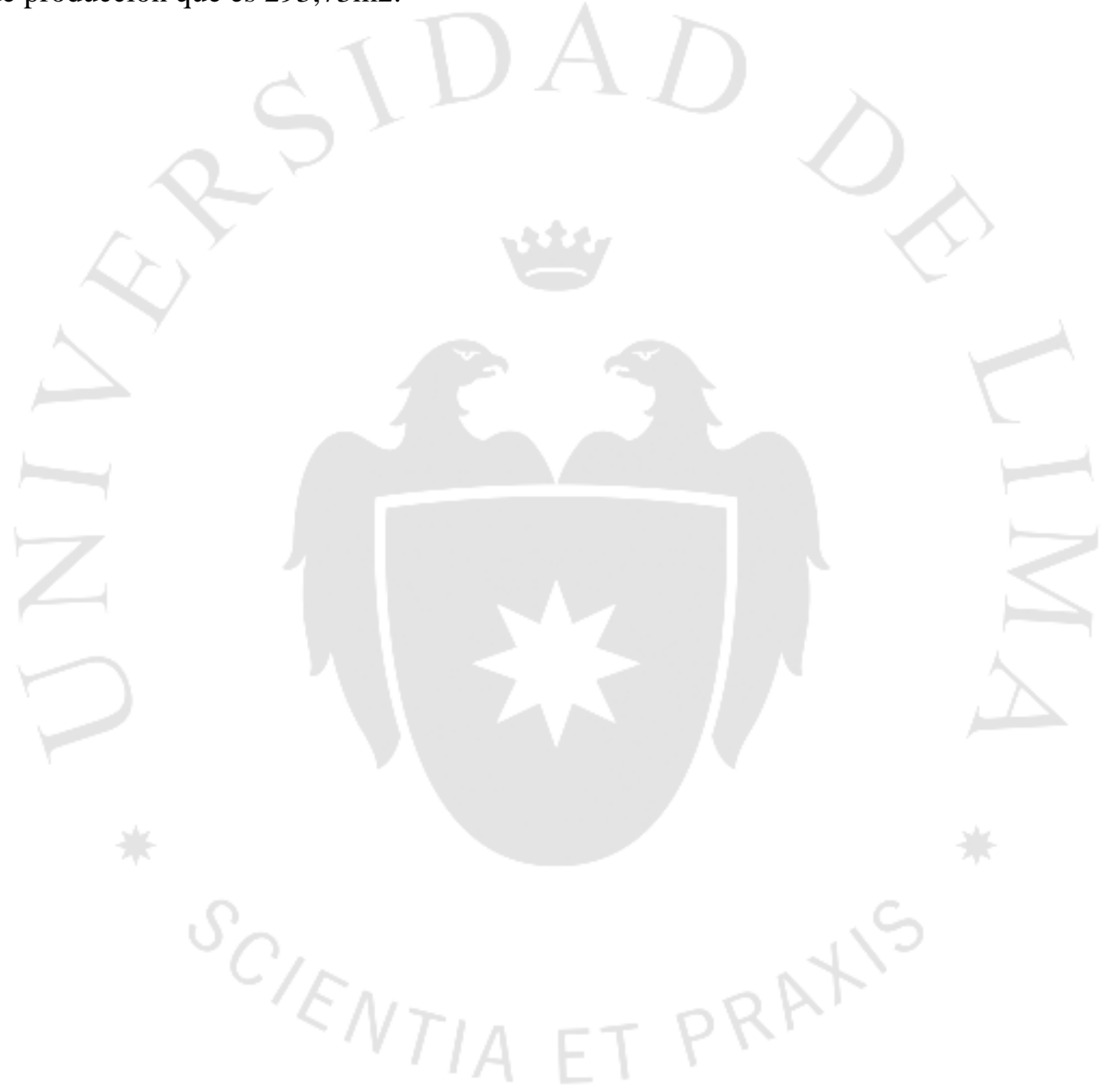


Tabla 5.14

Método de Guerchet para determinar el área de producción

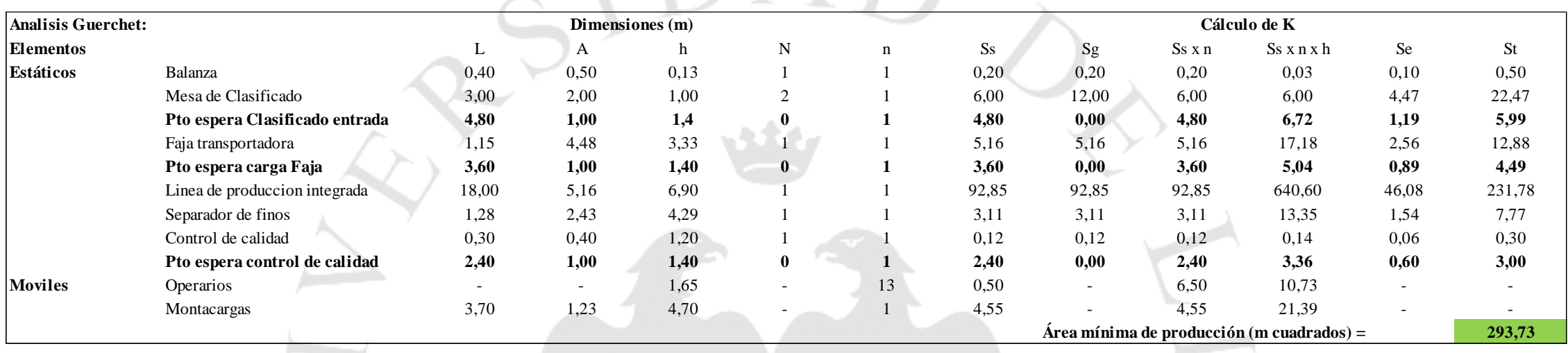

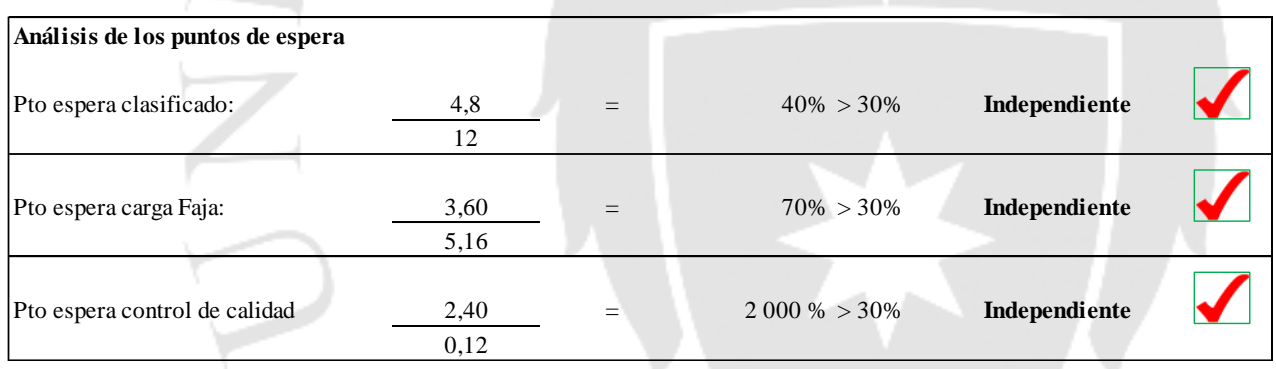

\begin{tabular}{ll} 
Cálculo del $\mathbf{K}$ & \\
hem $=$ & 2,91 \\
hee $=$ & 5,86 \\
$\mathbf{K}=$ & $\mathbf{0 , 2 5}$ \\
\hline
\end{tabular}

Elaboración propia 


\subsection{Cronograma de implementación del proyecto}

Figura 5.26

Cronograma de implementación del proyecto
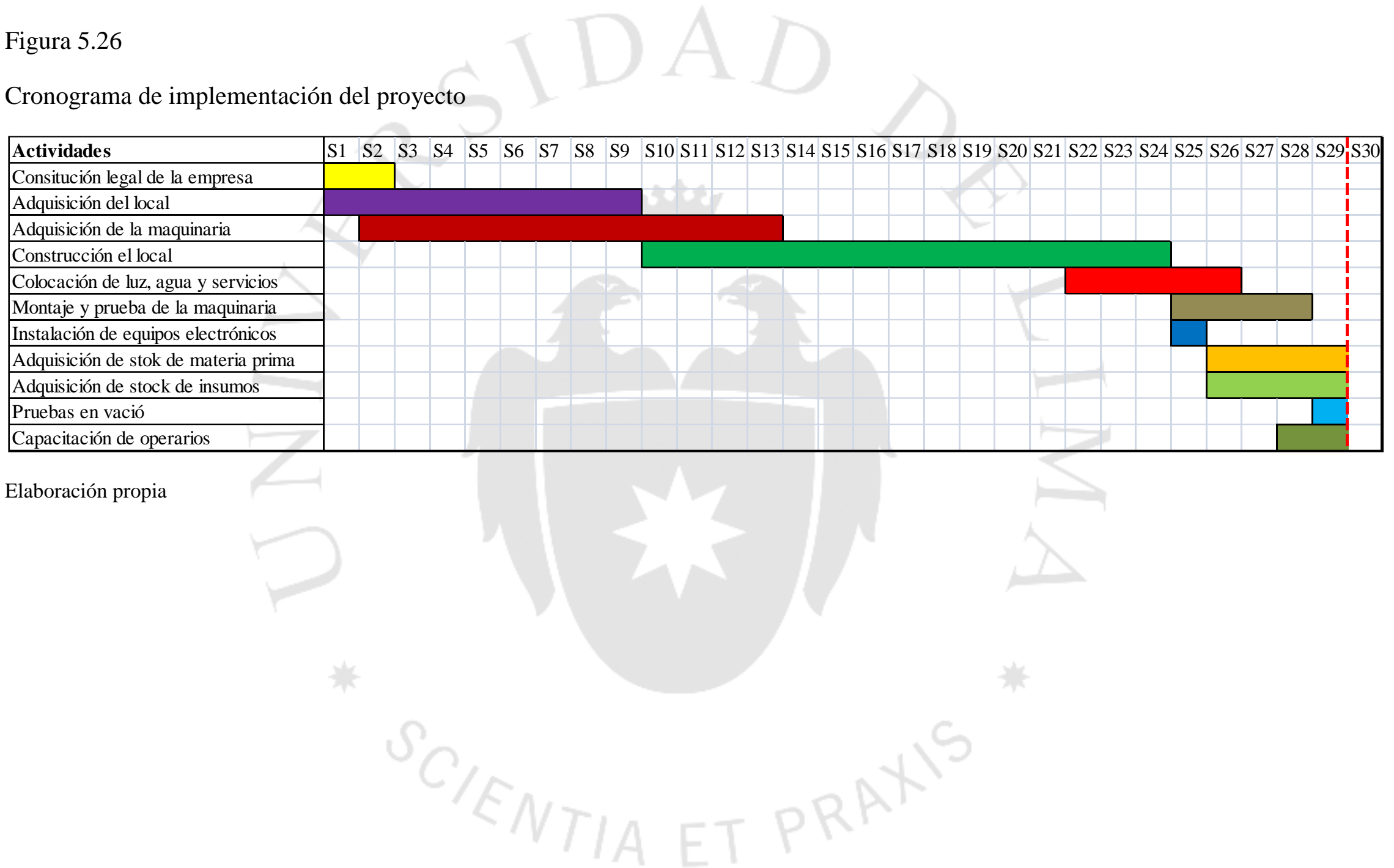


\section{CAPÍTULO VI: ORGANIZACIÓN Y ADMINISTRACIÓN}

\subsection{Formación de la organización empresarial}

Según las características propias del negocio y recomendaciones de expertos como Carmen Chasseloup, analista legal de la Sociedad Nacional de Industrias, el tipo de razón social adecuado para la empresa es sociedad anónima cerrada (S.A.C).

Las dos principales ventajas que otorga una S.A.C para quienes la constituyen, motivos por los cuales ha sido seleccionada dicha alternativa, son:

- Puede funcionar sin necesidad de un directorio

- No se ve limitada ante el manejo de grandes capitales

Sin embargo, constituir una S.A.C implica cumplir con ciertos requisitos, dentro de los cuales el más importante es no tener menos de dos ni más de veinte socios.

Los pasos a seguir para conformar una pequeña empresa como sociedad anónima cerrada, según WAPA-PERÚ (Proyecto de fundación Telefónica para apoyo a los emprendedores) son:

- Búsqueda y reserva del nombre

- Elaborar la minuta de constitución

- Escritura pública

- Inscripción en los registros públicos 
- Tramitar el registro único del contribuyente (RUC)

- Inscribir a los trabajadores en Essalud

- Solicitar permiso, autorización o registro especial

- Obtener la autorización del libro de planillas ante el Ministerio de Trabajo y Promoción del Empleo

- Legalizar los libros contables ante notario público

- Tramitar la licencia municipal de funcionamiento

\subsection{Requerimientos de personal directivo, administrativo y de servicios y funciones}

Las planas requeridas para permitir el funcionamiento de la planta son: directiva, conformada por los dos dueños de la compañía; administrativa, conformada por un colaborador; de servicios, conformada por un vigilante y una persona encargada parcialmente de la limpieza; y la plana obrera conformada por todos aquellos colaboradores encargados del proceso productivo en forma directa. Cada uno de los puestos ocupados en las diferentes planas asume distintas responsabilidades y funciones, que se detallan a continuación.

Gerente general: Puesto correspondiente a la plana directiva, cuyas funciones principales son de administración y dirección de la compañía. De manera más específica, el colaborador que ocupa dicha posición se hace cargo de:

- Relaciones con clientes y proveedores.

- Seguimiento del desempeño económico de la empresa 
- Motivación organizacional y creación de clima laboral

- Manejo de la caja chica y realización de cobros y pagos de la compañía tanto interna como externamente

Gerente de operaciones: Como su nombre lo indica dicha función se encuentra más asociada a la parte de producción, abastecimiento y despacho de la producción, es decir, una labor correspondiente más a la parte interna, que externa, de la organización.

- Supervisión de la producción y de los demás colaboradores de la organización.

- Seguimiento del desempeño operativo de la empresa

- Programación y pronóstico de la producción

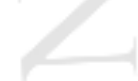

- Seguridad y salud ocupacional

Administrador: Las funciones que desempeña este puesto son principalmente de carácter financiero, siendo las principales:

- Contabilidad de la compañía

- Realización de trámites con distintas entidades externas 
Vigilante: Su función principal es el cuidado de la planta en todo momento, factor de suma importancia para evitar pérdidas materiales, así como también el flujo de elementos o individuos no autorizados a la planta.

Colaborador de orden y limpieza: Este puesto cumplirá la fundamental tarea de mantener la planta limpia y ordenada con la doble finalidad de que esta se mantenga en condiciones atractivas, visualmente hablando, para visitas e incluso para los propios colaboradores y por otro lado mantener, los distintos espacios que la componen, libres de elementos que obstaculicen el correcto desempeño de las funciones de los integrantes de la compañía.

Colaboradores de la producción: Este puesto estará ocupado por una serie de colaboradores cuyas funciones específicas buscarán la meta de lograr la producción con la mejor calidad posible y con el menor consumo de materiales e insumos, permitiendo así el crecimiento estable y sostenido de la compañía y de ellos mismos a su vez. Este puesto es de carácter clave para la organización ya que sin su existencia el proceso de agregación de valor, que permite transformar la materia prima en producto terminado, no sería posible y por ende la compañía no podría subsistir.

\subsection{Estructura organizacional}

A continuación, se muestra el organigrama que plasma lo mencionado en el acápite anterior. 


\section{Figura 6.1}

Organigrama de la compañía

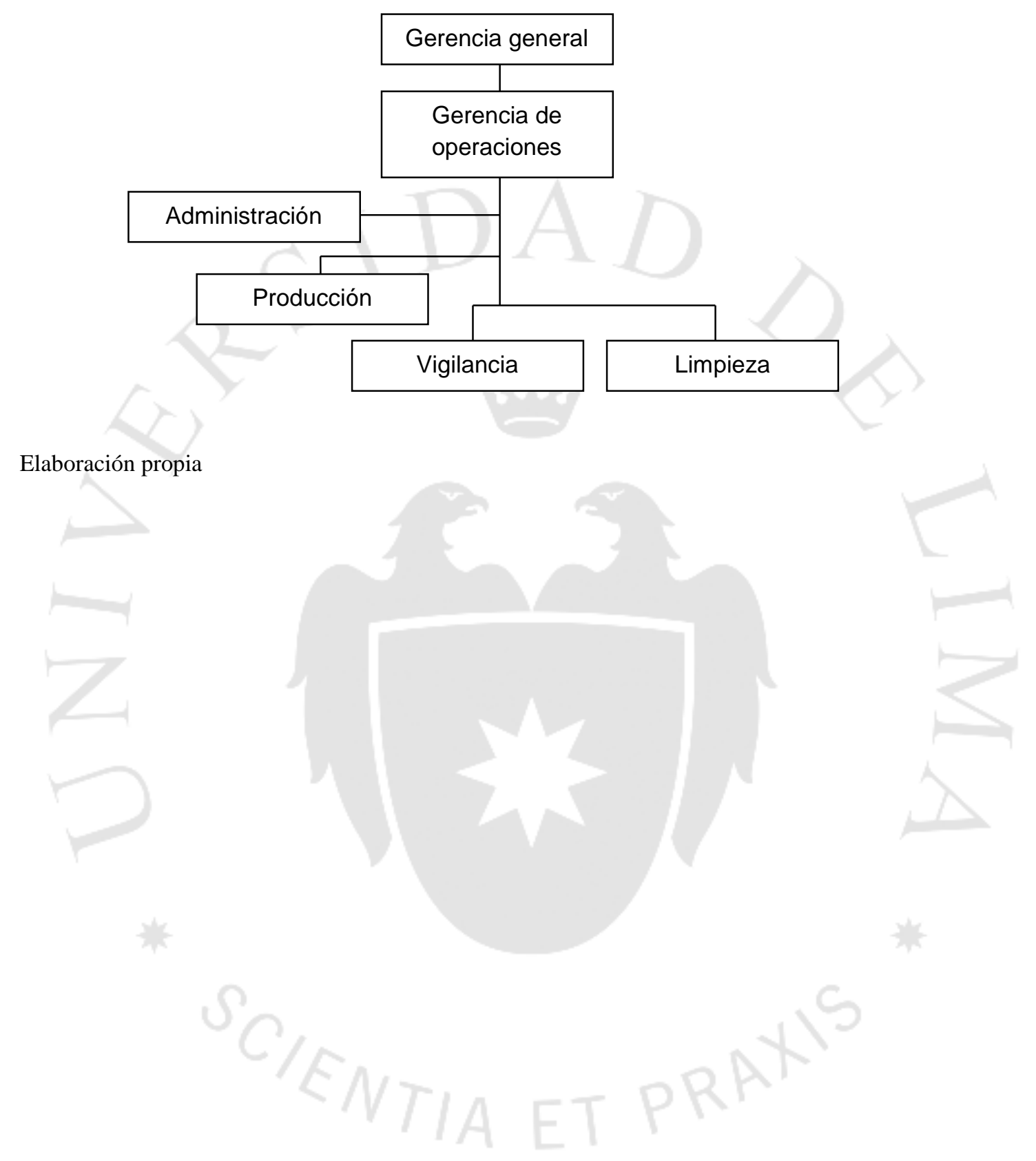




\section{CAPÍTULO VII: PRESUPUESTOS Y EVALUACIÓN DEL PROYECTO}

\subsection{Inversiones}

En este acápite se procede a detallar la estimación de las inversiones a largo (tangibles e intangibles) y corto plazo (capital de trabajo).

\subsubsection{Estimación de las inversiones de largo plazo (tangibles e intangibles)}

Tabla 7.1

Inversión en activos fijos tangibles

\begin{tabular}{l|r}
\hline Activos fijos tangibles & Val or Soles \\
\hline Terreno & S/ 489600,00 \\
Construcción & S/ 482854,40 \\
Muebles & S/ 6800,00 \\
Computadoras & S/ 6800,00 \\
Maquinaria & S/ 1030200,00 \\
Extintores y gabinetes & S/ 3100,00 \\
Transformador de energía & S/ 68000,00 \\
Servicios higiénicos & S/ 2167,60 \\
Total & S/ $\mathbf{2 0 8 9} \mathbf{5 2 2 , 0 0}$ \\
\hline
\end{tabular}

Elaboración propia 
Tabla 7.2

Inversión en activos fijos intangibles

\begin{tabular}{l|r}
\hline Activos fijos intangibles & Val or Soles \\
\hline Antivirus & S/ 320,00 \\
Software & S/ 1 618,40 \\
Licencias y permisos & S/ 1 263,08 \\
Estudios (prefactibilidad y factibilidad) & S 5000,00 \\
Imprevistos/Contingencias (5\% de la suma de lo anterior) & S/ 410,07 \\
Total & S/ 8 611,55 \\
\hline
\end{tabular}

Elaboración propia

\subsubsection{Estimación de las inversiones de corto plazo (capital de trabajo)}

Tabla 7.3

Inversión de corto plazo (capital de trabajo)

\begin{tabular}{l|rr}
\hline Criterio & Costo anual (S/.) & \multicolumn{1}{c}{ A 80 dias (S/.) } \\
\hline Materia Prima & $\mathrm{S} / 3793 \mathbf{3 5 8 , 1 9}$ & $\mathrm{S} / 842968,49$ \\
Bolsas & $\mathrm{S} / 97466,99$ & $\mathrm{~S} / 21659,33$ \\
Mano de Obra Directa & $\mathrm{S} / 837540,00$ & $\mathrm{~S} / 186120,00$ \\
Material indirecto & $\mathrm{S} / 513219,05$ & $\mathrm{~S} / 114048,68$ \\
Mano de Obra Indirecta & $\mathrm{S} / 69795,00$ & $\mathrm{~S} / 15510,00$ \\
Energía & $\mathrm{S} / 1000347,46$ & $\mathrm{~S} / 222299,44$ \\
Agua & $\mathrm{S} / 137109,72$ & $\mathrm{~S} / 30468,83$ \\
Mantenimiento & $\mathrm{S} / 48000,00$ & $\mathrm{~S} / 10666,67$ \\
Repuestos & $\mathrm{S} / 66720,00$ & $\mathrm{~S} / 14826,67$ \\
EPPS & $\mathrm{S} / 5226,00$ & $\mathrm{~S} / 1161,33$ \\
Gastos administrativos & $\mathrm{S} / 292800,00$ & $\mathrm{~S} / 65066,67$ \\
Gastos de ventas y logisticos & $\mathrm{S} / 522670,30$ & $\mathrm{~S} / 116148,96$ \\
Capital de trabajo total & $\mathrm{S} / \mathbf{7 ~ 3 8 4 ~ 2 5 2 , 7 1}$ & $\mathrm{S} / \mathbf{1 ~ 6 4 0 ~ 9 4 5 , 0 5}$ \\
\hline
\end{tabular}

Elaboración propia

\subsection{Costos de producción}

En este acápite se procede a detallar los costos de las materias primas, mano de obra directa y costo indirecto a fabricación. 


\subsubsection{Costos de las materias primas}

\section{Tabla 7.4}

Costo de materia prima

\begin{tabular}{|c|c|c|c|c|c|}
\hline Año/Costo materias primas & 2016 & 2017 & 2018 & 2019 & 2020 \\
\hline Polipropileno & S/ 3793358,19 & S/ 3680629,20 & S/ 3905852,90 & S/ 4144858,39 & S/ 4398489,02 \\
\hline Bolsas & S/ 97466,99 & S/ 94570,52 & S/ 100357,44 & S/ 106498,48 & S/ 113015,29 \\
\hline Total & S/ 3890825,18 & S/ 3775199,72 & $\mathrm{~S} / 4006210,34$ & S/ 4251356,87 & S/ 4511504,32 \\
\hline
\end{tabular}

Elaboración propia

\subsubsection{Costo de la mano de obra directa}

Tabla 7.5

Costo mano de obra directa

\begin{tabular}{l|rrrrr}
\hline Año/criterio & $\mathbf{2 0 1 6}$ & $\mathbf{2 0 1 7}$ & $\mathbf{2 0 1 8}$ & $\mathbf{2 0 1 9}$ & $\mathbf{2 0 2 0}$ \\
\hline Costo mano de obra directa & S/ 837540,00 & S/ 837540,00 & S/ 837540,00 & S/ 837540,00 & S/ 837540,00 \\
\hline
\end{tabular}

Nota: El costo base de la hora hombre utilizado es de 4,84 soles.

Elaboración propia

\subsubsection{Costo indirecto de fabricación}

\section{Tabla 7.6}

Costos indirectos de fabricación

\begin{tabular}{|c|c|c|c|c|c|}
\hline Año/Costos indirectos de fabricación & 2016 & 2017 & 2018 & 2019 & 2020 \\
\hline Materiales indirectos & S/ 513219,05 & S/ 559216,25 & S/ 587264,75 & S/ 616714,81 & S/ 647654,13 \\
\hline Mano de obra indirecta & S/ 69795,00 & S/ 69795,00 & S/ 69795,00 & S/ 69795,00 & S/ 69795,00 \\
\hline Energía & S/ 1000347,46 & S/ 971794,81 & S/ 1028840,77 & S/ 1089377,47 & S/ 1153618,50 \\
\hline Agua & S/ 137109,72 & S/ 133036,91 & S/ 141174,06 & S/ 149809,15 & S/ 158972,63 \\
\hline Mantenimiento & S/ 48000,00 & S/ 48000,00 & S/ 48000,00 & S/ 48000,00 & S/ 48000,00 \\
\hline Repuestos & S/ 66720,00 & S/ 66720,00 & S/ 66720,00 & S/ 66720,00 & S/ 66720,00 \\
\hline EPPS & S/ 5226,00 & S/ 5226,00 & S/ 5226,00 & S/ 5226,00 & S/ 5226,00 \\
\hline Depreciación fabril & S/ 134272,72 & S/ 134272,72 & S/ 134272,72 & S/ 134272,72 & S/ 134272,72 \\
\hline Total & S/ 1974689,95 & S/ 1988061,69 & S/ 2081293,31 & S/ 2179915,15 & S/ 2284258,97 \\
\hline
\end{tabular}

Elaboración propia 


\subsection{Presupuesto operativo}

En este acápite se procede a detallar los presupuestos de ingresos por ventas, operativo de costos y de gastos.

\subsubsection{Presupuesto de ingreso por ventas}

Tabla 7.7

Presupuesto de ingreso por ventas

\begin{tabular}{l|rrrrrr}
\hline Año / criterio & $\mathbf{2 0 1 6}$ & $\mathbf{2 0 1 7}$ & $\mathbf{2 0 1 8}$ & $\mathbf{2 0 1 9}$ & $\mathbf{2 0 2 0}$ \\
\hline Ventas & S/ 8179048,24 & S/ 8 679 537,51 & S/ 9210652,54 & S/ 9774267,36 & S/ 10372370,69 \\
\hline
\end{tabular}

Elaboración propia

\subsubsection{Presupuesto operativo de costos}

Tabla 7.8

Presupuesto operativo de costos

\begin{tabular}{|c|c|c|c|c|c|}
\hline Año/ Presupuesto de costos de operación & 2016 & 2017 & 2018 & 2019 & 2020 \\
\hline Materiales directos & S/ 3890825,18 & S/ 3775199,72 & 006210,34 & 4251356,87 & 5 \\
\hline Costo man & S/ 837540,00 & S/ 837540,00 & S/ 837540,00 & & 37540,00 \\
\hline Costo indirectos de fabricación & S/ 1974689,95 & S/ 1988061,69 & S/ 2081293,31 & S/ 2179915,15 & S/ 2284258,97 \\
\hline Total & S/ 6703055,13 & S/ 6600801,41 & S/ 6925043,65 & S/ 7268812,02 & S/ 7633303,29 \\
\hline
\end{tabular}

Elaboración propia 


\subsubsection{Presupuesto operativo de gastos}

\section{Tabla 7.9}

Presupuesto operativo de gastos

\begin{tabular}{|c|c|c|c|c|c|}
\hline Año/Criterio & 2016 & 2017 & 2018 & 2019 & 2020 \\
\hline Gastos administrativos & S/ 296257,91 & S/ 296257,91 & S/ 296289,91 & S/ 296289,91 & S/ 294621,91 \\
\hline Administración & S/. 48000,00 & S/. 48000,00 & S/. 48000,00 & S/. 48000,00 & S/. 48000,00 \\
\hline Amortización & $\mathrm{S} / 861,15$ & $\mathrm{~S} / 861,15$ & S/ 893,15 & S/ 893,15 & $\mathrm{~S} / 925,15$ \\
\hline Depreciación no fabril & S/ 2596,76 & S/ 2596,76 & S/ 2596,76 & S/ 2596,76 & S/ 896,76 \\
\hline Sueldos gerenciales & S/ 244800,00 & S/ 244800,00 & S/ 244800,00 & S/ 244800,00 & S/ 244800,00 \\
\hline Gastos de ventas & S/ 238675,57 & S/ 253273,18 & S/ 268764,03 & S/ 285202,80 & S/ 302647,48 \\
\hline Transporte producto terminado & S/ 238555,57 & S/ 253153,18 & S/ 268644,03 & $\mathrm{~S} / 285082,80$ & S/ 302527,48 \\
\hline Muestras a clientes & $\mathrm{S} / 120,00$ & $\mathrm{~S} / 120,00$ & $\mathrm{~S} / 120,00$ & $\mathrm{~S} / 120,00$ & S/ 120,00 \\
\hline Gastos de logística & S/ 283994,73 & S/ 301372,83 & $\mathrm{~S} / 319814,32$ & S/ 339384,28 & $\mathrm{~S} / 360151,76$ \\
\hline Transporte de materia prima & S/ 283994,73 & $\mathrm{~S} / 301372,83$ & $\mathrm{~S} / 319814,32$ & S/ 339384,28 & S/ 360151,76 \\
\hline Total & S/ 818928,22 & S/ 850903,92 & S/ 884868,27 & S/ 920877,00 & S/ 957421,15 \\
\hline
\end{tabular}

Elaboración propia

\subsection{Presupuestos financieros}

En este acápite se procede a detallar los presupuestos de servicio de deuda, estado de resultados, estado de situación financiera o balance general y flujo de caja de corto plazo.

\subsubsection{Presupuesto de servicio de deuda}

Tabla 7.10

Presupuesto de servicio de deuda

\begin{tabular}{|c|c|c|c|c|c|}
\hline Año/ Criterio & Deuda inicial & Amortización & Interés & Cuota & Deuda final \\
\hline 1 & S/ 17000 & S/ 494243,52 & S/ 194 & S/ 68 & $\mathrm{~S} / 1$ \\
\hline 2 & S/ 1205 756,48 & S/ 563 437,61 & S/ 125636,09 & S/ 689073,70 & S/ 642318,87 \\
\hline 3 & S/ 642318,87 & S/ 642318,87 & S/ 46754,83 & S/ 689073,70 & - \\
\hline
\end{tabular}

Elaboración propia 


\subsubsection{Presupuesto de estado de resultados}

Tabla 7.11

Presupuesto de estado de resultados

\begin{tabular}{|c|c|c|c|c|c|}
\hline Año/ Criterio & 2016 & 2017 & 2018 & 2019 & 2020 \\
\hline Ventas & S/ 8179048,24 & S/ 8679537,51 & S/ 9210652,54 & S/ 9774267,36 & S/ 10372370,69 \\
\hline (-) Costo de ventas & S/ 5885150,30 & S/ 6550752,49 & S/ 6871932,15 & S/ 7212450,54 & S/ 7573492,96 \\
\hline Utili dad bruta & S/ 2293897,94 & $\mathrm{~S} / 2128785,03$ & S/ 2338720,40 & S/ 2561816,83 & S/ 2798877,74 \\
\hline (-) Gastos de ventas & S/ 238675,57 & S/ 253273,18 & S/ 268764,03 & S/ 285202,80 & S/ 302647,48 \\
\hline (-) Gastos administrativos & S/ 296257,91 & S/ 296257,91 & S/ 296289,91 & S/ 296289,91 & S/ 294621,91 \\
\hline (-) Gastos de logística & S/ 283994,73 & $\mathrm{~S} / 301372,83$ & S/ 319814,32 & S/ 339384,28 & $\mathrm{~S} / 360151,76$ \\
\hline Utili dad operativa & S/ 1474969,72 & S/ 1277881,10 & S/ 1453852,13 & S/ 1640939,83 & S/ 1841456,58 \\
\hline (-) Gastos financieros & S/ 194830,18 & S/ 125636,09 & S/ 46754,83 & $\mathrm{~S} / 0,00$ & $\mathrm{~S} / 0,00$ \\
\hline (+) Ingresos financieros & $\mathrm{S} / 0,00$ & $\mathrm{~S} / 0,00$ & $\mathrm{~S} / 0,00$ & $\mathrm{~S} / 0,00$ & $\mathrm{~S} / 0,00$ \\
\hline Utilidad antes de prticipación labd & S/ 1280139,53 & S/ 1152245,01 & S/ 1407097,30 & S/ 1640939,83 & S/ 1841456,58 \\
\hline (-) Participación laboral & S/ 128013,95 & S/ 115224,50 & S/ 140709,73 & S/ 164093,98 & S/ 184145,66 \\
\hline Utilidad antes de impuestos & S/ 1152125,58 & S/ 1037020,51 & S/ 1266387,57 & S/ 1476845,85 & S/ 1657310,92 \\
\hline (-) Impuestos & S/ $339877,05^{\circ}$ & $\mathrm{S} / 305921,05^{\nabla}$ & S/ $373584,33^{\top}$ & S/ $435669,52^{\nabla}$ & S/ 488906,72 \\
\hline Utilidad neta & S/ 812248,53 & S/ 731099,46 & S/ 892803,24 & S/ 1041 176,32 & S/ 1168404,20 \\
\hline (-) Reserva legal & $\mathrm{S} / 81224,85^{\top}$ & $\mathrm{S} / 73109,95^{\mathbf{r}}$ & S/ $89280,32^{\top}$ & S/ $104117,63^{\nabla}$ & S/ 60082,96 \\
\hline Utilidad neta de libre disposición & $\mathrm{S} / 731023,68$ & S/ 657989,52 & S/ 803522,91 & S/ 937058,69 & S/ 1108321,24 \\
\hline
\end{tabular}

Elaboración propia

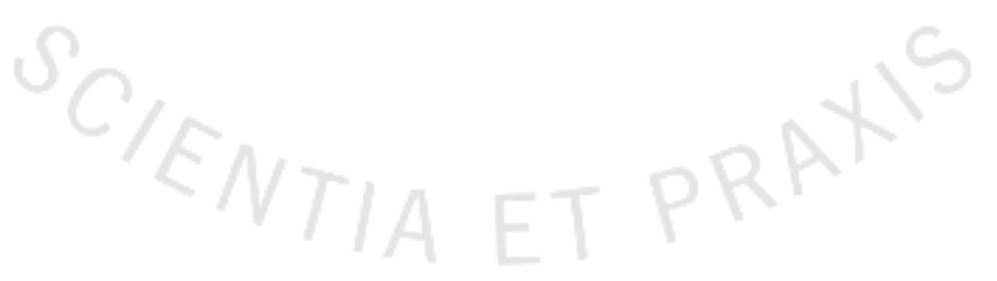




\subsubsection{Presupuesto de estado de situación financiera}

Tabla 7.12

Presupuesto de estado de situación financiera al final del año 1

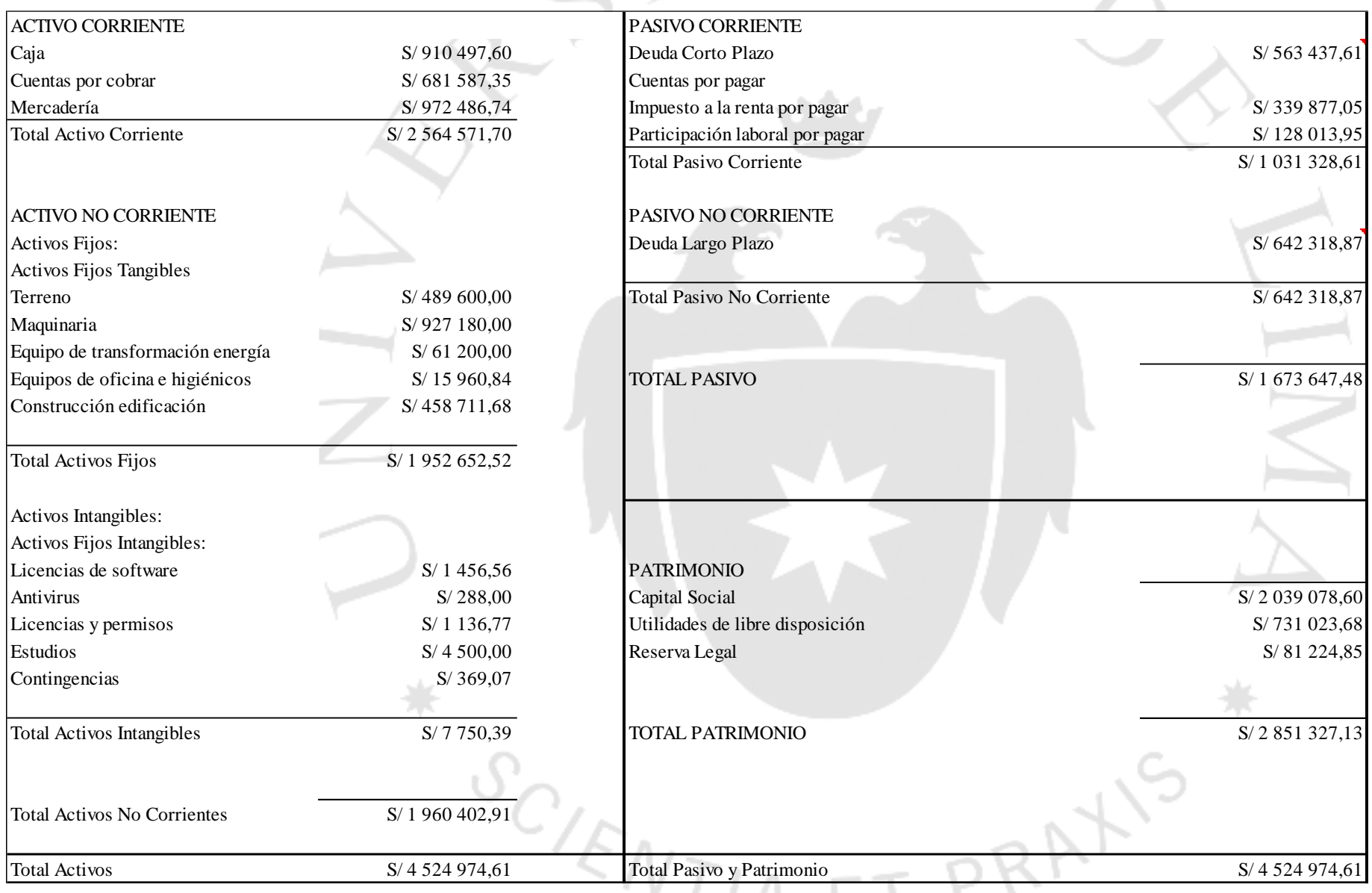

Elaboración propia 


\subsubsection{Flujo de caja de corto plazo}

\section{Tabla 7.13}

Flujo de caja de corto plazo

\begin{tabular}{|c|c|c|}
\hline Criterio & Monto & \\
\hline Ventas Cobradas & S/ 7497460,89 & Politica de Cobranzas: \\
\hline Ventas por cobrar & S/ 681587,35 & Cobramos con 30 dias de credito, por lo tanto para est \\
\hline Ingresos Totales & S/ 8179048,24 & entonces se ha cobrado 11 de 12 meses \\
\hline \multicolumn{3}{|l|}{ Ingresos } \\
\hline Ingresos por ventas & S/ 7497460,89 & Política de Gastos: \\
\hline Préstamo Bancario & S/ 1700000,00 & Se paga el $100 \%$ al contado \\
\hline Inversión Accionistas & S/ 2039078,60 & \\
\hline Total Ingresos & S/ 11236539,48 & \\
\hline \multicolumn{3}{|l|}{ Egresos } \\
\hline Compras & \multicolumn{2}{|c|}{ S/ 6568782,41 (- depreciacion fabril) } \\
\hline Gastos Generales & \multicolumn{2}{|c|}{ S/ 815 470,30 (-depreciacion no fabril y amortizacion) } \\
\hline Amortizacion de la deuda & \multicolumn{2}{|l|}{ S/ 494243,52} \\
\hline Pago de Intereses & S/ 194830,18 & $\alpha=$ \\
\hline Stock de MP e Insumos & \multicolumn{2}{|c|}{ S/ 154 581,92 (considerandos dos semanas de MP y media semana de insumos) } \\
\hline Inversión Tangibles & \multicolumn{2}{|l|}{ S/ 2089522,00} \\
\hline Inversión Intangibles & \multicolumn{2}{|l|}{$\mathrm{S} / 8611,55$} \\
\hline Total egresos & \multicolumn{2}{|l|}{ S/ 10326041,88} \\
\hline Flujo de efectivo & \multicolumn{2}{|l|}{ S/ 910497,60} \\
\hline
\end{tabular}

Elaboración propia 


\subsection{Flujo de fondos netos}

En este acápite se procede a detallar tanto los flujos económicos y financieros que luego servirán para la evaluación del capítulo VIII.

\subsubsection{Flujo de fondos económicos}

Tabla 7.14

Flujo de fondos económico

\begin{tabular}{|c|c|c|c|c|c|c|}
\hline Año/ Criterio & $\mathbf{0}$ & 1 & 2 & 3 & 4 & 5 \\
\hline Utilidad Neta & & S/ 812248,53 & S/ 731099,46 & S/ 892803,24 & S/ 1041176,32 & S/ 1168404,20 \\
\hline Depreciación Fabril & & S/ 134272,72 & S/ 134272,72 & S/ 134272,72 & S/ 134272,72 & S/ 134272,72 \\
\hline Depreciación no Fabril & & S/ 2596,76 & S/ 2596,76 & S/ 2596,76 & S/ 2596,76 & S/ 896,76 \\
\hline Amortización intangibles & & S/ 861,15 & S/ 861,15 & S/ 893,15 & S/ 893,15 & S/ 925,15 \\
\hline Gastos Financieros & & S/ 137355,28 & S/ 88573,44 & S/ 32962,15 & - & - \\
\hline Valor en Libros & & & & & & S/ 1275597,74 \\
\hline Pérdidas por venta tangibles $(50 \%)$ & & & & & & $-\mathrm{S} / 459215,19$ \\
\hline Capital de Trabajo & & & & & & S/ 1640945,05 \\
\hline Flujo de Fondos Económico & S/ -3 379078,60 & S/ 1087334,45 & S/ 957403,54 & S/ 1063528,02 & S/ 1178938,96 & S/ 3761826,44 \\
\hline
\end{tabular}

Elaboración propia

\subsubsection{Flujo de fondos financieros}

Tabla 7.15

Flujo de fondos financiero

\begin{tabular}{|c|c|c|c|c|c|c|}
\hline Capital de Trabajo & $\mathbf{0}$ & 1 & 2 & 3 & 4 & 5 \\
\hline Utilidad Neta & & S/ 812248,53 & S/ 731099,46 & S/ 892803,24 & S/ 1041176,32 & S/ 1168404,20 \\
\hline Depreciación Fabril & & S/ 134272,72 & S/ 134272,72 & S/ 134272,72 & S/ 134272,72 & S/ 134272,72 \\
\hline Depreciación no Fabril & & S/ 2596,76 & S/ 2596,76 & S/ 2596,76 & S/ 2596,76 & S/ 896,76 \\
\hline Amortización Intangibles & & S/ 861,15 & $\mathrm{~S} / 861,15$ & S/ 893,15 & S/ 893,15 & S/ 925,15 \\
\hline Amortización Deuda & & -S/ 494243,52 & $-S / 563437,61$ & $-S / 642318,87$ & - & - \\
\hline Valor en Libros & & & & & & S/ 1275597,74 \\
\hline Pérdidas por venta tangibles ( $50 \%$ ) & & & & & & $-S / 459215,19$ \\
\hline Capital de Trabajo & & & & & & S/ 1640945,05 \\
\hline Flujo de Fondos Financiero & S/ - 2039078,60 & S/ 455735,65 & S/ 305392,49 & S/ 388247,00 & S/ 1178938,96 & S/ 3761826,44 \\
\hline
\end{tabular}

Elaboración propia 


\section{CAPÍTULO VIII: EVALUACIÓN ECONÓMICA Y FINANCIERA DEL PROYECTO}

Para realizar ambas evaluaciones se utilizó un costo de oportunidad de $18,51 \%$ que es el costo de oportunidad promedio del mercado. Este porcentaje se obtuvo con el uso de la fórmula del modelo CAPM para obtener la tasa de rentabilidad mínima esperada por el accionista:

$$
\mathrm{CAPM}=\mathrm{Rf}+\beta *(\mathrm{Rm}-\mathrm{Rf})
$$

Las variables de $\mathrm{Rf}$ (tasa libre de riesgo), beta (riesgo sistémico) y Rm (tasa de retorno promedio de mercado) se obtuvieron con el apoyo del laboratorio de mercados capitales de la Universidad de Lima.

Por lo tanto, para que sea aceptable invertir en este proyecto debe darnos una rentabilidad mayor a 18,51\%. A continuación, se detalla si efectivamente se logra eso.

\subsection{Evaluación económica: VAN, TIR, B/C, PR}

Tabla 8.1

Evaluación económica del proyecto

\begin{tabular}{l|r}
\hline Indicador & Económico \\
\hline VAN & S/ 706 176,76 \\
TIR & $25,04 \%$ \\
Relación Beneficio/Costo & 1,19 \\
Periodo Promedio de Recupero & 4,56 \\
\hline
\end{tabular}

Elaboración propia

En primer lugar, se obtiene un VAN positivo, esto quiere decir que el flujo de ingresos futuros en el horizonte del proyecto es mayor a la inversión inicial y si es rentable económicamente. Luego, el TIR (Tasa Interna de Retorno) es mayor al costo de oportunidad lo cual refleja que es conveniente llevar a cabo el proyecto. 
La relación beneficio/costo es mayor a la 1, lo cual significa que el proyecto va a otorgar ganancias, y por último el periodo de recupero es menor a 5 años. Esto significa que se va a recuperar toda la inversión antes del cierre del proyecto lo cual es otro requisito para llevarlo a cabo.

\subsection{Evaluación financiera: VAN, TIR, B/C, PR}

Tabla 8.2

Evaluación financiera del proyecto

\begin{tabular}{l|r}
\hline Indicador & Financiero \\
\hline VAN & S/ 1 003242,57 \\
TIR & $31,60 \%$ \\
Relación Beneficio/Costo & 1,49 \\
Periodo Promedio de Recupero & 4,38 \\
\hline
\end{tabular}

Elaboración propia

La evaluación financiera, al igual que la económica, refleja que el proyecto es rentable y debería llevarse a cabo. Incluso, es mejor que el escenario económico, ya que en este escenario los accionistas no asumen toda la inversión y no representa un egreso tan fuerte en el año cero. Financieramente, la VAN, TIR, y la relación beneficio/costo son más elevados y el periodo de recupero de la inversión es menor.

En conclusión, realizar el proyecto asumiendo un porcentaje con acreedores externos es la mejor opción bajo los criterios detallados previamente. 


\subsection{Análisis de ratios (liquidez, solvencia, rentabilidad) e indicadores económicos y financieros del proyecto}

Tabla 8.3

Ratios de liquidez

\begin{tabular}{|c|c|c|c|}
\hline Ratios de liquidez & Restultado & Unidades & Formulas \\
\hline Liquidéz o razón corriente & 2,49 & veces & Activo Corriente/Pasivo Corriente \\
\hline Razón de acidez & 1,54 & veces & (Caja+Cuentas por cobrar)/Pasivo Corriente \\
\hline Razón de efectivo & 0,88 & veces & Caja/Pasivo Corriente \\
\hline Capital de trabajo & S/ 1533243,09 & soles & Activo Corriente-Pasivo Corriente \\
\hline
\end{tabular}

Elaboración propia

Luego del análisis de dichos ratios se puede afirmar que, por cada sol en deudas de corto plazo, la empresa tiene 2,49 soles de activo corriente para hacer frente a las mismas. A su vez, por cada sol en deudas de corto plazo, la empresa tiene 1,54 soles de caja y cuentas por cobrar para poder hacer frente a las mismas. Desde un punto de vista aún más ácido, por cada sol en deudas de corto plazo, la empresa tiene 0,88 soles en efectivo para hacer frente a las mismas. Finalmente, al final del primer año y luego de hacer frente a todas las obligaciones de corto plazo, la empresa dispone de 1533243 soles para poder operar el negocio. En conclusión, la empresa es líquida para hacer frente a sus obligaciones de corto plazo y a los costos y gastos de operación.

\section{Tabla 8.4}

Ratios de eficiencia

\begin{tabular}{|c|c|c|c|}
\hline Ratios de eficiencia & Resultado & Unidades & Formulas \\
\hline Rotación de cuentas por cobrar & 12,00 & veces & Ingresos totales/Cuentas por cobrar \\
\hline Periodo promedio de cobro & 30,00 & días & 360/Rotacion de cuentas por cobrar \\
\hline Rotación de cuentas por pagar & - & veces & Ingresos totales/Cuentas por pagar \\
\hline Periodo promedio de pago & - & días & 360/Rotacion de cuentas por pagar \\
\hline Rotación de inventarios & 7,20 & veces & Costo de ventas/(Inventario final x Precio de venta) \\
\hline Periodo promedio de inventarios & 50,03 & días & 360/Rotacion de inventarios \\
\hline Rotación de activo fijo & 4,17 & veces & Ventas/Activo no corriente \\
\hline Rotación de activo total & 1,81 & veces & Ventas/Total Activo \\
\hline
\end{tabular}

Elaboración propia 
Con respecto a la tabla anterior se puede concluir que las cuentas por cobrar se convierten en efectivo a razón de una vez cada mes del año, en comparación con la competencia esté indicador se encuentra en un nivel promedio. Por otro lado, ya que la empresa tiene una política de pago al contado, ningún indicador relacionado a cuentas por pagar aplica para la compañía. Con respecto al inventario, este se vende 7,20 veces en un año. Finalmente, por cada sol aportado en activo neto, la empresa genera 4,17 soles de venta; y por cada sol aportado en activo total, la empresa genera 1,81 soles en ventas.

\section{Tabla 8.5}

Ratios de endeudamiento

\begin{tabular}{|c|c|c|c|}
\hline Ratios de endeudamiento & Resultado & Unidades & Formulas \\
\hline Razón deuda patrimonio & 0,59 & veces & Total Pasivo/Total Patrimonio \\
\hline Deuda corto plazo patrimonio & 0,36 & veces & Pasivo Corriente/Total Patrimonio \\
\hline Deuda largo plazo patrimonio & 0,23 & veces & Pasivo No Corriente/Total Patrimonio \\
\hline Razón de endeudamiento & 0,37 & veces & Total Pasivo/Total Pasivo y Patrimonio \\
\hline Razón de cobertura de intereses & 7,57 & veces & Utilidad Operativa/Gastos financieros \\
\hline Calidad de deuda & 0,62 & veces & Pasivo Corriente/Pasivo No Corriente \\
\hline
\end{tabular}

Elaboración propia

Con respecto a la tabla anterior se puede concluir que, por cada sol aportado por los accionistas, la empresa tiene 0,59 soles de deuda con los acreedores. El apalancamiento financiero de corto plazo de la empresa es bajo, ya que tiene 0,36 soles de deuda de corto plazo con los acreedores por cada sol aportado por los accionistas. De manera similar el apalancamiento financiero de largo plazo de la empresa es bajo, ya que tiene 0,23 soles de deuda de largo plazo con los acreedores por cada sol aportado por los accionistas. Con respecto a los activos de la empresa, el $37 \%$ de ellos han sido financiados por acreedores. Finalmente, y en base a los dos últimos indicadores de la tabla anterior, se concluye que la empresa tiene una alta capacidad para hacer frente a sus obligaciones de intereses y hace uso de financiamiento de corto plazo en mayor grado que de largo plazo. En resumen, la compañía tiene un bajo grado de apalancamiento financiero ya que sus activos se encuentran financiados, en su mayoría, por los accionistas y no por acreedores, esto permite a la empresa acceder a crédito con bastante facilidad. 


\subsection{Análisis de sensibilidad del proyecto}

Tras el análisis del escenario base en los acápites previos, se presentan a continuación los escenarios pesimista y optimista con sus respectivos indicadores tanto financieros como económicos.

En el caso del escenario optimista las modificaciones realizadas son:

- Reducción del nivel de merma del proceso de $16 \%$ a $14 \%$.

- Reducción del costo de materia prima de 0,85 a 0,80 soles por kilogramo de materia prima.

Por otro lado, en el caso del escenario pesimista las modificaciones realizadas son:

- Aumento del nivel de merma del proceso de $16 \%$ a $18 \%$.

- Aumento del costo de materia prima de 0,85 a 0,90 soles por kilogramo de materia prima.

- Reducción del precio de venta de 2,4 a 2,3 soles por kilogramo de producto terminado.

Como resultado de los cambios mencionados para ambos escenarios se obtendrían los siguientes resultados de presentarse cualquiera de ellos, incluyendo el escenario base.

\section{Tabla 8.6}

Evaluación económica/financiera de los escenarios.

\begin{tabular}{|c|c|c|c|c|c|c|}
\hline \multirow{2}{*}{ Criterio/Escenario } & \multicolumn{2}{|c|}{ Escenario base } & \multicolumn{2}{|c|}{ Escenario optimista } & \multicolumn{2}{|c|}{ Escenario pesimista } \\
\hline & Económico & Financiero & Económico & Financiero & Económico & Financiero \\
\hline VAN & S/ 706176,76 & S/ 1003242,57 & S/ 1402603,23 & S/ 1660764,25 & $-S / 28796,17$ & S/ 269712,00 \\
\hline TIR & $25,04 \%$ & $31,60 \%$ & $31,50 \%$ & $40,49 \%$ & $18,30 \%$ & $22,09 \%$ \\
\hline $\begin{array}{l}\text { Relación } \\
\text { Beneficio/Costo }\end{array}$ & 1,19 & 1,49 & 1,38 & 1,82 & 0,99 & 1,13 \\
\hline $\begin{array}{l}\text { Periodo Promedio de } \\
\text { Recupero }\end{array}$ & 4,56 & 4,38 & 4,18 & 4,06 & 5,02 & 4,82 \\
\hline
\end{tabular}

Elaboración propia

Las probabilidades de ocurrencia de cada uno de estos escenarios son 50\% para el escenario base, $35 \%$ para el escenario pesimista y finalmente, un $15 \%$ para el escenario 
optimista. Estos porcentajes han sido definidos en base a la experiencia de expertos en el rubro, es decir, personas que llevan en esta clase de negocio más de 10 años y por ende conocen la fluctuación del mismo.

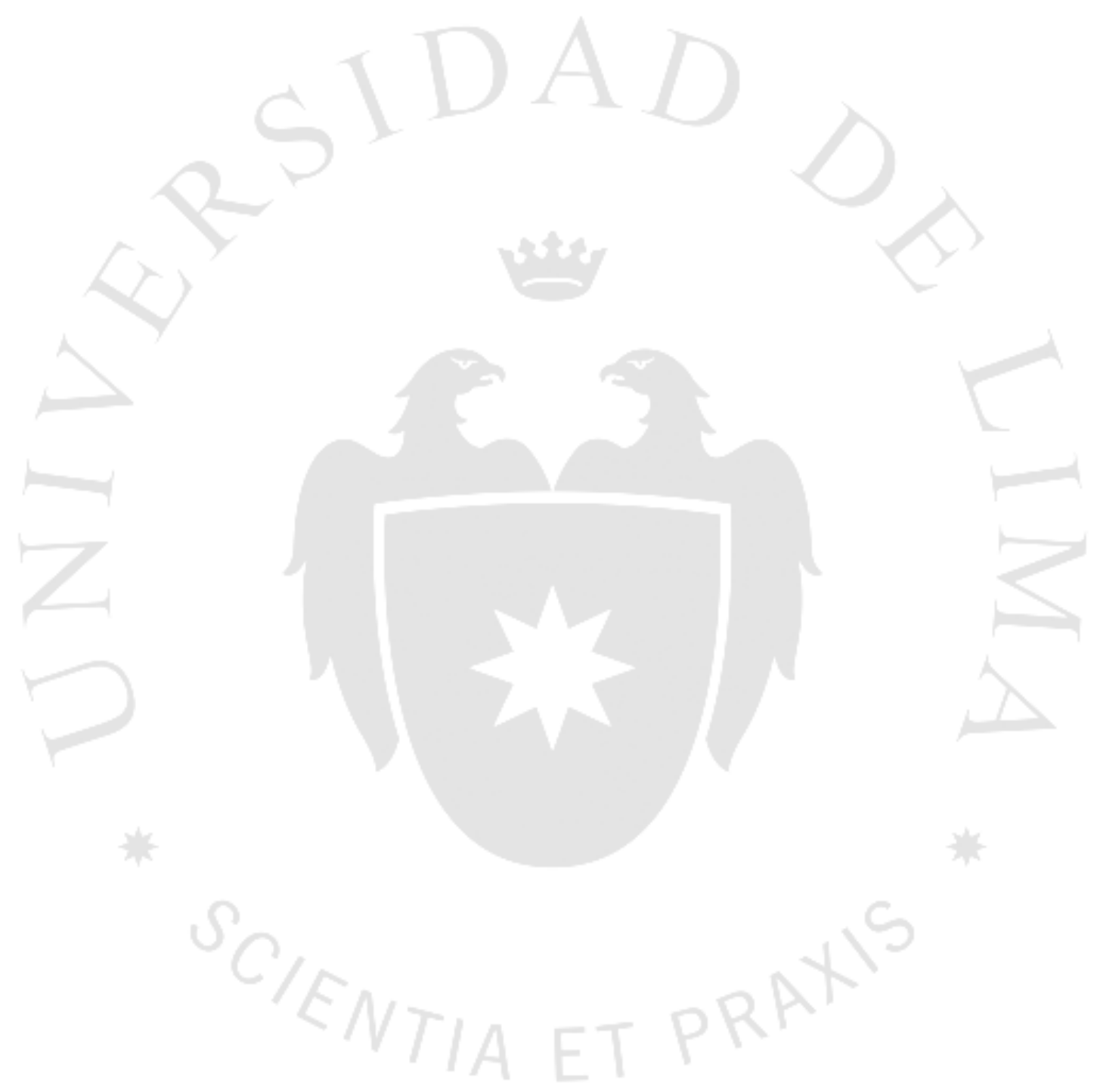




\section{CAPÍTULO IX: EVALUACIÓN SOCIAL DEL PROYECTO}

\subsection{Identificación de las zonas y comunidades de influencia del proyecto}

Con la finalidad de obtener una mayor precisión, la descripción de este punto se divide en dos grandes aristas: zonas y comunidades afectadas por el proyecto y zonas y comunidades que afectan al proyecto.

Como parte de la primera arista mencionada previamente se encuentran las siguientes zonas y comunidades:

- Clientes: Este grupo se verá afectado por la empresa mediante el producto que está última le entrega. Dicho producto será utilizado por los clientes para la elaboración de productos finales, cuya calidad dependerá del insumo adquirido. Es por ello que se buscará entregar un insumo de alta calidad a los clientes, con la finalidad de que sus productos finales sean líderes en el mercado objetivo.

- Población peruana: Este segundo grupo será afectado por la empresa de manera positiva en dos aspectos principales. En primer lugar, la compañía generará puestos de trabajo para los pobladores y estos recibirán un trato adecuado por parte de la empresa, es decir, recibirán un sueldo justo, beneficios de ley, ambiente adecuado de trabajo, etc. Por otro lado, la empresa reducirá la contaminación a la cual se enfrenta dicha población, mejorando así el nivel de vida que tienen tanto ellos como el que tendrán sus generaciones futuras.

- Medio ambiente: Este grupo será afectado, de manera neta, positivamente por la empresa; esto se debe a qué, como cualquier empresa productora, la empresa en cuestión generará contaminación por el uso de recursos (Agua, electricidad, materiales, etc.) para la producción; sin embargo, reducirá de manera importante el nivel de desechos que 
generan los seres humanos producto del consumo diario de los diversos productos ofrecidos en los diferentes mercados. Esto se logrará mediante la reutilización de dichos desechos para la creación de nuevos productos finales reciclados.

- Vecinos: Debido a la localización contemplada para este proyecto, una zona netamente industrial, todos los vecinos de la planta son otras plantas industriales. El efecto que se tendrá sobre estos es mínimo ya que nuestro proceso productivo tiene como desechos aguas residuales, que no son contaminantes debido a los bajos niveles de concentración que tienen de los diversos insumos que pueden haber sido utilizados durante el proceso productivo; los polímeros no utilizados que han sido segregados en las primeras etapas del proceso y que serán desechados correctamente junto con los demás residuos sólidos de la planta; y cierto ruido, el cual no será elevado al estar parcialmente aislado por el techo que cubre el área de producción donde se ubica la maquinaria y las paredes que la limitan.

- Botaderos municipales y rellenos sanitarios: Ambos grupos se verán beneficiados por el proyecto ya que obtendrán mayores ingresos a la vez que reducen sus inventarios, al realizar la venta de los residuos que tiene acumulados en forma de materia prima para la empresa JD polímeros peruanos. De este modo ellos obtienen ganancias por el previo trabajo de recolección llevado a cabo y la empresa obtiene grandes niveles de materia prima concentrada en algunos de estos establecimientos, facilitando así el aprovisionamiento de la misma.

Desde el punto de vista opuesto, la segunda arista se encuentra constituida por:

- Consumidores finales: De este grupo dependerá si la empresa tendrá o no suficientes recursos para efectuar su producción, ya que si no se generan desechos que recuperar y reciclar la compañía no tendrá un proceso de producción que ejecutar. A su vez, es de suma importancia, la consciencia que posee este grupo ya que de ello dependerá si la recolección de los desechos generados es sencilla o compleja para la compañía. 
- Proveedores: Este grupo tiene una similitud importante con el grupo visto anteriormente, ya que el aprovisionamiento de la materia prima dependerá en gran parte de su capacidad para obtener los desechos y venderlos a empresas como la empresa de este proyecto. $\mathrm{Si}$ dichos proveedores no poseen la materia prima o sus precios son demasiado elevados la empresa no contará con insumos suficientes para satisfacer a los clientes, generándose así una escasez en el mercado.

Todos y cada uno de estos grupos deben ser tomados en cuenta con la finalidad de generar un todo articulado que funcione bajo una perspectiva ganar-ganar, es decir, cada una de las partes aporte valor agregado al sistema y todos reciben algo a cambio.

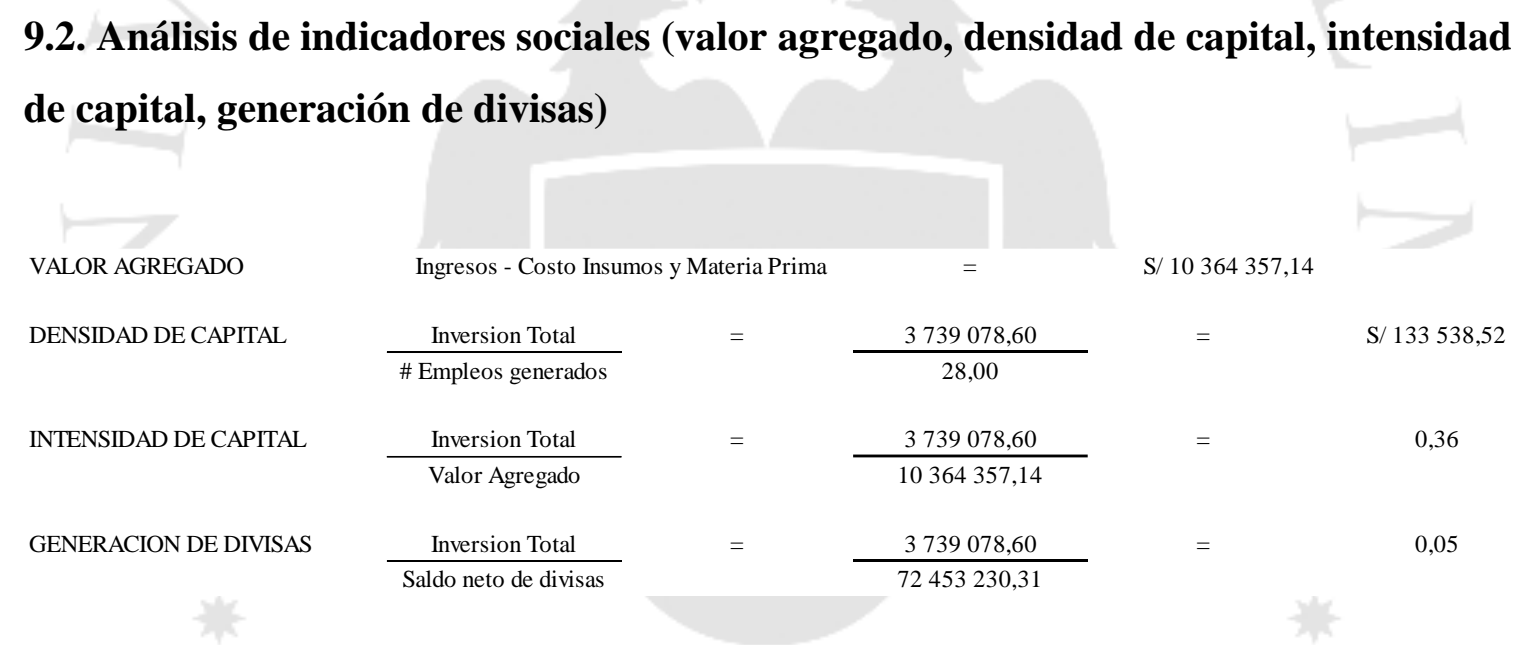

El análisis realizado de los indicadores dio las siguientes conclusiones:

- Valor agregado: El aporte que se realiza a los insumos y materia prima para su transformación tiene un valor de S/ 10364 357,14.

- Densidad de capital: Se invierten S/ 133539 por cada empleo generado en el presente proyecto 
- Intensidad de capital: El valor agregado generado es mayor a la inversión total, lo cual muestra que el proyecto genera un impacto social positivo (aproximadamente 2,7 veces mayor a la inversión).

- Generación de divisas: La generación de divisas es extremadamente positiva ya que ingresa mucho más dinero de lo que sale del país y es mayor a la inversión total (en un ratio de casi 20 veces).

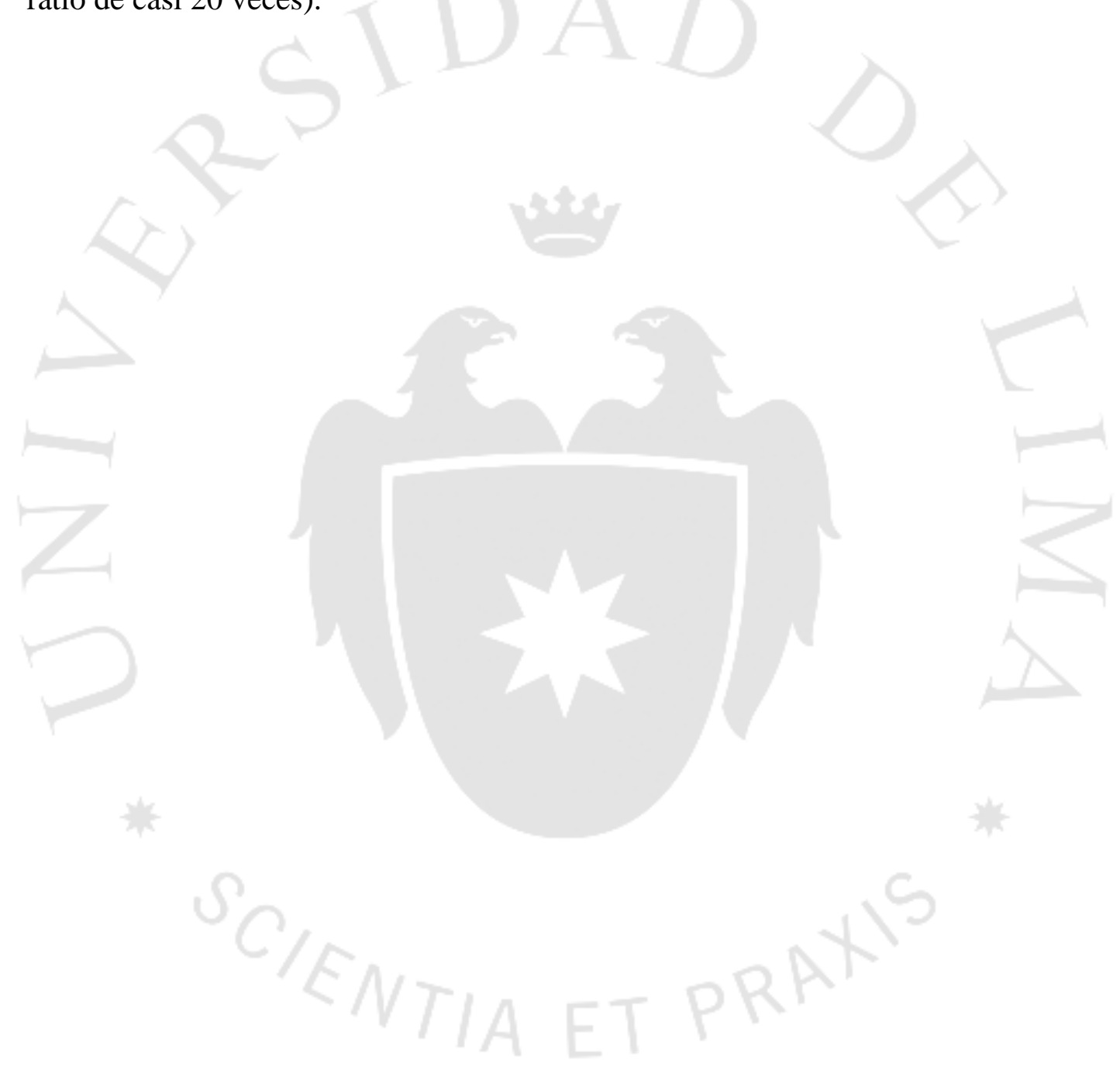




\section{CONCLUSIONES}

A continuación, se detallan las conclusiones:

- La demanda del proyecto para el último año del horizonte de vida útil del proyecto es de 4 321,82 toneladas, equivalentes a 10372 370,69 soles.

- Según el análisis realizado durante la investigación, la localización óptima de la planta es Lurín, Lima Metropolitana. Dicho lugar se selecciona por el menor precio del terreno y la seguridad que ofrece.

- Tras el análisis de los diversos tamaños posibles, el tamaño de planta óptimo para la compañía es el tamaño mercado, equivalente a 4 321,8 toneladas por año.

- Una línea integrada de ritmo 1000 kilogramos por hora y de procedencia mexicana, es la tecnología más adecuada para la fabricación de un producto de alta calidad, alto nivel de automatización, bajo nivel de pérdidas y reducción de costos.

- El proyecto es rentable en sus tres escenarios en términos financieros; mientras que en términos económicos los escenarios optimista y base son rentables y el pesimista no lo es. Esto se sustenta en los diferentes indicadores calculados, como es el caso del VAN financiero y económico cuyos valores son de S/ 1003 242,57 y S/ 706 176,76 en el escenario base; S/ 1660 764,25 y S/ 1402 603,23 en el escenario optimista y S/ 269 712,00 y S/ -28 796,17 en el escenario pesimista. Los valores positivos indican que el proyecto es rentable, mientras un valor negativo indica que no lo es. 


\section{RECOMENDACIONES}

A continuación, se detallan las recomendaciones:

- Cuando se investigó la tecnología existente en la actualidad se determinó que existe el reciclaje químico, el cual es un método que involucra mayor grado de tecnología. Este innovador método ha surgido en los últimos años y aún no ha llegado al Perú, por ello se recomienda ahondar con mayor profundidad dicha temática debido a las oportunidades que puede generar para la industria del reciclaje.

- El reciclaje de otros materiales es otro tema que se recomienda profundizar ya que en el presente documento el enfoque fueron los polímeros y específicamente el polipropileno. Pero, el reciclaje aplica a diversos materiales como cartón, papel, metal, vidrios, entre otros. Un aporte muy importante sería determinar si sería factible recibir toda la basura mezclada como materia prima y reutilizarla toda.

- Se recomienda a cualquier potencial ingresante de este mercado y a aquellas empresas que ya se encuentran operando en el rubro revisar el presente proyecto ya que incluye información relevante y clave para entender el rubro y poder operar con eficacia en él. 


\section{REFERENCIAS}

Adonde.com. (2016). Distancia entre ciudades del Perú. Recuperado de http://adonde.com/turismo/distancia-ciudades.php

BBC Mundo. (20 de julio de 2016). "Hay tantos residuos de plástico en el mundo que podrían cubrir un país como Argentina". Recuperado de https://www.bbc.com/mundo/noticias-40664725

Calle, C., Castillo, H., Vásquez, R. y Vidaurre, E. (junio del 2014). Estudio de Mercado de Polímero Polipropileno. Recuperado de http://www.academia.edu/7345199/Estudio_de_Mercado_de_Polimero_Polipropile no

EnPerú. (2015). Departamento de Lima. Recuperado de http://www.enperu.org/informacion-util-lima-peru-ubicacion-geografica-clima-enlima-sitios-atractivos.html

Floplastics. (2017). Línea para reciclado de polietileno y polipropileno con una producción de $1000 \mathrm{Kg} / \mathrm{h}$. Recuperado de http://www.floplastics.com/images/pdf/LINEA-DERECICLADO-DE-PE-PP-1000.pdf

Galvis Gutierrez, N. (2014). Caracterización del polipropileno reciclado disponible a partir de tapas, para reincorporarlo en procesos productivos, mezclado con polipropileno virgen (tesis para optar el título profesional de Ingeniero de Producción, Universidad EAFIT de Medellín, Colombia). Recuperada de https://repository.eafit.edu.co/bitstream/handle/10784/8278/Nataly_GalvisGuti\%C3 $\%$ A9rrez_2014.pdf?sequence $=2$

Garzón, J., González, O., Galeano, J., Flechas, W. y Montenegro, L. (2015). Planta de reciclaje de plástico. Bogotá: Procesos virtuales.

Gestión. (23 de noviembre 2016). Perú cae diez puestos en ranking de dominio del inglés y su nivel es bajo, ¿Por qué? Gestión. Recuperado de https://gestion.pe/tendencias/management-empleo/peru-cae-diez-puestos-rankingdominio-ingles-nivel-148895

Harper, C. (2011). Tecnología de los plásticos. Recuperado de http://tecnologiadelosplasticos.blogspot.com/2011/06/deshimidificacion-de-deplasticos.html 
Hernandez, A. (5 de septiembre de 2016). Sophimania. Recuperado de https://www.sophimania.pe/medio-ambiente/contaminacion-y-saludambiental/pera-el-90-del-reciclaje-de-plasticos-es-informal/

House Online. (2016). Inmuebles ofrecidos. Recuperado de hol.pe/modulos/inmuebles.php\#

Industrial Safety. (2018). Señales de seguridad. Recuperado de http://www.industrialsafety.com.pe/portfolio-view/senales-de-seguridad/

Instituto Nacional de Estadística e Informática (2016). Cerca de 10 millones de personas viven en Lima Metropolitana. Recuperado de https://www.inei.gob.pe/prensa/noticias/cerca-de-10-millones-de-personas-vivenen-lima-metropolitana-8818/

Instituto Nacional de Estadística e Informática. (2015). Anuario de estadísticas ambientales. Recuperado del sitio de Internet del INEI: https://www.inei.gob.pe/media/MenuRecursivo/publicaciones_digitales/Est/Lib134 2/libro.pdf

Instituto Nacional de Estadística e Informática. (2015). Compendio estadístico Perú 2015. Recuperado del sitio de Internet del INEI: https://www.inei.gob.pe/media/MenuRecursivo/publicaciones_digitales/Est/Lib125 3/compendio2015.html

La planta de reciclaje más grande del país abrió sus puertas. (23 de julio de 2016). El Comercio. Recuperado de https://elcomercio.pe/lima/planta-reciclaje-grande-paisabrio-puertas-239732

Metrotec. (2017). Analizador de humedad en pellets/granzas plásticas FMX. Recuperado de https://www.metrotec.es/producto/analizador-de-humedad-en-pelletsgranzasplasticas-fmx-7461/

Ministerio del Ambiente. (2016). Anuario de estadísticas ambientales. Recuperado del sitio de Internet del Ministerio del Ambiente del Perú: http://sinia.minam.gob.pe/documentos/anuario-estadisticas-ambientales-2016

Ministerio de la Producción. (2015). Estudio de la situación actual de las empresas peruanas. Lima: Ministerio de la Producción.

Naciones Unidas. (2016). Evaluaciones del desempeño ambiental Perú. Recuperado del sitio de Internet de la OECD: https://www.oecd.org/environment/countryreviews/16-00313\%20Evaluacion\%20desempeno-Peru-WEB.pdf

Olazar, S. y López, G. (2016). Proyecto final "Reciclado de Polipropileno". Mendoza. 
Oviedo, T. (2014). Estudio de factibilidad para planta de reciclado de residuos de plásticos (tesis para optar el título profesional de Ingeniero Industrial, Universidad Nacional de Córdoba, Argentina). Recuperada de https://rdu.unc.edu.ar/bitstream/handle/11086/1542/Proyecto\%20Integrador\%20$\% 20$ Estudio\%20de $\% 20$ Factibilidad $\% 20$ para\%20Planta\%20de\%20Reciclado\%20de $\% 20$ Residuos $\% 20 \mathrm{de} \% 20 \mathrm{P} 1 \% \mathrm{C} 3 \% \mathrm{~A} 1$ stico\%20PET.pdf?sequence $=1$

Pagani. (2017). Tecnología en reciclado de plástico. Recuperado de http://www.pagani.com.mx/es/productos.htm

Petysolopet. (2014). Servicios y procesos PET. Recuperado de http://www.petysolopet.com/servicios.html

Plastics technology México. (2016). Tipos de contaminación durante el reciclado de plásticos. Recuperado de https://www.pt-mexico.com/art\%C3\%ADculos/tipos-decontaminacin-durante-el-reciclado-de-plsticos

Quiminet. (2017). Vendedor ofrece polipropileno reciclado. Recuperado de https://www.quiminet.com/centro-negocios/se-ofrece/316411525813.htm

Scorp. (2016). Medidor de humedad para el material de plástico sistema balanza. Recuperado de https://www.interempresas.net/Graficas/FeriaVirtual/ProductoMedidor-de-humedad-para-el-material-de-plastico-sistema-balanza-PCE-MB49284.html

Solostocks. (2016). Triturado taponería. Recuperado de https://www.solostocks.com/ventaproductos/plastico-reciclado/triturado-taponeria-22137018

Solostocks. (2017). Polipropileno reciclado homopolímero gránulos de color blanco. Recuperado de http://www.solostocks.com/venta-productos/plastico-reciclado/pppolipropileno-reciclado-homopolimero-granulos-de-color-blanco-9496471

Tecnología de los plásticos. (2011). Códigos de los plásticos. Recuperado de http://tecnologiadelosplasticos.blogspot.com/2011/03/codigos-de-los-plasticos.html

UDEP. (s.f.). Reciclaje de plásticos. Recuperado de http://www.biblioteca.udep.edu.pe/bibvirudep/tesis/pdf/1_63_186_28_558.pdf

Veritrade. (2016). Veritrade. Recuperado de

http://business.veritrade.info/Veritrade/Main.aspx

Wastetireoil. (2015). Planta de pirólisis. Recuperado de http://es.wastetireoil.com/Pyrolysis_plant/Pyrolysis_Plant/ 


\section{BIBLIOGRAFÍA}

Abad, A. (2014). Programas y líneas de financiamiento para las PYMES exportadoras.

Recuperado del sitio de Internet de COFIDE:

http://export.promperu.gob.pe/Miercoles/Portal/MME/descargar.aspx?archivo=DB3 67C6B-13EB-403F-9657-D230D28A0732.PDF

Anguita, R. (1977). Extrusión de plásticos. Madrid: Blume ediciones.

Azul Ambientalistas. (2016). Proceso para el reciclaje de plástico. Recuperado de http://www.azulambientalistas.org/reciclaje-de-plastico.html

Barletta, F., Pereira, M., Robert, V. y Yoguel, G. (2013). Argentina: Dinámica reciente del sector de software y servicios informáticos. Revista de la CEPAL, 137-155.

Banrepcultural. (2016). Actividad y cultura. Recuperado de http://www.banrepcultural.org/

Caballero, C. (2015). Mercados Verdes. Recuperado de http://www.portafolio.co/opinion/cesar-caballero/mercados-verdes-31102

Capeco. (19 de junio de 2014). Así cuestan los departamentos en cada distrito de Lima y

Callao. El Comercio. Recuperado de https://elcomercio.pe/economia/peru/cuestandepartamentos-distrito-lima-callao-172347

Carpeta pedagógica. (2015). Principales puertos del Perú. Recuperado de http://cienciageografica.carpetapedagogica.com/2012/11/principales-puertos-delperu.html

Carpeta pedagógica. (2015). Carreteras del Perú. Recuperado de http://cienciageografica.carpetapedagogica.com/2012/11/carreteras-en-el-peru.html

Choy, M. y Chang, G. (2014). Medidas macroprudenciales aplicadas en el Perú (DT. N 2014-007 Serie de documentos de trabajo). Recuperado del sitio de Internet del Banco Central de Reserva del Perú: http://www.bcrp.gob.pe/docs/Publicaciones/Document os-deTrabajo/2014/documento-de-trabajo-07- 2014.pdf

DANE. (2016). Pobreza monetaria y multidimensional en Colombia 2016.Recuperado de https://www.dane.gov.co/index.php/estadisticas-por-tema/pobreza-y-condiciones- 
de-vida/pobreza-y-desigualdad/pobreza-monetaria-y-multidimensional-encolombia-2016

Dávila, E. (2016). Colombianos construyen casas con plástico reciclado. Recuperado de https://www.elespectador.com/noticias/actualidad/colombianos-construyen-casasplastico-reciclado-articulo-651312

Datosmacro. (2018). IPC desciende en Colombia. Recuperado de https://www.datosmacro.com/ipc-paises/colombia

Dinero. (24 de abril del 2017). Analistas rebajan sus proyecciones sobre crecimiento, tasas e inflación. Recuperado de https://www.dinero.com/economia/articulo/proyecciones-de-inflacion-y-tasas-deinteres-abril-2017/244438

ECOPLAS. (2011). Manual de valorización de los residuos plásticos. Recuperado del sitio de Internet de ECOPLAS: http://www.ecoplas.org.ar/pdf/11.pdf

Egúsquiza Economistas. (4 de diciembre del 2007). Principales líneas de crédito de COFIDE para las microempresas. Recuperado de http://consultasfinancierasyempresariales.blogspot.com/2007/12/cules-son-lasprincipales-lneas-de.html

Encolombia. (2015). Colombia: Características de la población. Recuperado de https://encolombia.com/libreria-digital/lsalud/demografia/saludsex-capitulo1d/

Escobar Moreno, N., Gil Rueda, A. y Restrepo Botero, A. (2013). Caracterización preliminar del consumidor verde antioqueño: el caso de los consumidores del Valle de Aburrá. Bogotá.

Finanzas Personales. (2016). Colombianos continúan apostándole a la tendencia verde. Recuperado de http://www.finanzaspersonales.co/ultimasnoticias/articulo/colombianos-continuan-apostandole-tendencia-verde/43383

Frers, C. (9 de septiembre de 2017). El reciclado de plásticos. Recuperado de http://contenidos.ulima.edu.pe/bibliofiles/gsu/Guias_tutoriales/citas_referencias_ap a.pdf

García, J. (2013). Construye tu web comercial; de la idea al negocio. Madrid: RA-MA.

Grupo RPP. (2015). A dónde va la basura que sale de los hogares. Recuperado de http://files.gruporpp.info/integracion/296846473-A-donde-va-la-basura-que-salede-los-hogares.pdf 
Goicovic, G. (s.f.). Guía de taller de plásticos: El reciclaje. Recuperado de https://www.scribd.com/document/71711805/el-reciclado-de-plasticos-1

Instituto Nacional de Estadística e Informática. (2015). Producción de las industrias de caucho y plástico, minerales no metálicos y metales comunes. Recuperado del sitio de Internet del INEI: https://www.inei.gob.pe/estadisticas/indicetematico/economia/

Instituto Nacional de Estadística e Informática. (2016). Más de 1 millón de habitantes residen en la Provincia Constitucional del Callao. Recuperado de https://www.inei.gob.pe/prensa/noticias/mas-de-1-millon-de-habitantes-residen-enla-provincia-constitucional-del-callao-9257/

Instituto Nacional de Estadística e Informática. (2017). Lima tendrá 9 millones 111 mil habitantes. Recuperado de:

http://m.inei.gob.pe/media/MenuRecursivo/noticias/nota-de-prensa-n012-2017-inei2.pdf

Instituto Pacífico. (2013). Tratamiento de la depreciación para efectos tributarios. Recuperado de http://aempresarial.com/web/revitem/1_15254_11584.pdf

Lanchipa Merino, C. (1998). Investigación de pre factibilidad para la instalación de una planta de reciclaje de plástico (tesis para optar el título profesional de Ingeniero Industrial). Universidad de Lima.

Mareco. (2015). El símbolo del reciclaje, su historia y significado. Recuperado de http://isrmareco.com.mx/el-simbolo-de-reciclaje-su-historia-y-significado/

Marina Casique, J. (2009). Investigación de pre factibilidad para la implementación de una planta de producción y comercialización de escamas de PET reciclado (tesis para optar el título profesional de Ingeniero Industrial). Universidad de Lima.

MINCETUR. (2017). Acuerdos comerciales del Perú. Recuperado de http://www.acuerdoscomerciales.gob.pe/index.php?option=com_content $\& v i e w=c a t$ egory\&layout=blog\&id=36\&Itemid $=27$

Ministerio del Ambiente. (2013). Diagnóstico de los residuos sólidos en el Perú.

Recuperado del sitio de Internet del NEFCO: http://www.nefco.org/sites/nefco.org/files/pdffiles/1_diagnostico_de_los_residuos_solidos_en_el_peru.pdf

Mink, W. (1991). El plástico en la industria - inyección de plásticos. Naucalpan: Ediciones G.Gili. 
Moreno, M. (2017). Este año no se alcanzaría meta de inflación en Colombia. Recuperado de http://www.portafolio.co/economia/inflacion-en-colombia-en-2017-503144

Polonsky, M. (1994). An introduction to green marketing [version PDF]. Recuperado de http://www.greenprof.org/wp-content/uploads/2010/06/An-Introduction-to-GreenMarketing.pdf

PQS. (2015). Pasos para inscribir a tu empresa. Recuperado de http://www.pqs.pe/emprendimiento/sunarp-pasos-para-inscribir-tu-empresa

PQS. (2016). Sociedad anónima cerrada: Características y beneficios. Recuperado de http://www.pqs.pe/actualidad/noticias/sociedad-anonima-cerrada-caracteristicas-ybeneficios

Procolombia. (2016). Inversión en el sector empaques plásticos. Recuperado de http://www.inviertaencolombia.com.co/sectores/manufacturas/empaques-deplastico.html

Rivera, R. (2004). Propuesta de reciclaje mecánico de plásticos en la ciudad de Piura. Recuperado del sitio de Internet de la Universidad de Piura: https://pirhua.udep.edu.pe/bitstream/handle/11042/1180/ING_418.pdf?sequence=1

Sánchez Gallo, E. (2015). Estudio de factibilidad de una empresa de elaboración de pellets a partir de plástico reciclado (tesis para optar el título profesional de Ingeniero Industrial, Universidad politécnica Salesiana, Ecuador). Recuperada de https://dspace.ups.edu.ec/bitstream/123456789/10270/1/UPS-GT001304.pdf

Sedapal. (2015). Estructura tarifaria aprobada mediante resolución de consejo directivo. Recuperado de http://www.sedapal.com.pe/c/document_library/get_file?uuid=e52230b3-8b484f56-8af4-10e7fcb849e8\&groupId=29544

Sulem Hauyon, R., Molina Quenaya, S., Rojas Delgado, M., Power Porto, G. y Goñi Delión, J. (2014). Tecnología industrial. Lima: Universidad de Lima.

SUNAT. (2016). Depreciación de activos. Recuperado de http://www.sunat.gob.pe/legislacion/oficios/2006/oficios/i1962006.htm

SUNAT. (2018). Tipo de cambio. Recuperado de http://www.sunat.gob.pe/cl-atittipcam/tcS01Alias

Universidad de Lima. (s.f.). Ciencia y tecnología de los plásticos - Polimerización. Lima: Universidad de Lima.

Ureta, E. (1989). Polímeros, estructura, propiedades y aplicaciones. México D.F.: Limusa. 
Vallvé Pozaric, M. (1992). Investigación de pre factibilidad para la instalación de una planta de desechos plásticos (tesis para optar el título profesional de Ingeniero Industrial). Universidad de Lima.

Velarde, E. y Pérez, O. (1998). Reciclaje de desechos plásticos en el Perú. Revista de Química, 53-63.

Villar Navarro, C. (2013). Evaluación técnica y económica para implementar una planta de procesamiento de plástico reciclado en Chincha (tesis para optar el título profesional de Ingeniero Industrial). Universidad San Martín de Porres.

Wade, L. (2012). Química orgánica. Naucalpan de Juárez: Pearson Educación.

Fundación Telefónica. (2016). Nueve pasos para crear una empresa con personería jurídica en el Perú. Recuperado de http://wapaperu.mpdl.org/index.php?option=com_content\&view=article\&id=181\&I temid $=24$

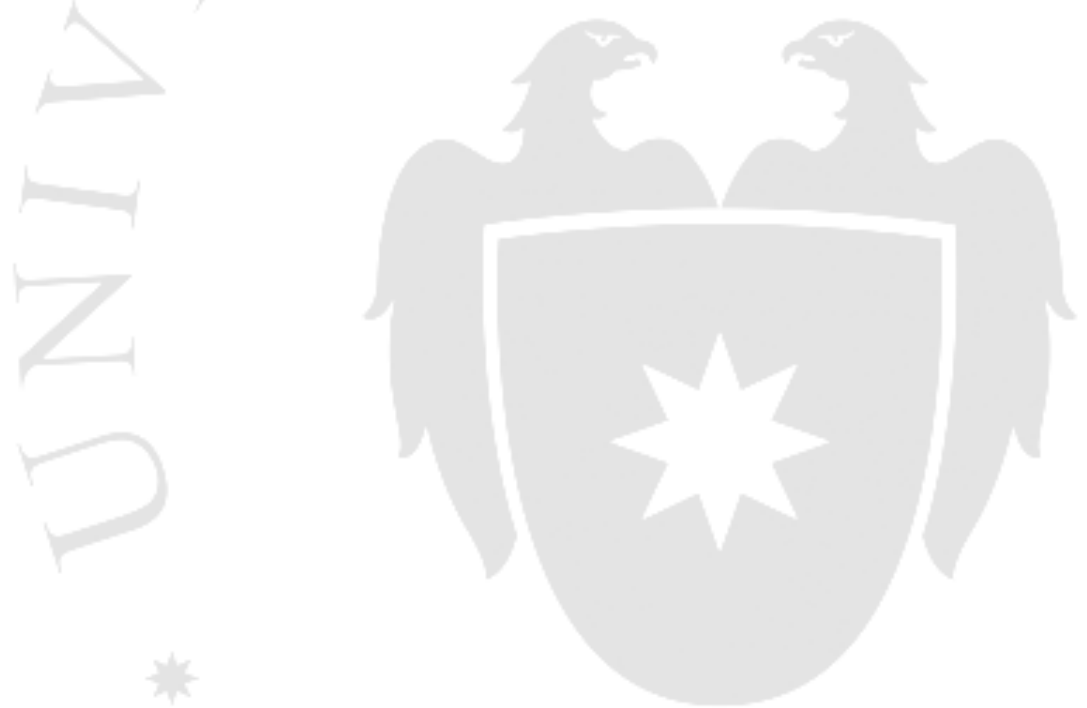




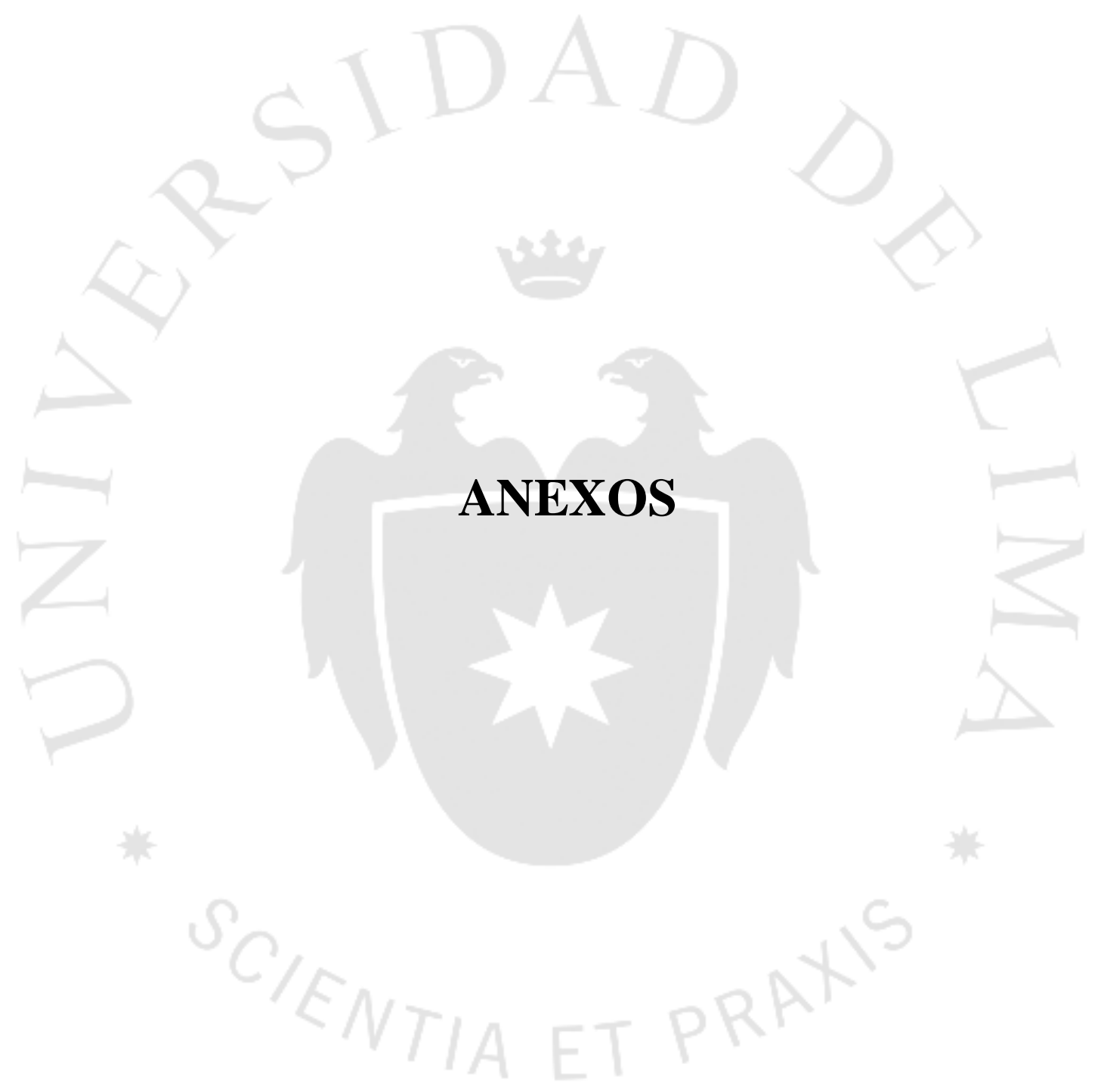




\section{Anexo 1: Cuestionario desplegado}

\section{Encuesta Plásticos:}

E1 presente trabajo de investigación presenta la hipotética empresa que se especializaría en la producción de escamas de polipropileno recuperado. Este se buscaría que compita con el polipropileno virgen otorgándole mayor calidad que un plástico recuperado regular (es decir, sin mayor procesamiento). Los dos puntos clave de diferenciación serian la separación por polímero y por color para garantizar su calidad.

Las siguientes preguntas las realizamos con el objetivo de determinar la entrada que tendría en el mercado actual:

1. ¿Usted estaría dispuesto a comprar un plástico con las características mencionadas previamente para ser capaz de utilizar un mayor porcentaje de plástico recuperado en sus mezclas vs. el virgen?
a. $\mathrm{Si}$
b. No
c. Puede ser

2. ¿Si tuviera que dar una puntuación del 1 al 10, que tan dispuesto estaría a comprar el producto?

a. Escribir número

3. ¿Con cuanta frecuencia compraría el producto?
a. Semanal
b. Mensual
c. Trimestral
d. Semestral
e. Anual
f. Otros-Detallar:

4. ¿Qué volumen en kilogramos pediría en cada compra?

a. Escribir número

5. Sabiendo que el precio actual de un kilogramo es de 1.8 a 2 soles, ¿estaría dispuesto a pagar 2.5 soles por el producto?

a. $\mathrm{Si}$

b. No, en caso ser "No", ¿cuánto estaría dispuesto a pagar?

i. Escribir número

6. ¿Qué características le parecen más importantes del producto? Ordenar por prioridad, 1 es lo más importante y 6 lo menos:

a. Tamaño del pellet

b. Precio

c. Humedad (que no exista)

d. Forma

e. Pureza de material

f. Color 


\section{Anexo 2: Glosario de términos}

En base a los libros revisados de Ureta Barrón y Wade, se elaboró el marco pertinente:

- Termoplástico: Tipo de plástico que se vuelve un líquido viscoso a temperaturas altas, y al enfriarse se vuelve un material duro nuevamente al entrar en un estado de transición vítrea.

- Temperatura de transición vítrea: Temperatura a la cual las propiedades mecánicas de un plástico cambian radicalmente debido a movimientos internos de las cadenas poliméricas que componen al mismo.

- Polimerización: Proceso mediante el cual las moléculas simples reaccionan entre sí para formar moléculas mayores.

- Degradación: En el caso de polímeros, se refiere a cuando sus moléculas se enlazan permanentemente y dejan de ser trabajables.

- Viscosidad: Característica de fluidos en movimiento, muestra tendencia de oposición a su flujo ante la presencia de una fuerza.

- Índice de Viscosidad: Medida de la facilidad de flujo de un termoplástico. Se le asocia con el nivel de calidad que tiene el material.

- Aditivo: Sustancia agregada al plástico para modificar sus propiedades y comportamiento.

- CIF: incoterm costo, seguro y flete de una mercancía.

- FOB: incoterm franco a bordo

- PP: Abreviación de polipropileno 
- DIA: Abreviación de demanda interna aparente

- CIIU: clasificación industrial internacional uniforme

- CAGR: tasa de crecimiento anual compuesto

- PEA: población económicamente activa

- PVC: policloruro de vinilo

- ABS: acrilonitrilo butadieno estireno

- PET: polietileno tereftalato

- CIO: Capacidad instalada ociosa

- VAN: valor actual neto

- TIR: tasa interna de retorno

- B/C: Relación beneficio/costo

- PR: Periodo promedio de recupero 